\title{
ANALYSIS OF HEAT-SPREADING THERMAL MANAGEMENT SOLUTIONS FOR LITHIUM-ION BATTERIES
}

\section{THESIS}

Presented in Partial Fulfillment of the Requirements for the Degree Master of Science in the Graduate School of The Ohio State University

\author{
By \\ Hussam Jihad Khasawneh \\ Graduate Program in Mechanical Engineering
}

The Ohio State University

2011

Master's Examination Committee:

Marcello Canova, Advisor

Yann Guezennec, Co-advisor 
Copyright by

Hussam Jihad Khasawneh 2011 


\begin{abstract}
Electrical storage technologies (i.e., batteries) play a ubiquitous role in all facets of modern technologies for applications ranging from very small to very large scale, both stationary and mobile. In the past decade, Li-ion batteries are quickly emerging as the preferred electrical energy storage technology due to the intrinsic power and energy storage density compared to older battery chemistries. All electrochemical batteries are strongly linked to their thermal state: on one hand, their electrical characteristics are strongly dependent on temperature and, on the other hand, their thermal state is a result of both their environmental temperature, but also their electrical usage due to internal heat generation. Furthermore, their life (and potentially safety) is also strongly affected by their thermal state. Li-ion batteries, due to their high electrical power capability and density tend to be used aggressively in many applications, rendering the thermal issues more acute. Finally, Li-ion battery packs (like all packs) are made of many cells interconnected in various series/parallel arrangements in tightly confined spaces. Hence, thermal management solutions need to be implemented for two primary reasons: rejecting the heat generated inside the pack to the environment to avoid high (or unsafe) temperatures leading to premature (or catastrophic) failure and providing a good thermal uniformity among all the cells so that their electrical performance (and aging) in well
\end{abstract}


matched in a pack. This thesis focuses on the thermal modeling of Li-ion packs and the development of passive thermal management solutions for such packs. The thesis first provides an extensive review of the current literature on Li-ion batteries electrical and thermal modeling and current approaches for thermal management solutions of Li-ion packs. This study then focuses on a particular current application using a small Li-ion pack, namely a contractor-grade 36v cordless drill. This particular application was chosen as it encapsulates many of the features of larger automotive packs and represent and leads to an aggressive usage pattern where battery life is always an issue. This pack was experimentally studied to establish typical usage patterns and to measure the thermal and electrical state of the stock pack during such usage. The study then developed and validated a FEM computational pack model in the stock configuration. This experimentally validated models was then used as a proxy to reality to numerically investigate multiple possible configurations of passive thermal management solutions using a high thermal conductivity, Graphite-based heat spreading material to both reduce temperature non-uniformities within the pack and decrease of overall pack temperature (better heat rejection) during aggressive use. Finally, a preliminary experimental validation of one of the promising configurations of heat spreaders was investigated. The work described in this thesis clearly demonstrates that passive heat spreading technology can be very beneficial to reduce thermal stress on batteries and lead to more thermally homogenous packs. Furthermore, this study demonstrated that the investigation of such solutions can be performed with validated thermal FEM models to speed up the 
development of actual solution and reduce experimental prototype building. Future work will include more configurations, but also experimental investigation of battery life for both thermally managed and unmanaged packs under similar (aggressive) usage patterns. Finally, the conclusions from this study conducted on a cordless power tool are probably equally applicable to large automotive battery packs where life and costs are critical. 


\section{Dedication}

This thesis is dedicated to my father, mother, brother, and sisters. They directly and indirectly shared all difficulties and enjoyment of my studies. For their love, support, and firm belief in my completion of this thesis, I am wholeheartedly thankful. 


\section{Acknowledgments}

Many people favorably influenced the progression and completion of my Master thesis. My sincere gratitude is due to my supervisors Professor Yann Guezennec and Professor Marcello Canova of The Ohio State University for their invaluable help during all stages of my Master studies. Both Professor Canova and Professor Guezennec have been unfailingly generous with their time, advice, assistance, and support. I am also thankful to John Neal and Jim Shively for their sensitive assistance in conducting experiments relevant to my research. I thank our partners from GrafTech for considerable contribution to the project and some stimulating and very helpful discussions. I gratefully acknowledge that this research was conducted with support from the Ohio Third Frontier Advanced Energy Program. My heartfelt thanks also go to my colleagues in The Center for Automotive Research, whose discussions of various problems were highly inspiring, and to my friends, who offered their unwavering support and warmth during the progressions and regressions of my research. 
Vita

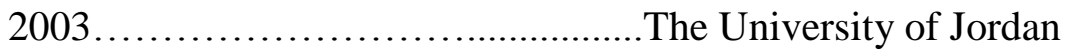

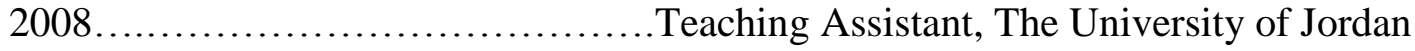

$2009 \ldots \ldots \ldots \ldots \ldots \ldots \ldots \ldots \ldots \ldots . . . \ldots \ldots$ The Ohio State University

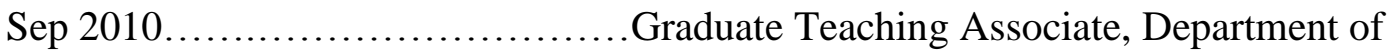

Mechanical and Aerospace Engineering, the Ohio

State University

2011..............................Graduate Research Associate, Center for

Automotive Research, the Ohio State University

\section{Fields of Study}

Major Field: Mechanical Engineering 


\section{Table of Contents}

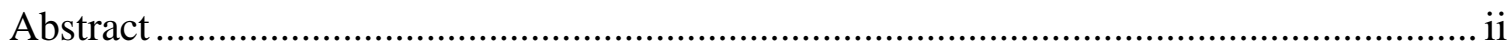

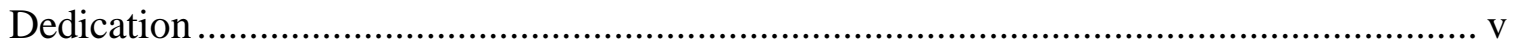

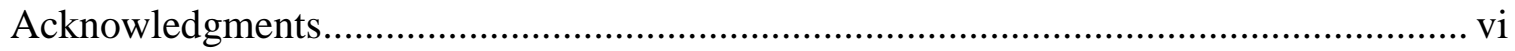

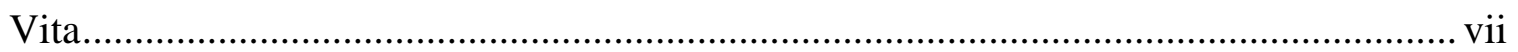

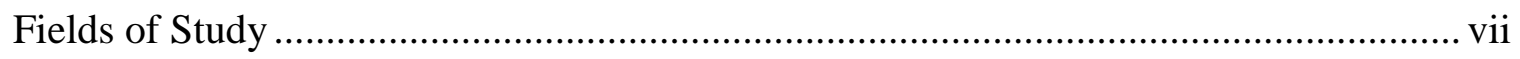

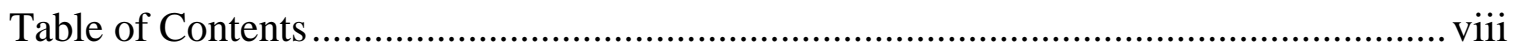

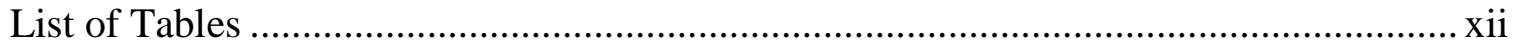

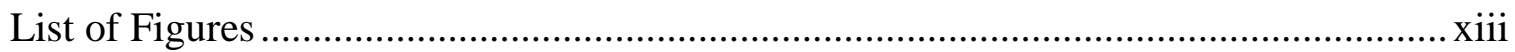

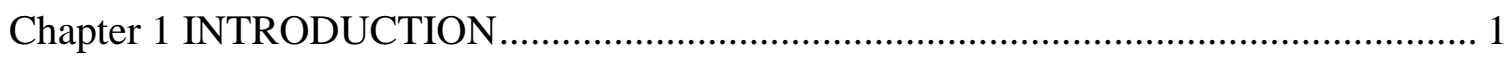

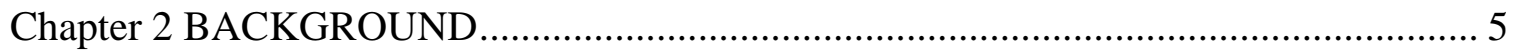

2.1 General Considerations on Li-Ion Batteries ....................................................... 5

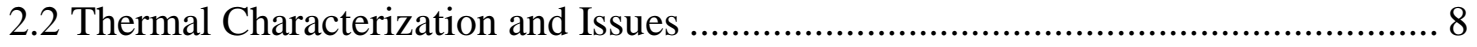

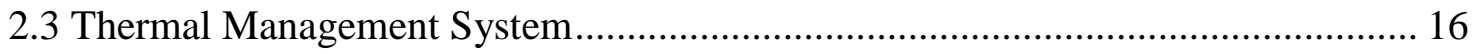

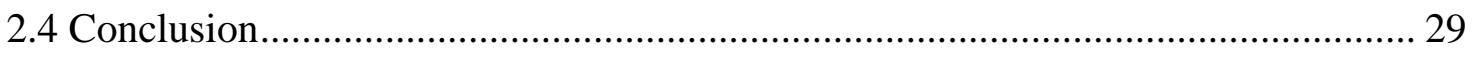


3.1 Overview of Battery Models ........................................................................... 33

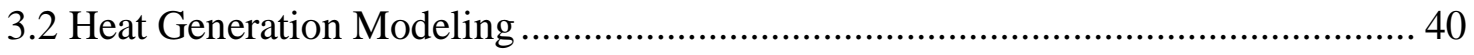

3.3 Overview of Heat Transfer........................................................................... 42

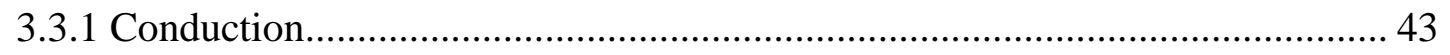

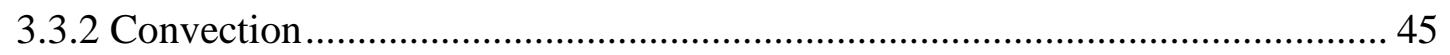

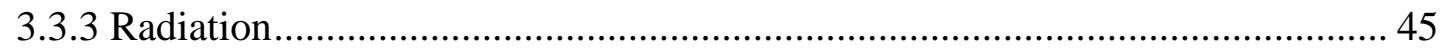

3.4 Finite Element Method..................................................................................... 46

3.5 Literature Review of Mathematical Models....................................................... 49

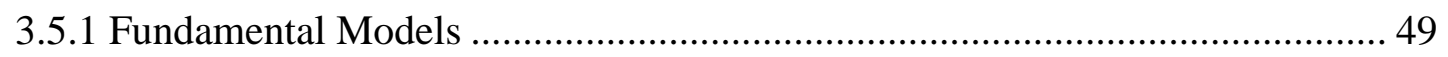

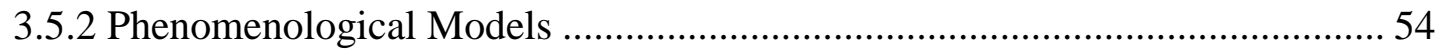

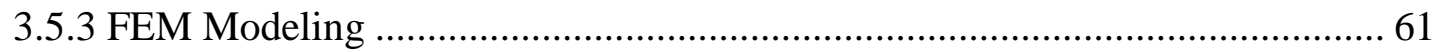

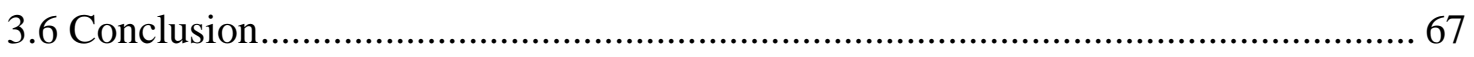

Chapter 4 DEVELOPMENT OF BATTERY PACK THERMAL MODEL AND

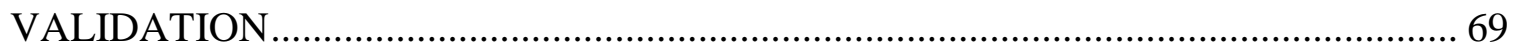

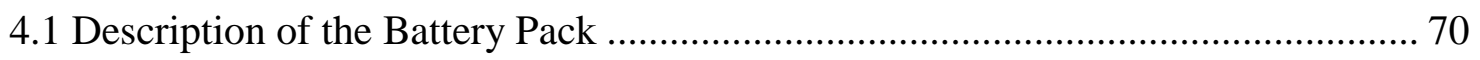

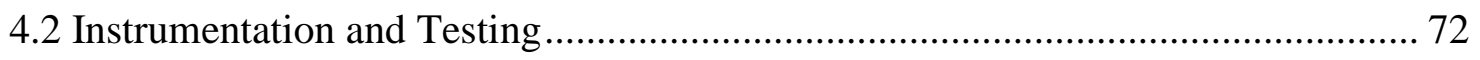

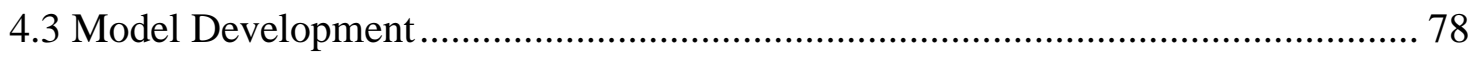


4.3.1 Electro-Thermal Model

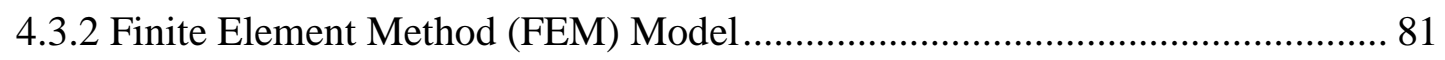

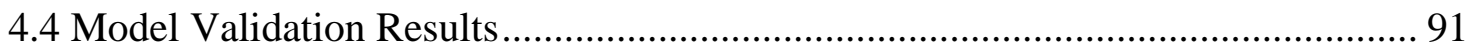

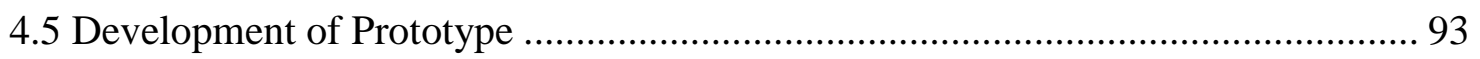

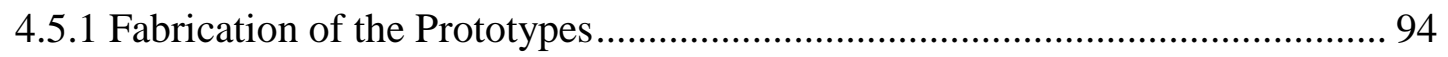

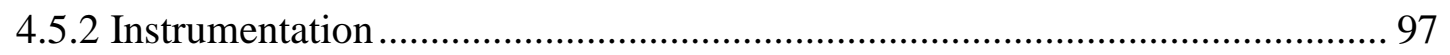

4.5.3 Testing Current Profile Synthesis ............................................................... 99

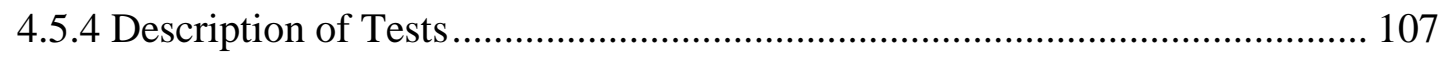

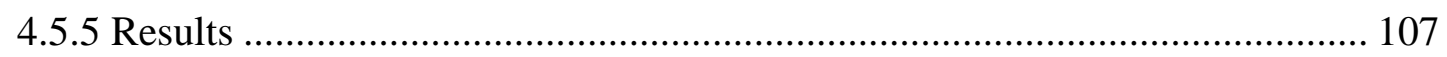

Chapter 5 APPLICATION TO THERMAL MANAGEMENT SYSTEM DESIGN AND

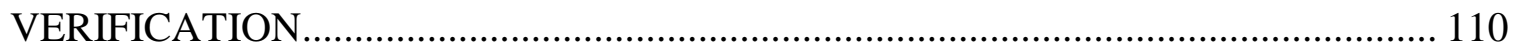

5.1 Design Study for Thermal Management of Li-Ion Battery Pack ........................... 110

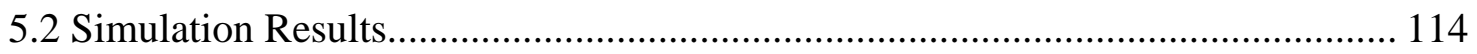

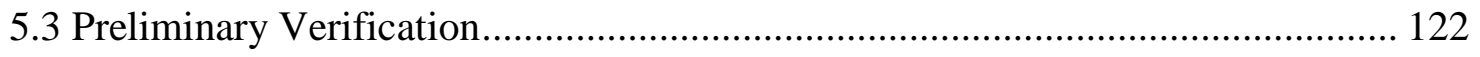

Chapter 6 CONCLUSIONS AND RECOMMENDATIONS.......................................... 127

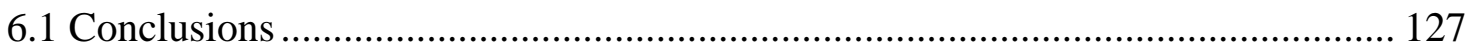

6.2 Recommendations ....................................................Error! Bookmark not defined.

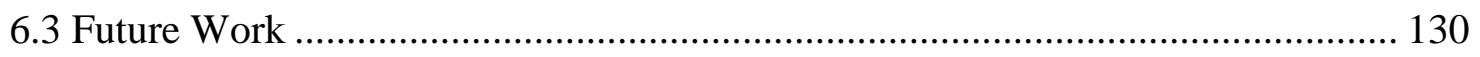




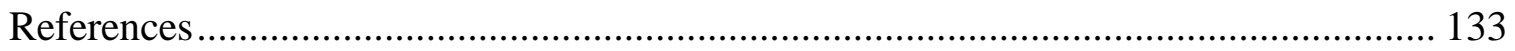




\section{List of Tables}

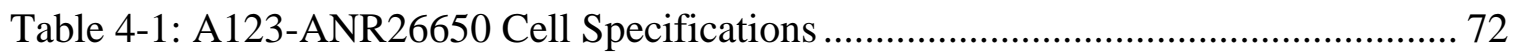

Table 4-2: Thermal Parameters of the A123 cell ........................................................ 84

Table 4-3: Thermal Parameters of the Battery Pack components.................................. 84

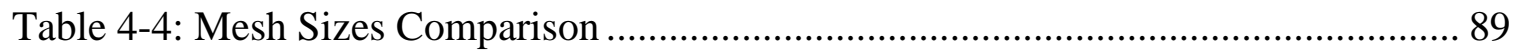

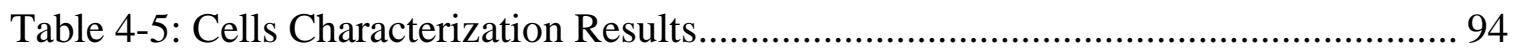

Table 4-6: Summary of Characteristic Event Metrics ............................................ 103

Table 5-1: Thermal Properties of Heat Spreading Materials ..................................... 111

Table 5-2: Max, Min, Average and Temperature Gradient Comparison $\left({ }^{\circ} \mathrm{C}\right)$............... 119

Table 5-3: Cells Characterization Results................................................................... 123 


\section{List of Figures}

Figure 2-1: Energy and Power Densities for Various Electro-Chemical Conversion

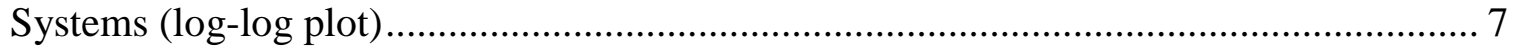

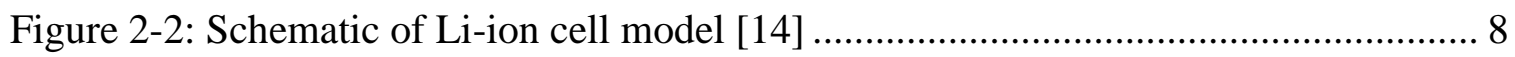

Figure 2-3: Specific Joint Resistance versus Thickness [40]..................................... 26

Figure 2-4: Average Thermal Resistance [40] ..................................................... 27

Figure 2-5: Knurled Flexible Graphite Sheet with Pet Layer Peeled Back [41] ............. 28

Figure 3-1: Dual-insertion cell sandwich consisting of composite negative and positive

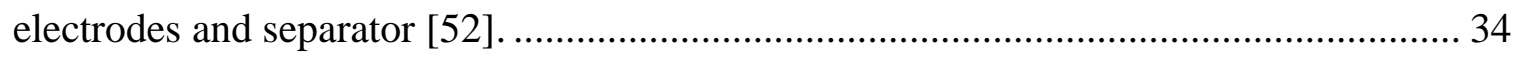

Figure 3-2: Randle Equivalent Electrical Circuit Model [42] ..................................... 36

Figure 3-3: Control-oriented Model Block Diagram ............................................... 38

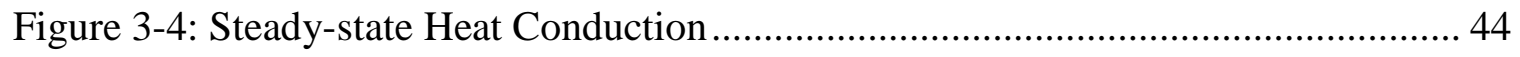

Figure 3-5: Approximation of the circumference of a circle by line elements: (a) Circle of radius R; (b) uniform and non-uniform meshes; (c) a typical element [59] ................... 49

Figure 3-6: Schematic of the spherical hydride particles [68] ................................... 51

Figure 3-7: Experimental and simulated of cell voltages: constant current (a) charge and (b) discharge, and constant temperature (c) charge and (d) discharge [70] .................... 53

Figure 3-8: Internal Resistance Battery Model (ADV model) [71] ............................. 55

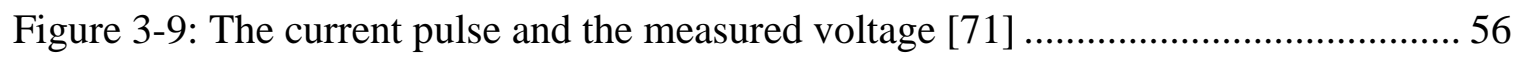


Figure 3-10: Two-capacitance battery model (RC model) [71] .................................. 57

Figure 3-11: Validation of ADV and RC models over a US06 cycle [71] ..................... 58

Figure 3-12: Voltage response over the first $100 \mathrm{sec}$ of US06 cycle [71] ..................... 58

Figure 3-13: Voltage Response to a Current Step Profile [42] .................................... 59

Figure 3-14: Voltage Response to a Current Pulse Profile [42] .................................... 60

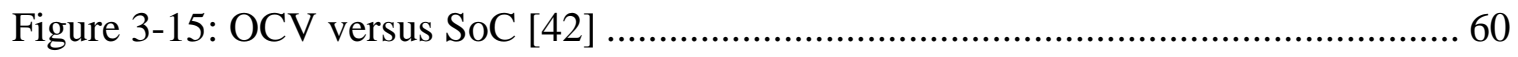

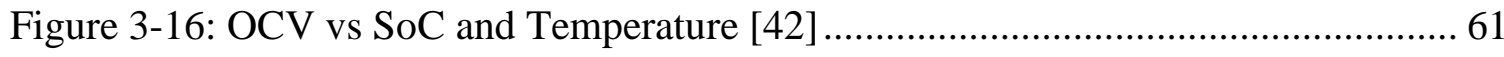

Figure 3-17: (a) Cross-section of a spiral wound lead/acid cell and (b) its FEM model [72] 62

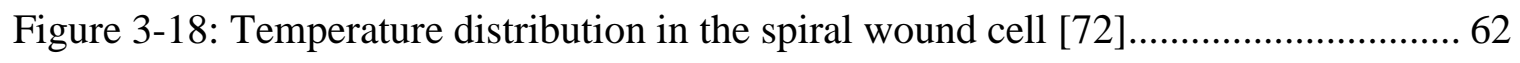

Figure 3-19: (a) Three-dimensional model and (b) temperature distribution for Optima $[72]$ 63

Figure 3-20: The temperature distribution of battery pack with (a) series and (b) parallel cooling systems [3] 64

Figure 3-21: Panasonic NiMH module used in 2001 Toyota Prius [73] 65 Figure 3-22: Simulated model of the 2001 Panasonic module: (a) the case with terminal connectors, and (b) the core and current collectors [73] 65 Figure 3-23: Temperature distribution (a) in the case and (b) in the core after 3 minutes

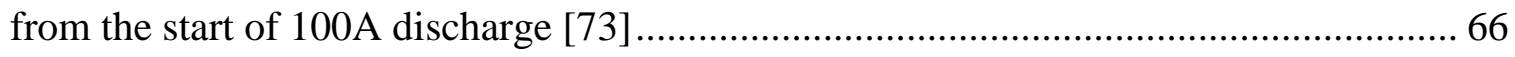

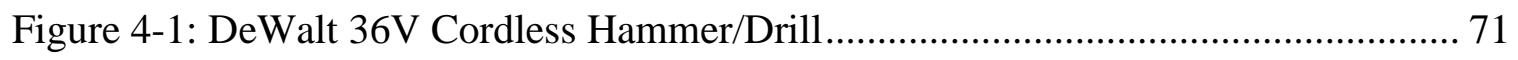

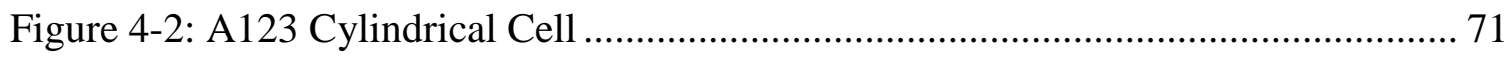




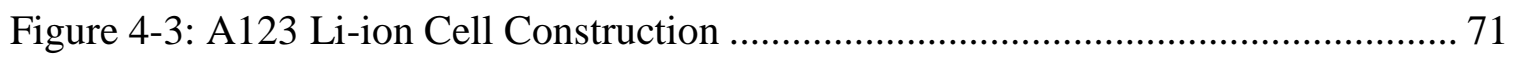

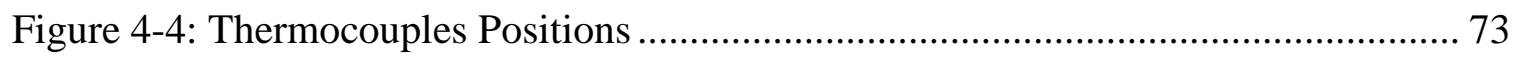

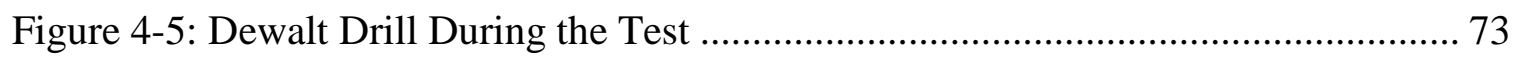

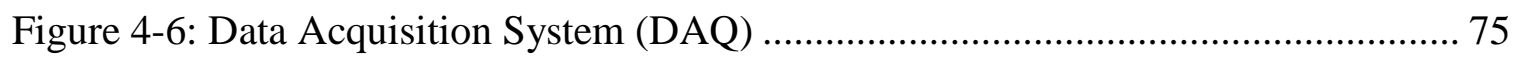

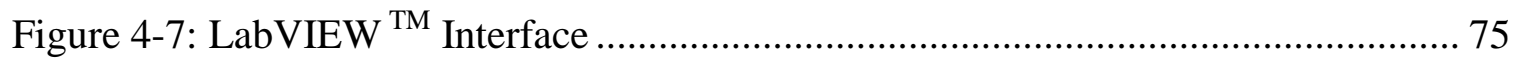

Figure 4-8: Current and Voltage Profiles during the Test ......................................... 76

Figure 4-9: Power and Energy Profiles during the Test ........................................ 76

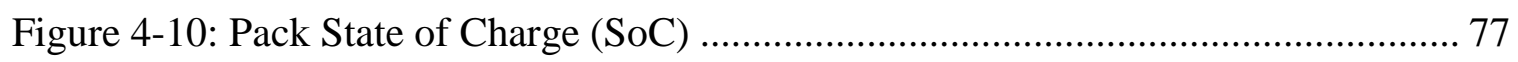

Figure 4-11: The measured temperatures during the test (positions shown in Figure 4-4)

Figure 4-12: Open-Circuit Voltage Curve for ANR26650 Cell [10]............................... 79

Figure 4-13: Total Terminal Voltage and Open Circuit Voltage.................................. 80

Figure 4-14: Heat Generation Rate per Cell ….................................................. 80

Figure 4-15: COMSOL Multiphysics User Interface .......................................... 81

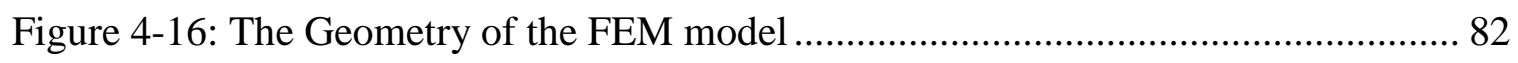

Figure 4-17: Enclosure Mesh, Fine (left), Normal (middle), and Coarse (right)............. 88

Figure 4-18: Battery Cell Mesh, Fine (left), Normal (middle), and Coarse (right) .......... 89

Figure 4-19: Temperature Grid, Fine mesh (left), Normal mesh (middle), and Coarse

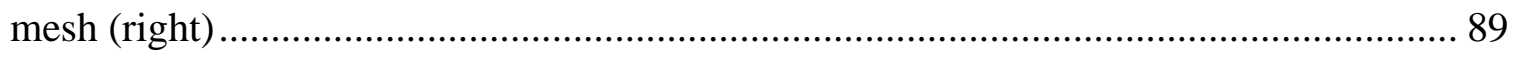

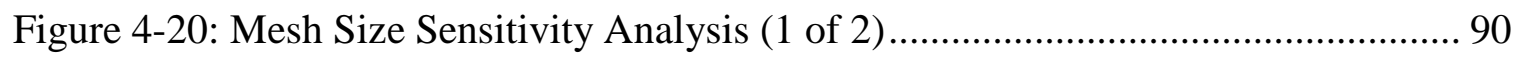

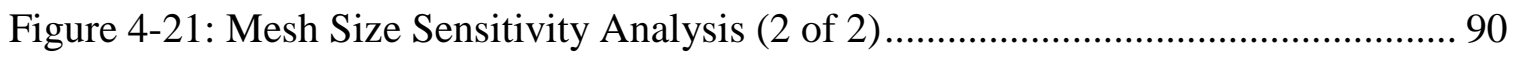


Figure 4-22: Comparison of Experimental (Top) and Predicted (Bottom) Temperatures at

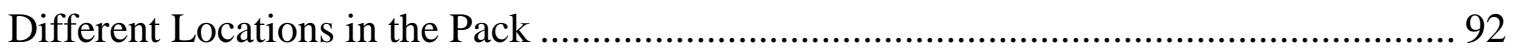

Figure 4-23: FEM Model Error on Prediction of Cells Temperatures............................ 93

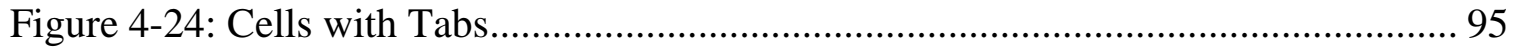

Figure 4-25: Case I (Baseline) Prototype ................................................................ 95

Figure 4-26: Transmission of IR material as a Function of Wavelength........................ 96

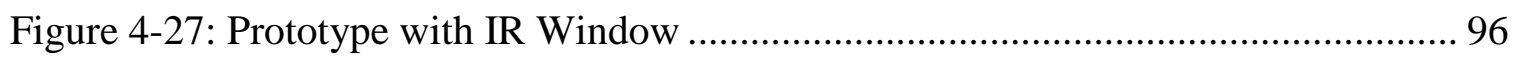

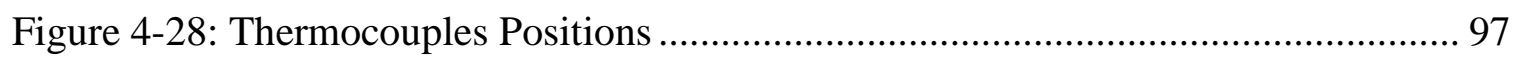

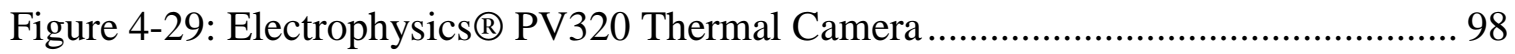

Figure 4-30: Current Cycler Programmable DC Electronic Load ................................. 98

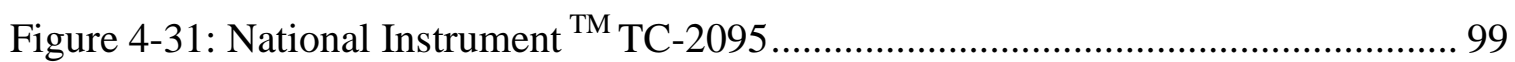

Figure 4-32: Sample Current, Voltage, and Power Profiles for 100 seconds ................ 100

Figure 4-33: Statistical Distribution of Event and Rest Durations ............................. 100

Figure 4-34: Statistical Distribution of Max Current and Max Power ......................... 101

Figure 4-35: Statistical Distribution of Max Center and Surface Temperatures ............ 101

Figure 4-36: Average Profile and Duty Cycle ...................................................... 104

Figure 4-37: The "Worst Case Scenario" Current Profile .......................................... 104

Figure 4-38: OCV and Voltage per cell for the "Worst Case Scenario" ....................... 105

Figure 4-39: Heat Generation Rate per cell for the "Worst Case Scenario" ................. 105

Figure 4-40: Overview of the Three Pack Utilization Scenarios Considered for the

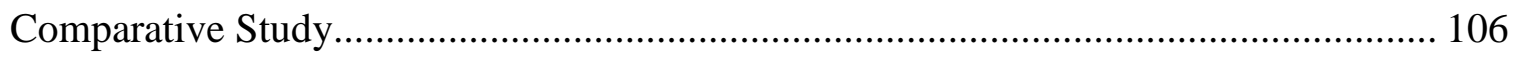




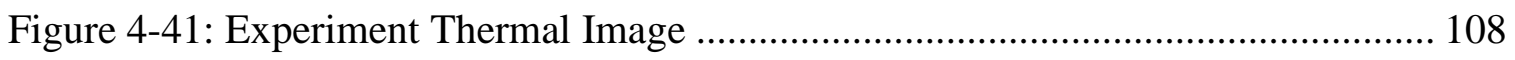

Figure 4-42: Simulation Thermal Image............................................................. 108

Figure 4-43: Prototype Validation: Simulation and Experiment Temperatures, and

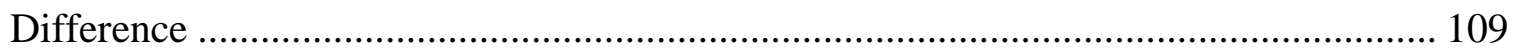

Figure 5-1: Overview of the Different Design Cases Compared for Pack Thermal

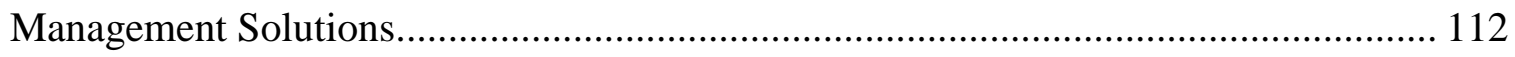

Figure 5-2: Dirichlet Boundary Conditions ......................................................... 113

Figure 5-3: Coordinate Systems Comparison ..................................................... 114

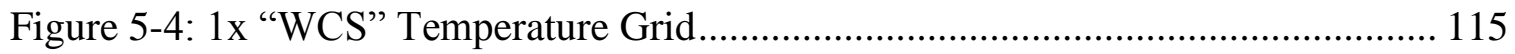

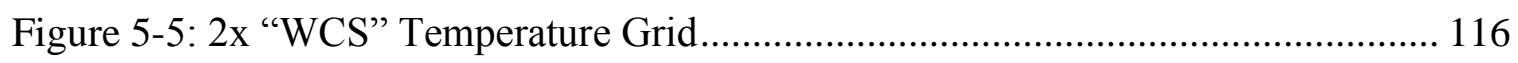

Figure 5-6: 4x "WCS” Temperature Grid................................................................. 117

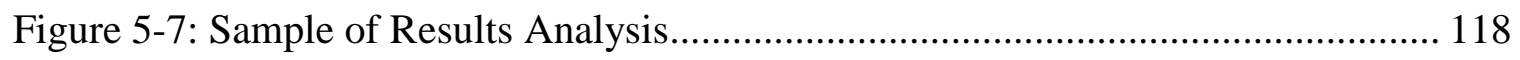

Figure 5-8: Case II and Case III Compared to Baseline for all scenarios .................... 121

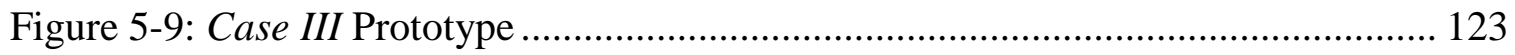

Figure 5-10: Experiment Thermal Image for Case III ........................................... 124

Figure 5-11: Simulation Thermal Image for Case III ............................................. 125

Figure 5-12: Case III (Graphite HS) Prototype Validation: Simulation and Experiment

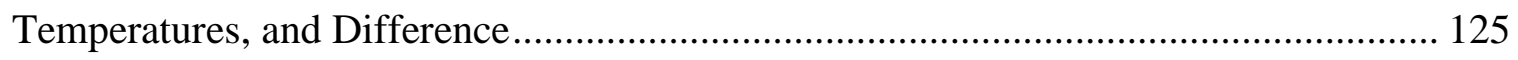

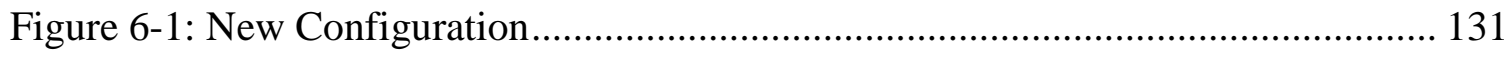




\section{Chapter 1}

\section{INTRODUCTION}

Secondary (rechargeable) batteries have become a dominant power source in our everyday lives. Indeed, batteries have moved far beyond the laptop PC and mobile phone to be a potential source of power for portable power tools, electric vehicles (EV), and hybrid electric vehicles (HEV) [1, 2]. The advancement of battery technology has become the driving force behind recent developments for EV and $\mathrm{HEV}$.

Despite the widespread use of the batteries, there are still significant technical challenges to their use that can be attributed, to a high degree, to the thermal behavior of battery cells [3-5]. It is well known that the heat generated during operation of a battery cell by both electrical resistance and electrochemical reactions can significantly affect the available capacity and power of the pack, as well as its cost, durability, reliability, and life [6].

For this reason, thermal management system is applied to most battery packs. The thermal management system could be air or liquid cooling, phase-change materials PCM, heat spreaders, or even a microprocessor-controlled thermal management system, including an array of temperature and voltage sensors and an a combination of active cooling systems and passive solutions [3, 5-9]. 
However, as the complexity of the thermal management system increases, so do its weight, volume and parasitic power consumption, all factors that adversely affect the vehicle's performance. Hence, an improved thermal management system based on passive solutions could decrease the load on active components like pumps and blowers and, ultimately, also reduce the weight and costs of the system.

This thesis contributes to the research conducted in the area of passive thermal management solutions and discusses experimental and simulation studies aimed at evaluating the effectiveness of flexible graphite heat spreading materials as a thermal management solution for battery packs. In this thesis, a commercial Li-ion pack for power tools was adopted as a case study. The study starts with statistical analysis of typical usage patterns, which leads to synthesizing a duty cycle profile for simulation and laboratory testing. Then, the electro-thermal behavior of the battery pack is characterized through combined experimental investigation and 3D Finite Element Method (FEM) modeling. This is done in order to determine the heat generation rate of the battery cells during utilization and in order to evaluate the temperatures and thermal gradients within the battery pack.

On the basis of the obtained results, a thermal management solution based on flexible graphite heat spreading material was designed and implemented. This thesis presents a comparative study between different designs. The comparative study is conducted in simulation to evaluate the improvements in the pack thermal performance. After that, prototypes that mimic the simulation are built and subjected to experiments in a 
laboratory. Finally, the results of the experiments are compared to the simulation results for validation.

As a starting point of this thesis, Chapter 2 investigates the thermal issues and characterization of secondary batteries, in general, and Li-ion batteries, in particular. Furthermore, this Chapter provides a literature review of the thermal characterization and discusses the available thermal management solutions and cooling technologies in published literature. Chapter 3 continues the investigation but focuses mostly on the mathematical tools and methods in literature to model $\mathrm{Li}$-ion battery and heat generation. It also includes the necessary heat transfer equations and finite element method basics.

The discussion of the case study is taken up in Chapter 4. In this chapter, a description of the case study is provided; the experimental characterization of the battery pack is presented; a FEM model of the pack is described, built, and validated. Furthermore, the chapter 4 presents a statistical analysis in order to define the discharge pattern that will be used in a laboratory or simulation. After that, this chapter compares the results of two design cases, in which graphite-based heat spreading materials are applied.

The last chapter aims at building prototypes that mimic the design cases discussed in Chapter 4. The prototypes are tested in a laboratory; the results are, then, compared to the simulation results for validation purposes.

The ultimate goal of this study is to design an efficient thermal management system based on graphite material that improves the temperature uniformity and heat rejection capability. Furthermore, this study aims at obtaining a FEM model and a prototype that 
are valid to describe the thermal behavior of the original Dewalt battery pack with the thermal solution with a high degree of fidelity. 


\section{Chapter 2}

\section{BACKGROUND}

\subsection{General Considerations on Li-Ion Batteries}

Lithium ion batteries are the enabling technology for storage solutions in many applications. Due to their high energy storage capacity and ability to rapidly discharge and recharge, lithium ion batteries have almost completely replaced competing secondary batteries in today's cordless power tools and portable electronic devices [10].

Power density and energy density are two key technical characteristics in describing batteries. Energy density is the amount of energy stored in the battery per unit mass, measured in $\mathrm{W}-\mathrm{h} / \mathrm{kg}$. Electronic Devices such as mobile phones and laptops need high energy density. Power density (or specific power) is the amount of power that the battery can deliver per unit mass, measured in $\mathrm{W} / \mathrm{kg}$. Power density is an important consideration in some power applications where space is constrained, such as battery-powered tools [3, 11-13].

Figure 2-1 provides a quick look at various electro-chemical systems. The ideal case is located at the top right corner of the plot. Li-ion batteries provide a realistic compromise between the energy density and power density. Unlike fuel cells, Li-ion has a relatively higher power density compared to fuel cells and Lead-acid batteries which makes it a good 
storage system for high-power applications, such as regenerative braking in electric vehicles. On the other hand, Li-ion batteries have a higher energy density compared to super capacitors which make them better for portable applications. Furthermore, Lithium-based batteries are attractive as energy storage systems since they are less toxic than nickel cadmium or lead acid cells, and their disposal poses fewer environmental problems. In addition, it offers $40-50 \%$ battery weight reduction and $20-30 \%$ volume reduction as well as some margin of efficiency improvement compared to nickel cadmium battery [14].

A typical Li-ion cell consists of negative electrode (or anode), electrolyte, separator, and positive electrode (or cathode); the two electrodes are separated by the separator, and electrodes are filled with electrolyte as shown in Figure 2-2. The electrolyte, often a good ionic conductor but an electronic insulator, provides a transport-medium for $\mathrm{Li}$-ions to travel between the two electrodes and keeps electrons in the external circuit [14].

In batteries, the chemical energy is converted into electrical energy. According to the second law of thermodynamics, any conversion between two forms of energy occurs with an energy loss. These thermal issues are studied in this chapter. It discusses different sources of heat in batteries and shows some common mathematical models to predict heat generation rate. Then, this chapter provides a literature review on thermal characterization. Finally, this chapter presents the available thermal management solutions and cooling technologies in the published literature. 


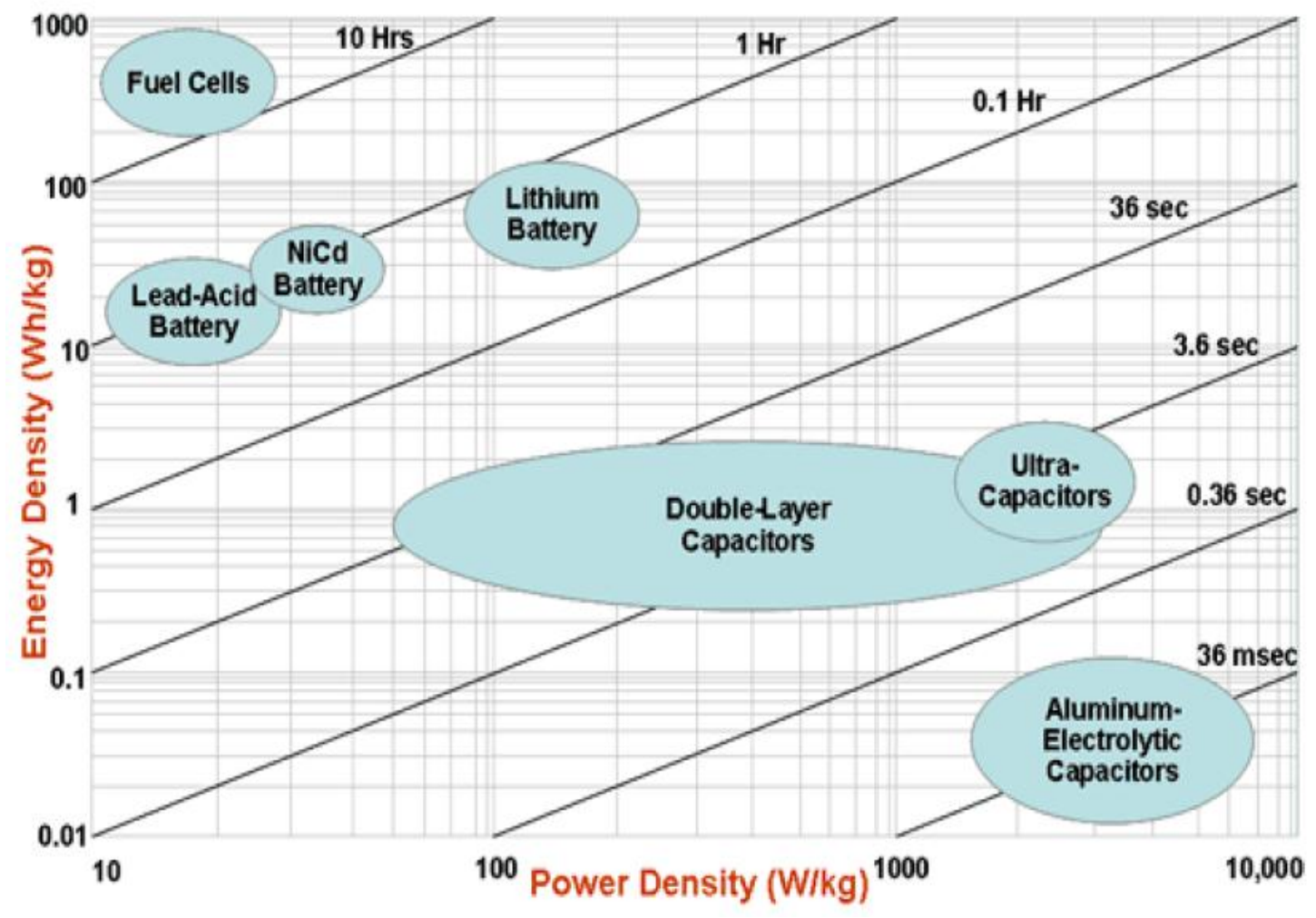

Figure 2-1: Energy and Power Densities for Various Electro-Chemical Conversion Systems $(\log -\log$ plot $) 1$

${ }^{1}$ US Defense Logistics Agency http://www.dla.mil 


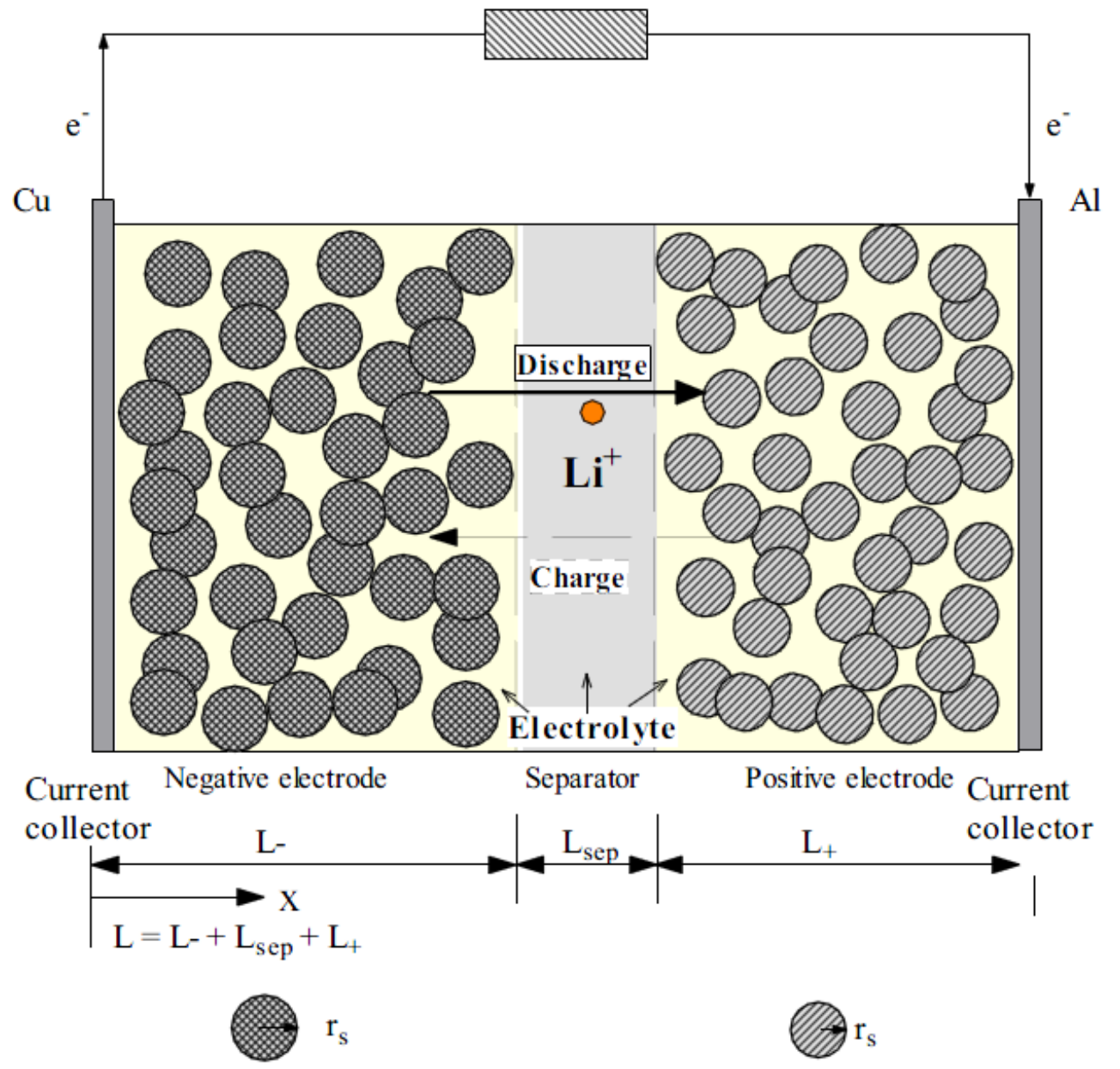

Figure 2-2: Schematic of Li-ion cell model [14]

\subsection{Thermal Characterization and Issues}

In an ideal case, secondary battery cells allow for an electrically reversible conversion of energy. For instance, during discharging operations, chemical reactions occur inside the cell, leading to a conversion of chemical energy into electrical energy.

On the other hand, the second law of thermodynamics limits the rate of energy conversion during charging and discharging, leading to a non-ideal process with energy 
losses in the form of heat [1]. Bernardi et al. [15] is considered one of the classical works that estimates heat generated from batteries using a mathematical model. According to their study, the heat is generated due to four main reasons: the irreversible resistive heating, the reversible entropic heat, the heat change of chemical side reactions, and the heat of mixing due to the generation and relaxation of concentration gradients.

The irreversible ohmic heat loss occurs during both charge and discharge when the battery current flows through internal resistances. Resistive heating is caused by the deviation of the cell potential from its equilibrium potential due to internal resistance. When the pack current flows out or in the battery, the pack terminal voltage decreases from the open circuit voltage. Therefore, the difference between the terminal voltage and the open circuit voltage is converted into heat according to Equation 2-1 [6, 15-17].

$$
Q_{O}=I\left(V_{o}-V\right)
$$

The reversible change in entropy is given by equation $2-2$, where Tcell is the cell temperature, Vo is the cell open circuit voltage, and I is the cell current, which is positive during discharge and negative during charge.

$$
Q_{S}=-T_{\text {cell }} I \frac{d V_{o}}{d T_{\text {cell }}}
$$

The work of Bernardi et al. [15] was extended, in 2003, by Thomas and Newman [17] to consider the effect of lithium concentration in intercalation compounds. They derived a general energy balance equation that includes the four sources of heat generation inside lithium ion batteries during operation. In addition to the irreversible resistive heating, this equation included the second term for the reversible entropic heat, the third term for the 
heat change of chemical side reactions, and the fourth term, the heat of mixing due to the generation and relaxation of concentration gradients. (For further details, see [17].) In practice, the heat $\mathrm{Q}_{s}$ by entropy change is relatively small compared to the heat $\mathrm{Q}_{o}$ by ohmic losses. Thus, for simplicity, the heat is assumed to be generated from the battery because of the internal resistances $[3,12]$; the heat generation modeling will be discussed in details in Section 3.2.

Apart from being estimated by mathematical modeling, heat generation can also be determined experimentally by such methods as temperature measurements, thermal imaging, and using calorimeter $[1,4,6,11,18-19]$. Calorimeter is a device that measures the quantity of heat energy released or absorbed during a process. Because there are many processes that can be studied over a wide range of temperature and pressure, a large variety of calorimeters have been developed. Nonisothermal calorimeters measure the temperature change that occurs during the process. It is normally constructed of a material having a high thermal conductivity, such as copper, so that there is rapid temperature equilibration. The other type of calorimeters is the isothermal calorimeter, which measures the quantity of heat energy generated under constant temperature such as the phase-change heat $[13,17,20-21]$. (For further details on calorimeters, see [22].) The Li-ion battery cell has relatively large volume with small surface area; therefore, extracting heat from battery is necessary. If the heat generated in the cell is not removed, it increases the temperature of the cell, which could affect the battery's ability to deliver energy from the pack, charge acceptance during recharging, and limit the life of the 
battery. On the other hand, lower battery temperatures lead to decreasing power capability $[3,4,5,11,23]$.

To get optimum performance and maximize the useful life of a battery cell, it is necessary to operate the pack under a specific temperature range, defined by the battery's manufacturer. The battery manufacturers set an optimum operating temperature range for the battery much narrower than the operating range for any application. For instance, the preferred operating temperature for a lead acid battery is $25^{\circ} \mathrm{C}$ to $45^{\circ} \mathrm{C}$, while the desired operating temperature for a lithium ion battery is $20^{\circ} \mathrm{C}$ to $40^{\circ} \mathrm{C}$. However, the indicated vehicle operating range could be $-30^{\circ} \mathrm{C}$ to $60^{\circ} \mathrm{C}[5,7,24]$, and between -20 to 45 for a portable power tool [25].

Another critical issue for battery pack which should be considered in addition to the issue of operating temperatures of battery cells is the temperature non-uniformity between different cells in the same pack. Differences in the temperatures of the cells may lead to variations in the charge/discharge performance between cells in the same pack, which may result in electrical imbalance, if not compensated by the battery management system (BMS) $[1,3-6,11]$.

The work addressing thermal issues in batteries started as early as in 1986, when J. Lee [8] discussed the effects of the heat caused by the ohmic losses and the change in entropy during charge and discharge. The self-heating phenomenon affects the battery performance, life, and reliability, ultimately requiring a thermal management system capable of (1) controlling battery temperature within a suitable range; and (2) keeping temperature of different batteries uniform in the same pack. In [8], three equations were 
presented to formulate a battery thermal model: (1) thermal energy balance differential equation; (2) the rate of heat generation equation, which is a function of the chemical reaction thermodynamic properties, the voltage-current characteristics of the battery, and the rates of charge and discharge; and (3) the boundary conditions equation at the surface of the battery assuming that its material is quasi-homogenous. By solving these three equations, the temperature distribution can be calculated. The results showed that several design parameters -- ampere-hour capacity, number of cells, packing and cooling orientations, and the space between cells -- influence the thermal behavior of a battery module.

In the same year (1986), Sharpe and Conell [9] studied the charging behavior of lead-acid batteries at low temperatures. Their procedure was to leave the fully charged battery for 16 hours under $-18^{\circ} \mathrm{C}$, then to discharge it at $405 \mathrm{~A}$ in two 30 -second periods, after that to leave it for another 16 hours under a certain temperature, and, finally, to charge it at $25 \mathrm{~A}$ maximum current in order to test the charge acceptance of the battery. They found out that the charge acceptance rates dropped noticeably at temperatures below $0^{\circ} \mathrm{C}$. They found that the charge acceptance rate at $-18^{\circ} \mathrm{C}$ decreases by $20 \%-40 \%$ of the charge acceptance rate measured at $25^{\circ} \mathrm{C}$. At low temperatures the counter Electro Motive Force (e.m.f) rises at a faster rate than it does at ambient temperatures, so that the charging current drops before full SoC is reached. This means that the battery polarization increases when the temperature decreases, which makes the charging current fall down earlier. 
In 1990, Anderson [23] observed that the operating temperature is one of the factors that significantly affect life, performance, and durability of the battery. Chrysler Motors found that battery life cycles dropped from 4000 cycles to 2000 cycles when the operating temperature increased from $37^{\circ} \mathrm{C}$ to $66^{\circ} \mathrm{C}$. In 1993, Wicks and Doane [26] performed some charge/discharge tests on lead-acid battery to study the temperature dependence. The effect of temperature on the energy efficiency of the battery was studied. The energy efficiency was defined as the ratio of the electric energy to the load and the electric energy to recharge to the initial charge condition. The co-authors found that at $-26^{\circ} \mathrm{C}$ the energy efficiency is $73.4 \%$, while it rises to $88.1 \%$ at operating temperature of $64^{\circ} \mathrm{C}$. Furthermore, the effect of temperature on the maximum power was studied, which can be drawn from a battery when the load resistance equals the battery internal resistance. As a result, the maximum power of the lead-acid battery increased from $850 \mathrm{~W}$ to $1562 \mathrm{~W}$ when the temperature increases rose from $26^{\circ} \mathrm{C}$ to $64^{\circ} \mathrm{C}$. The results of this study were used to predict the lead-acid battery's performance over a range of conditions by an equivalent circuit model. The co-authors suggested that any thermal technique should maintain a temperature of the lead-acid of no less than $65^{\circ} \mathrm{C}$, but they didn't study the effect of elevated-temperature on the lead-acid battery.

This effect was explored by Dickinson and Swan in [27], by studying a number of leadacid battery packs of different manufacturers. The problem of short life and low capacity of lead-acid batteries was addressed. It was found that the high operating temperatures and uneven temperatures across the stack of batteries cause this problem. The authors recommended an even temperature in the range of $35^{\circ} \mathrm{C}-40^{\circ} \mathrm{C}$ in order to optimize the 
pack performance; higher temperatures reduce life and lower temperatures decrease capacity of the battery and increase its internal resistance. Battery packs with temperature gradients have low performance because the cold battery in the pack will reach the discharged state faster than warmer batteries; therefore the entire pack will be undercharged. They claimed that the results published in their paper would help the electric vehicles and batteries manufacturers to understand and design battery management systems (BMS) that will reduce the battery pack degradation. Furthermore, they pointed the equal importance of charging batteries in the same pack and of preventing charge imbalance that causes forced discharge of weak cells in the pack and results in hot spots that increase the overall pack temperature.

Ramadass et al. [28] quantitatively estimated the influence of the capacity fade of Sony $18650 \mathrm{Li}$-ion cells on cycling at elevated temperatures of $25^{\circ} \mathrm{C}, 45^{\circ} \mathrm{C}, 50^{\circ} \mathrm{C}$, and $55^{\circ} \mathrm{C}$. The results of their study show that after 800 cycles, the cells cycled at $25^{\circ} \mathrm{C}$ and $45^{\circ} \mathrm{C}$ lost $31 \%$ and $36 \%$ of their rated capacity respectively. The cells cycles at $45^{\circ} \mathrm{C}$ lost about $60 \%$ of its initial capacity after only 600 cycles. The largest loss was for the cells tested under temperature of $55^{\circ} \mathrm{C}$ with a $70 \%$ loss in capacity. Thus, keeping the operating temperature within a reasonable range is a necessity, which can be achieved by an efficient thermal management system. 
National Renewable Energy Laboratory ${ }^{2}$ (NREL) conducted a chassis dynamometer test on a 2000 Honda Insight and 2001 Toyota Prius. Kelly at al. (2002) presented the results of this test in [29]. One part of this test was the thermal performance evaluation of the battery packs used in these two vehicles during chassis dynamometer testing. Even though both vehicles have adequate battery thermal management system, the results showed that the Insight limited battery usage is to $60 \%$ of its rated capacity, while the Prius limited battery usage is to $40 \%$ of its rated capacity. In other words, they sacrificed the battery capacity and power to limit the rise of temperature, thus increasing the life time of the battery. It is noteworthy that both vehicles were using nickel-metal hydride (NiMH) battery pack, which has specific heat lesser than heat of Li-ion battery [24]. This clearly shows the need for more effective thermal management solutions, which ideally should allow the usage of $100 \%$ of the battery's rated capacity without exceeding its operating temperature limits.

Based on the factors listed above and due to the negative effect of the heat generated during operation on battery, the heat generated must be dissipated to improve reliability, performance, life and to prevent failure. In order to do this, battery packs need a thermal management system that has the ability to dissipate generated heat during operation in order to reduce the battery temperature. This will be discussed in detail in the remaining parts of this chapter.

${ }^{2}$ NREL is a federal laboratory dedicated to the research, development, commercialization and 


\subsection{Thermal Management System}

The ultimate target of thermal management system is to maintain an operating temperature within reasonable range (depending on a type of the battery). In other words, it is required to keep the temperature of the battery in a specific range that doesn't affect its performance [3]. Furthermore, thermal management system needs to minimize the differences in temperatures between different battery cells in the same pack. However, the thermal management system needs to be compact so it can be easily applied without the need of extra space in the battery system. Also, it has to be light so it will not add an extra load especially to smaller applications; and it has to be cheap so it will not add some more cost to the overall system [5]. Therefore, "[a]n ideal thermal management system should be able to maintain the desired uniform temperature in a pack by rejecting heat in hot climates, adding heat in cold climates, and providing ventilation if the battery generates potentially hazardous gases.” (Pesaran et al.) [4].

A thermal management system could be designed with a range of methods, from "simple energy balance equations" to more "sophisticated thermal and computational fluid dynamics models." Regardless of the method, the basic performance of the management system is constrained by the thermal design of each cell or module [21].

Techniques for heat dissipation include air cooling, liquid cooling, phase-change materials, heat spreaders and heatsinks. This section of the chapter overviews the available thermal management solutions for batteries in published literature.

Based on the thermal analysis presented above, it is possible to conclude that batteries that are used for high power applications need consideration to thermal management. In 
some cases, the thermal management can be achieved by simply monitoring the batteries temperature and cutting the current off whenever the temperature reaches a maximum limit. On the other hand, this solution limits the battery's performance. Therefore, it is necessary to dissipate the heat from the battery to avoid reaching the temperature limit during battery's operation. Pesaran et al. [4] summarized the possible thermal management solutions. The very basic and most common solution is based on air cooling. The heat transfer in this case is convective; hence, in order to maximize cooling, the surface area needs to be increased. Although the air cooling is relatively simple and inexpensive, the thermal capacity of the air is relatively low, which reduces the effectiveness of dissipating the heat. Another thermal management solution is liquid cooling. Nelson et al. [28] compared thermal management of a Li-ion battery for hybrid electric vehicle applications between air cooling and liquid cooling (silicon transformer fluid). They found out that fluid cooling would be better as a heat transfer medium for cooling and heating purposes than air, since air has low conductivity and low heat capacity per unit volume. In order to compensate for this, large volume of air needed to be pumped, which requires high power. In addition, air needed large cross-sections in the flow passages from and to the supply and exit manifolds.

Ovonic Battery Company used liquid cooling in their high-power $\mathrm{NiMH}$ modules to achieve uniform temperature distribution in the pack beside better temperature control [4]. The way of performing liquid cooling can be classified according to their flow paths into direct and indirect [5]. In the direct liquid cooling system, the battery pack is immersed into a dielectric liquid, such as silicon or mineral oils, to prevent electrical 
shorts. In the indirect liquid cooling systems, heat transfer with liquid is achieved through pipes or jackets that contain the coolant; they surround each module in the battery pack. The coolant in the indirect systems can be simply water/glycol, but other coolants such as ethylene glycol can be used more because of their higher thermal capacity.

The advantage of liquid cooling system is that the system components such as pump, piping, coolant reservoir and heat exchanger are arranged outside the battery and have more flexibility than air-cooling system [7]. On the other hand, the mass of the coolant and of the other components add significant weight to the total weight of the system. In addition, cooling systems with several components have an increased potential for faults (e.g., leaks), and add more complexity and cost to the original battery pack system due to maintenance and repair [5].

Air and liquid cooling systems exploit the sensible heat of the cooling medium (i.e., air or liquid) to extract heat from the pack. The sensible heat appears as a change in the temperature of the medium without any change of its phase. Another approach is to exploit the latent heat, which is amount of energy that is required to a thermodynamics phase change of the cooling medium. The latent heat exchanged without affecting the temperature of the medium. Based on the phase change material (PCM), an innovative thermal management system was conceived [30]. This is the third thermal management solution presented in this literature review.

S. Al-Hallaj and his colleagues have conducted extensive research on PCM technology $[12,18,25,30-36]$. In their research, they used finite-element software to simulate the thermal behavior of a $100 \mathrm{Ah}$ Li-ion Sony US18650 during discharge at different rates 
and under different cooling conditions. Simulation results showed a significant decrease in the temperature rise for the module when the PCM is used. Khateeb et al. [18] introduced two patents of novel thermal management system by Al-Hallaj and Selman [33-34], in which they built a prototype for Li-ion battery in order to replace the existing lead-acid battery in Zappy electric scooter model no. 02815B. In [18], the step-by-step procedure to develop the prototype of the Li-ion battery was presented. First of all, a simulation of a battery module containing eighteen 18650 type Li-ion cells was done. The heat generation rate of Li-ion was assumed on the bases of an experimental data obtained from accelerating rate calorimeter (ARC); heat transfer coefficient during the natural convection inside the pack was assumed to be $5 \mathrm{~W} / \mathrm{m}^{2} \mathrm{~K}$; forced cooling was assumed for the outer surfaces when the scooter is moving with a heat transfer coefficient of 20 $\mathrm{W} / \mathrm{m}^{2} \mathrm{~K}$. The researchers conducted simulation for three discharge/charge cycles to check the thermal behavior of the prototype. The resulting temperature of the Li-ion cells was high enough to risk the safety of the battery. In order to solve this problem, the authors introduced a thermal solution using a phase change material.

The phase change material was chosen to be paraffin wax. Paraffin waxes are cheap and have moderate thermal energy storage density but low thermal conductivity [30]. At this stage of the test, the low thermal conductivity of PCM made it liquid at some places inside the pack while it is mushy or solid at some other places; this caused uneven temperature distribution between modules inside the same battery pack. The next stage was to add aluminum foam to the PCM to enhance the overall thermal conductivity. After adding Al-foam, the melting and solidification became uniform; therefore, the 
temperature across the pack became more even. The last stage was to add aluminum fins to boost the heat dissipation rate from the cell in order to guarantee the same initial temperature at the start of each discharge cycle.

One year after the previous study, was published an experimental validation to the simulation results of the Li-ion battery prototype of the electric scooter [35]. The validation experiment was performed by testing four different Li-ion battery module types: Li-ion cells alone, cells with PCM, cells with aluminum foam, and cells with PCM and aluminum foam. Each module type was examined at various charge/discharge Crates; these represented slow to fast charge/discharge rates. The results of the validation tests showed that the temperature rise in the absence of PCM and aluminum foam at $\mathrm{C} / 1$ rate charging was $16^{\circ} \mathrm{C}$. This clearly proved the importance of using thermal management system in Li-ion battery applications. The addition of aluminum foam alone decreased the rise in temperature to $8^{\circ} \mathrm{C}$, while the addition of $\mathrm{PCM}$ alone decreased the rise in temperature to $7^{\circ} \mathrm{C}$. Mixing the $\mathrm{PCM}$ with the aluminum foam minimized the temperature rise to only $6^{\circ} \mathrm{C}$. There was a similar thermal behavior in all different charge/discharge rates. The authors noticed that as the rate of charge/discharge decreased, the potential of the PCM and the aluminum foam did not show a significant reduction in temperature rise. A good candidate as a PCM is the hydrated salts because of their high volumetric storage density, reasonable cost, and relatively high thermal conductivity compared to paraffin waxes [30]. Mixtures of chlorobenzene and bromobenzene, which crystallize at narrow temperature range, are suitable for precise temperature control between 30 to $45^{\circ} \mathrm{C}$. Other candidates are stearic acid, with a melting point of $70^{\circ} \mathrm{C}$, and esters of stearic acid with 
methyl, propyl, and butyl alcohols, which have melting points in the range of $17-34^{\circ} \mathrm{C}$ [31]. A graphite matrix is a worthwhile alternative to Al-foam in order to improve the PCM overall thermal conductivity [36].

A comprehensive comparison between active and passive thermal management system was done by Sabbah et al. [12]. In their research, the air was considered as an example of active thermal management system, and graphite/PCM-composite material was considered as an example passive thermal management system. These materials were tested during normal and abusive discharge currents on type $18650 \mathrm{Li}$-ion cells which is the theoretical replacement of the NiMH battery pack of a Hybrid Ford Escape. This comparison was conducted for two levels of discharge rate: $3 \mathrm{~A}$ (2C rate) and 10A (10C rate), and for two ambient temperatures: $25^{\circ} \mathrm{C}$ and $45^{\circ} \mathrm{C}$. The results showed that both active and passive management systems were adequate because of the low heat generation at $3 \mathrm{~A}$ under ambient temperature of $25^{\circ} \mathrm{C}$. By raising the ambient temperature from $25^{\circ} \mathrm{C}$ to $45^{\circ} \mathrm{C}$ at the same discharge current, active cooling (air) was still sufficient to limit the cell temperature below $55^{\circ} \mathrm{C}$, which was chosen to be the maximum permissible temperature; but this required a higher flow rate with one order of magnitude. The passive cooling using PCM showed similar cooling effectiveness at ambient temperature of $25^{\circ} \mathrm{C}$, while it was less effective than active cooling when the ambient temperature rose to $45^{\circ} \mathrm{C}$ because of the high air speed. The authors concluded that passive (PCM) cooling performs similarly to active cooling (air) under moderate conditions of current load or ambient temperature. 
The increase in the discharge current to 10A showed a difference between PCM and air cooling. The active cooling, which was tolerable for moderate conditions of discharge current, as shown above, could not keep the cell temperature below the safety limit; it reached $65^{\circ} \mathrm{C}$ at an ambient temperature of $45^{\circ} \mathrm{C}$. The only way to avoid such high temperatures of the cell at high discharge currents and high ambient temperature is by increasing the air flow rates, which increases the required fan power. This increase in the parasitic power would decrease the cooling index, which is the ratio of the heat dissipated from the cell to the energy required to power the fan [25].

On the other hand, PCM absorbed sensible heat until the battery pack reached the melting point of the PCM, which was designed to be $55^{\circ} \mathrm{C}$. At this temperature, PCM started to melt, utilizing the latent heat, which in its turn kept the battery pack temperature around $55^{\circ} \mathrm{C}$. The results showed also that the temperature gradient for passive cooling was negligible under normal conditions ( $3 \mathrm{~A}$ and $25^{\circ} \mathrm{C}$ ambient), and it was below $0.5^{\circ} \mathrm{C}$ under severe conditions (10A and $45^{\circ} \mathrm{C}$ Ambient). At the end of this study, the authors recommended passive cooling PCM for stressful conditions of discharge current and operating temperature in order to get better temperature distribution, if the melting point temperature of the PCM matrix is chosen properly.

Kizilel et al. compared, in a simulation study, the ability of PCM to prevent thermal runaway propagation, if one cell in the pack failed [25]. The results showed that the failure of one cell triggered runaway throughout the pack if air cooling is used; they also assumed that heat transfer coefficient between the cells and the air passing between them was $20 \mathrm{~W} / \mathrm{m}^{2} \mathrm{~K}$. Conversely, the runaway did not spread and the temperature of the pack 
cooled down to near-ambient when the PCM-graphite matrix was used; this happened because of its relatively high thermal conductivity.

New thermal management solution approach is to dissipate the heat of the battery using natural graphite-based heat-spreader material. Natural graphite is the crystalline form of carbon. The carbon atoms in graphite are connected in layers. The carbon-carbon bonds in one layer are relatively strong compared to the forces between different layers [37]. Therefore, natural graphite has anisotropic thermal properties; this means it has a high thermal conductivity in the plane of the sheet but very low thermal conductivity through the thickness of the plane. The ratio of in-plane to thru-thickness thermal conductivity can reach 500. The thermal conductivity in the plane is ranging between $140-1500 \mathrm{~W} / \mathrm{m}$ $\mathrm{K}$, and is ranging between $3-10 \mathrm{~W} / \mathrm{m}-\mathrm{K}$ through the thickness of the plane [19]. The graphite-based heat spreader takes advantage of this property to control the transfer of the heat in some directions and prevent it from other directions; thus, it is used to both spread heat efficiently and to eliminate hot spots by insulating a surface adjacent to the heat source. The more anisotropic the graphite is, the more effective is heat transfer area, and the better temperature distribution become [38]. Another advantage of using graphite is in its low density, which makes these heat spreaders a better alternative of aluminum and copper in weight sensitive applications [39].

The natural graphite heat-spreader is manufactured in two forms: (1) laminate material, using a laminating process to produce thick plates of graphite, (2) compression molded material; this allows manufacturer to produce more complex shapes [39]. Its high flexibility and conformability to surfaces make graphite-based heat-spreader interesting 
as a thermal management solution [40]. Flexible heat spreaders maximize the effective surface area, through which heat is transferred with the cooling medium [37]. These heat spreaders have been widely used in electronics cooling applications where heat flux density is low and accessible space is limited, such as laptops and cell phones. However, if the heat flux density is high, the low thru-thickness thermal conductivity will not be efficient. In this case, there is a significant drop in temperature across the thickness of the heat spreader. Temperatures on the contact surface between the heat spreader and the heat source are significantly higher than temperatures on the opposite surface. This temperature gradient decreases the effectiveness of heat dissipation. To overcome this problem, a high-conductive isotropic material with relatively high thru-thickness thermal conductivity is embedded in the graphite material. The effectiveness of this spreader is better than it is of spreaders made from aluminum, copper, or natural graphite alone [40]. Smalc et al. in their paper [40] discussed the flexible graphite materials as Thermal Interface Materials (TIM's); it takes advantage of its high thermal conductivity and their ability to conform well to surfaces. Furthermore, the graphite sheets were impregnated with various materials (i.e., polymers such as mineral oils and synthetic oils) to improve properties; this is possible since graphite sheets are porous with open interconnected pores. This paper [41] reviews the thermal properties of TIM's made by adding two different polymer materials to a grade of flexible graphite.

The aim at adding polymeric materials to the graphite sheets is to lower the thermal resistance of the material [40]. At lower contact pressures, the contact resistance tends to dominate the overall thermal resistance. Thus, to improve the thermal performance of 
TIM's at low pressures, it is important to reduce the contact resistance of the material. In the test described in [40], the thermal conductivity and contact resistance was measured on various thicknesses. Then, the measure contact resistances were plotted against thickness. A straight line was fitted to the points, as shown in Figure 2-3, and the thermal conductivity was determined by the inverse slope of this straight line:

$$
k=\frac{\Delta t}{\Delta r_{j}}
$$

The graphite material used in this test [40] was eGraf ${ }^{\mathrm{TM}} 1200$ series $^{3}$. This comparative study compares the baseline 1200 series material, the baseline material with Polymer A, and the baseline material with Polymer B. Polymer A was mineral oils, while Polymer B was synthetic oils.

\footnotetext{
${ }^{3}$ eGraf is a trademark of GrafTech Inc.
} 


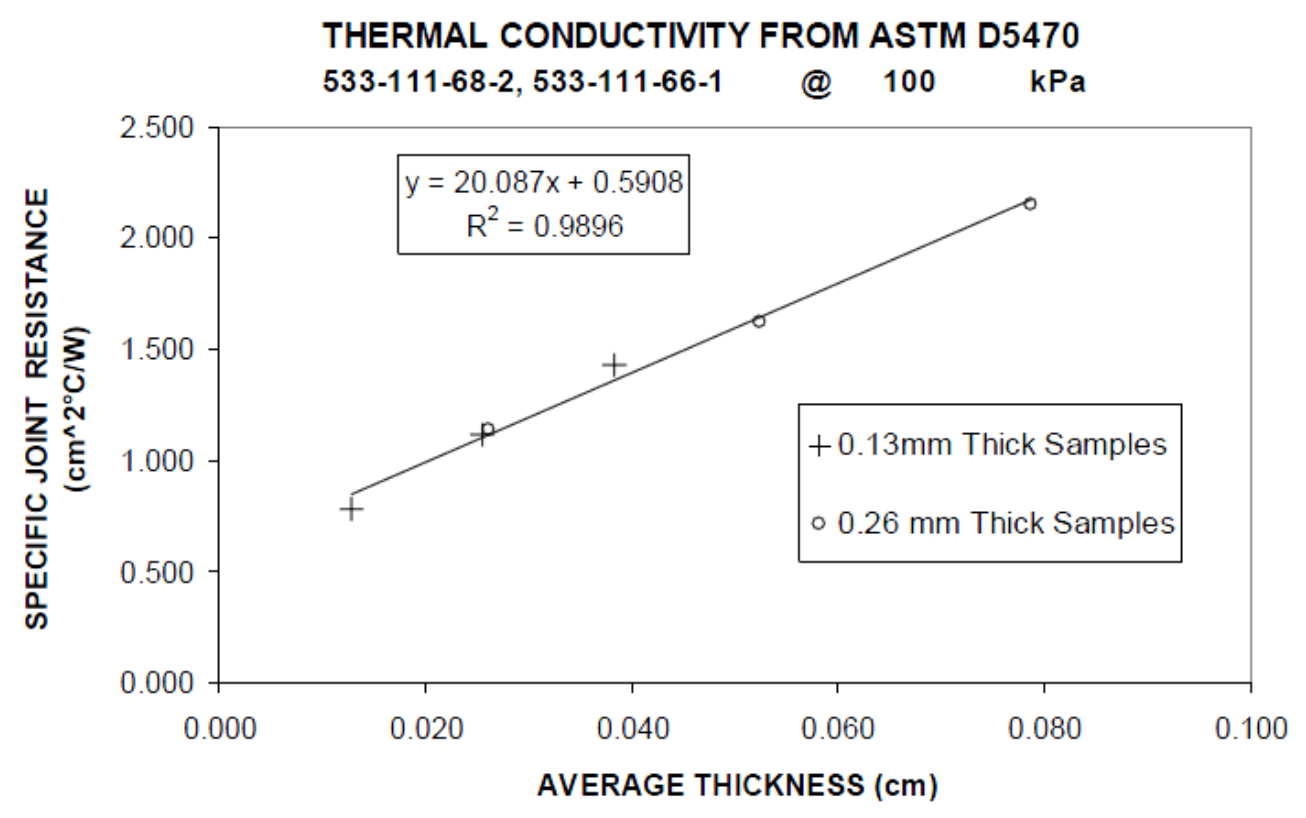

Figure 2-3: Specific Joint Resistance versus Thickness [40]

The results showed that the average joint resistance of the 1200 series baseline material was $1.62 \mathrm{~cm}^{2}-{ }^{\circ} \mathrm{C} / \mathrm{WS}$, while it was $0.85 \mathrm{~cm}^{2}-{ }^{\circ} \mathrm{C} / \mathrm{WS}$ for the baseline material with Polymer A, and $0.94 \mathrm{~cm}^{2}-{ }^{\circ} \mathrm{C} / \mathrm{W}$ for the addition of Polymer B. So, the addition of polymers reduced the average joint resistance by $48 \%$ and $42 \%$ for Polymer A and Polymer B, respectively. In addition, the contact resistance was reduced from $1.32 \mathrm{~cm}^{2}$ ${ }^{\circ} \mathrm{C} / \mathrm{W}$ of the baseline material to $0.59 \mathrm{~cm}^{2}-{ }^{\circ} \mathrm{C} / \mathrm{W}$ and $0.67 \mathrm{~cm}^{2}-{ }^{\circ} \mathrm{C} / \mathrm{W}$ with the addition of Polymer A and Polymer B, respectively. The average thermal conductivity was in the range between 4.2 to $4.9 \mathrm{~W} / \mathrm{m}-\mathrm{K}$.

Figure 2-4 summarizes the results of the comparative study in [40]. It shows that the contact resistance is dominant compared to bulk resistance. It also shows that the decrease in joint resistance is due to a reduction in the contact resistance. 
In another paper [41], Smalc and his coworkers measured the thermal performance of commercially available aluminum heat spreaders and of advanced heat spreaders made from flexible graphite. This paper describes the development of a test method, using thermal imaging, to measure the performance of these heat spreaders in a hydronic heating systems. Two flexible graphite materials, provided by GrafTech Inc., each with a different thermal conductivity and thickness were tested. Graphite material A had a thickness of $0.52 \mathrm{~mm}$, an in-plane thermal conductivity of $338 \mathrm{~W} / \mathrm{m} . \mathrm{K}$ and a thruthickness thermal conductivity of $3.0 \mathrm{~W} / \mathrm{m} . \mathrm{K}$. Graphite material B had a thickness of 0.41 $\mathrm{mm}$, an in-plane thermal conductivity of $367 \mathrm{~W} / \mathrm{m} . \mathrm{K}$ and a thru-thickness conductivity of 3.2 W/m.K [30]. A 13 micron layer of polyethylene terephthalate (PET) was laminated to the graphite to provide abrasion resistance and the material was mechanically knurled to improve flexibility (see Figure 2-5).

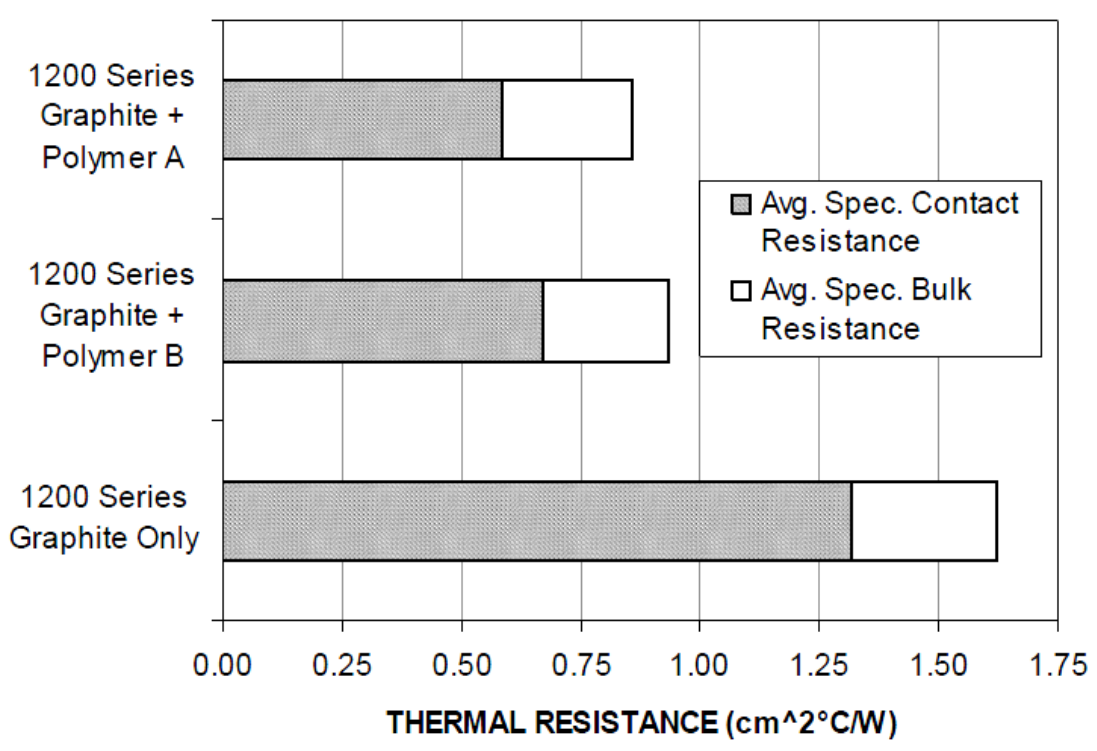

Figure 2-4: Average Thermal Resistance [40] 


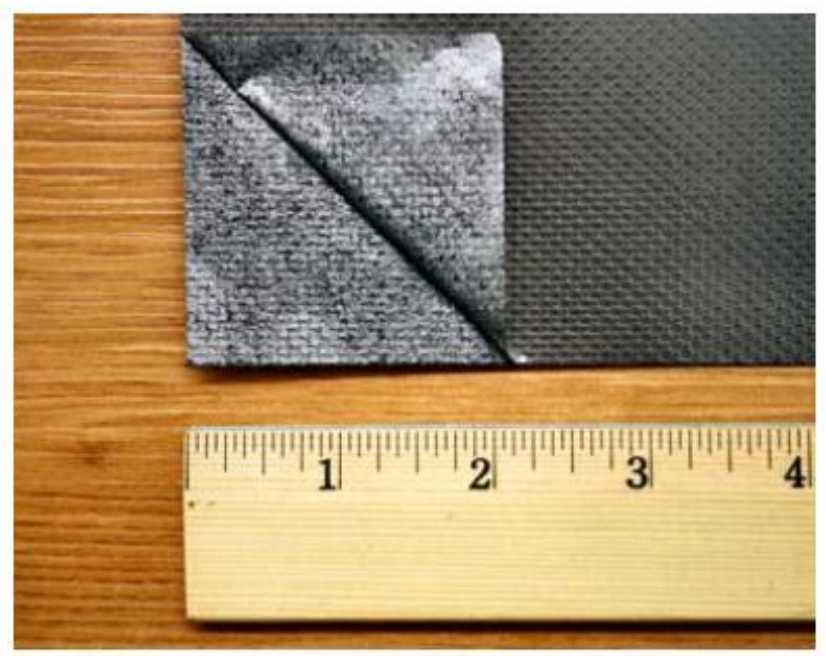

Figure 2-5: Knurled Flexible Graphite Sheet with Pet Layer Peeled Back [41]

The results showed that the graphite heat spreaders provide a $13 \%$ improvement in heat transfer compared to the rolled aluminum spreader, regardless of floor material. A comparison in terms of spreading coefficient $\mathrm{C}_{\mathrm{s}}$ was done, where $\mathrm{Cs}$ is given by:

$$
C_{s}=k . t
$$

where $\mathrm{k}$ is the spreader thermal conductivity and $\mathrm{t}$ is the spreader thickness. Based on the results, the spreading coefficient of the graphite spreaders with graphite material A was $0.175 \mathrm{~W} / \mathrm{K}$, while it was $0.151 \mathrm{~W} / \mathrm{K}$ of the graphite spreaders with graphite material $\mathrm{B}$. On the other hand, the spreading coefficient was 0.105 of the rolled aluminum spreader. This means that a graphite-based heat spreader has $44 \%-67 \%$ better spreading coefficient than an aluminum-based heat spreaders. 


\subsection{Conclusion}

The electrical battery is an electrochemical cell that converts chemical energy into electrical energy. Any change in energy from any form to another occurs with heat loss, according to the second law of thermodynamics. This heat loss increases the temperature of the cell. This increase in temperature affects the battery's efficiency; therefore, it should be removed. In order to do this, a thermal management system needs to be installed in order to keep the battery temperature within its operating range.

In general, the thermal management system can be passive, occurring without power consumption, or active; some external power-consuming source provides heating and/or cooling, such as fans and pumps. Air and liquid cooling are very common thermal solutions for batteries. In addition, new cooling technologies have been used such as PCM, graphite-bases heat spreaders.

Many factors affect the design of a thermal management system, such as the total cost effect on the system, heat exchanger possibilities, available space, as well as safety constraints. The choice of the heat transfer medium has a significant impact on the performance and cost of the thermal management system. 


\section{Chapter 3}

\section{MATHEMATICAL TOOLS AND METHODS}

Li-Ion batteries have become the main battery technology in high power applications. Yet they must be used properly to prevent accelerated aging, decreasing of performance, or damages [42]. The battery management system (BMS) helps to assess and control parameters that affect the performance of the battery, such as the state of charge (SoC), state of health $(\mathrm{SoH})$, and instantaneous available power [43], (see [44] for study on BMS). These parameters allow the vehicle energy management system (EMS) to determine the optimal operating strategy so that fuel consumption is minimized and battery pack durability is maximized [42].

In practice, however, some of the battery's parameters above are difficult quantities to estimate because direct measurements are either unreliable or impossible [44]. For example, SoC can be measured via current integration, but noise in the electrical current measurement can cause the estimate to deviate from the true value. SoH is often assessed in terms of capacity or power fading; both are measurable in a laboratory environment but are almost impossible to estimate during vehicle operations [42]. Many algorithms have been proposed in literature to solve this problem [45], ranging from data correlation 
methods such as artificial neural networks [46] and fuzzy logic systems [47-48] to model based approaches such as Kalman filtering [49] and sliding mode observers [50].

The need to analyze problems in more depth requires model-based approaches, which need a relatively minor effort for calibration in order to provide reasonable results; this makes the model-based approaches more favorable [42]. Various models of batteries have been built to predict their behavior. Different models have different ways of describing the battery; this depends on the complexity of the model and on how exactly it describes the essential factors that influence the performance of the battery. Therefore, research in the field of battery modeling aims at increasing the accuracy and the precision of the models without increasing their complexity.

This chapter discusses the tools and methods used to design and develop mathematical models for Li-ion battery. It starts with an overview of battery models; this overview briefly describes the fundamental battery models. Then, it presents, in details, the phenomenological battery models (i.e., Randle equivalent circuit). Further are introduced the control-oriented models, related to Randle equivalent circuit, and the determination of its parameters is explained. After that, this chapter shows the energy balance calculations in order to estimate heat generation rate of Li-ion batteries. This is done by studying different sources of heat generation inside lithium ion batteries with the aim to simplify the heat generation model. After that, a brief overview of heat transfer is presented, listing the major heat transfer equations of conduction, convection, and radiation that will be used later in solving our case study. Furthermore, finite element method FEM is 
introduced in this chapter, including a simple example to show how FEM solver works. Finally, this chapter reviews the open literature in mathematical models.

\subsection{Overview of Battery Models}

The mathematical models are often based on fundamental laws that represent an existing system. A mathematical battery model can be defined as a set of equations that express the main features of battery system in terms of variables that comprehensively describe the behavior of the system. Battery modeling, or the mathematical description of batteries, plays an important role in the design and use of batteries. The objective of battery modeling is to estimate battery performance under specific conditions of interest to the user of the battery.

This section discusses different approaches of Li-Ion battery modeling. This discussion covers and explains the two categories of model-based approaches: fundamental models and phenomenological models. Fundamental models (also known as first-principle models or electrochemical models) present the first principle properties of the battery based on its physical and chemical fundamentals, which makes it very accurate. However, they are generally not very suitable for use in control and estimation applications due to their inherent complexity in describing the chemical behavior of the battery.

A common fundamental model was made by Newman, Fuller, and Doyle of the University of California at Berkeley [51,52]. In their work, the mass diffusion equation was applied and a general 1+1D model using porous electrode and concentrated solution 
theories was introduced. This model contained two composite electrodes and a separator for predicting the discharge behavior of dual insertion cells (see Figure 3-1). The galvanostatic charge and discharge of the cell sandwich shown in Figure 3-1 was modeled. One-dimensional transport of lithium ions from the negative electrode through the separator into the positive electrode was considered. The composite electrodes consist of an inert conducting material, the electrolyte, and the solid active insertion particles. The model is general and can be used to simulate any cell utilizing two composite electrodes composed of a mixture of active insertion material, electrolyte, and inert conducting material.

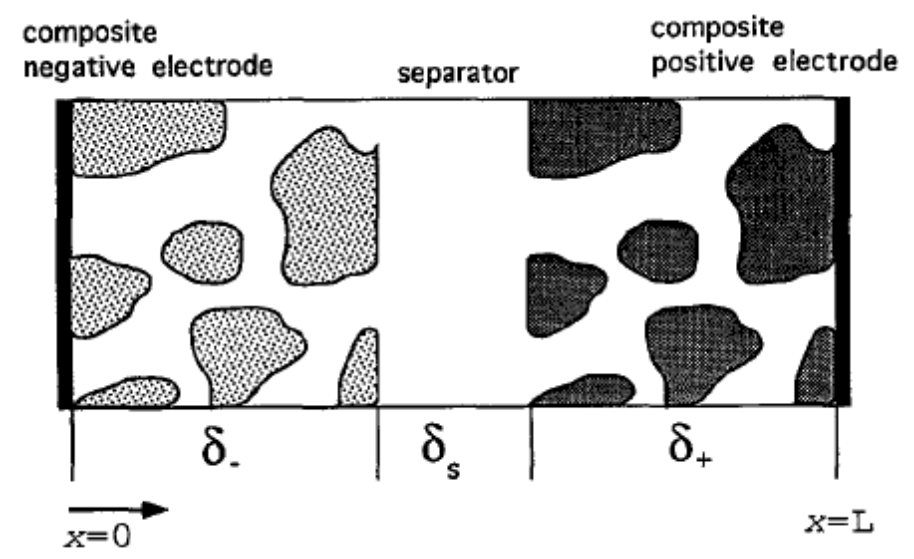

Figure 3-1: Dual-insertion cell sandwich consisting of composite negative and positive electrodes and separator [52]. 
The fundamental models allow the total understanding of the physics beyond a Li-Ion battery cell; and they can be used to compare or calibrate other models that neglect the physical diffusion problems.

The other type of models is the phenomenological models, which do not represent the physical foundations principles of the battery cell. Instead, they provide a representation of the input/output relationship of the battery. In contrast with fundamental models, phenomenological models provide a representation of the dynamic behavior of the battery without investigating the physical fundamental. The phenomenological models use the common electrical components (e.g. resistors, capacitors, voltage sources, and current sources) as well as nonlinear components (such as a Warburg impedance) to approximate the underlying chemical behavior of the battery (diffusion effects, concentration gradients, etc) [42].

The challenge in using phenomenological models is that in their most basic form, they cannot account for the battery behavior over all applicable operating regions. To date, most work on equivalent circuit modeling and identification available in the open literature focuses on isothermal (single temperature) models [42,53].

Examples of phenomenological models are the equivalent circuit models. The equivalent circuit model has a simple structure but can capture sufficient dynamics under both temperature and SoC variation, thus making it applicable for use with real-time modelbased estimation algorithms in automotive applications [53-54].

The most common phenomenological model is the Randle equivalent circuit model. This model consists of a voltage source (open-circuit voltage, $\mathrm{V}_{\mathrm{oc}}$ ) and an internal resistance 
$\mathrm{R}_{0}$, which is connected in series to $\mathrm{n}$-times parallel RC circuits. All of them depend on SOC and temperature. This model is shown in Figure 3-2.

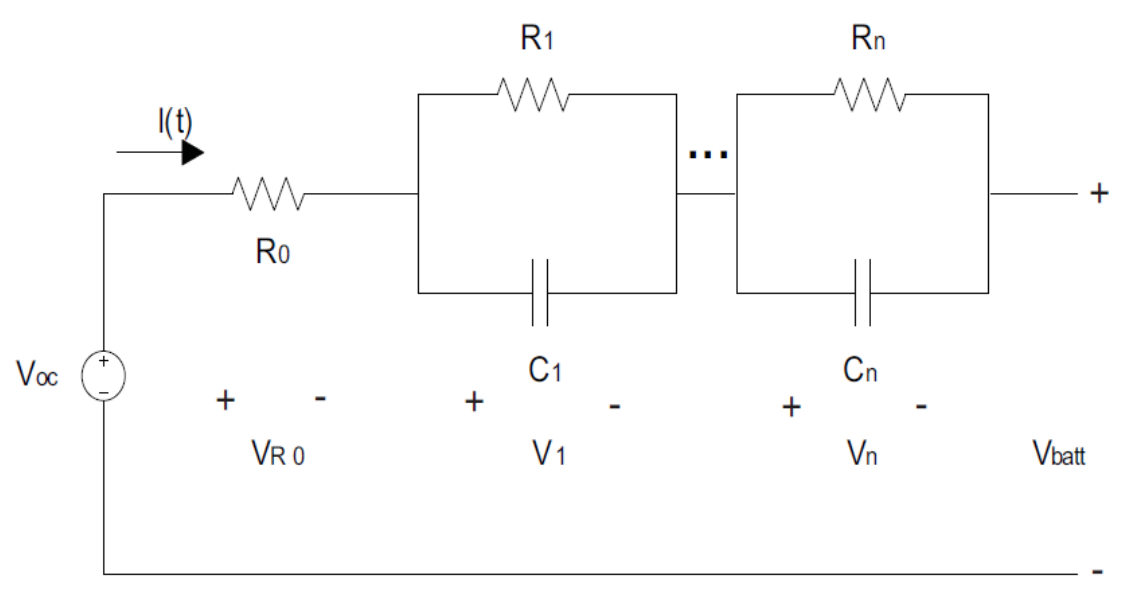

Figure 3-2: Randle Equivalent Electrical Circuit Model [42]

In order to determine the parameters of the Randle equivalent circuit model, a first order dynamic system is used to describe the model:

$$
\frac{d V_{i}}{d t}=-A_{i} V_{i}+A_{i} B_{i} I
$$

where $A_{i}=1 /\left(R_{i} C_{i}\right)$, and $B_{i}=R_{i}$.

The first parameter to be determined in the model is the OCV. Since the $\mathrm{SoC}$ in the model ranges in a relatively large transition, the relation between the OCV and SoC is approximately linear. The OCV is modeled by a double exponential:

$$
V_{o c}(z)=V_{0}+\alpha\left(1-e^{-\beta z}\right)+\gamma z+\zeta\left(1-e^{-\frac{\varepsilon}{1-z}}\right)
$$


where $\mathrm{z}$ is the SOC as a decimal value (between 0 and 1), while all other parameters are tunable as functions of time.

The second component of the model is the capacitance, and it can be related to SoC (or z) by Equation 3-3; this is based on the definition of the nominal capacity of a battery to be the amount of Ah's that can be drawn from the battery at 1C-rate discharge at room temperature after a full charge before the battery.

$\dot{z}=-\frac{1}{3600 C(T)} I$

In addition, hysteresis voltage effect was taken into consideration in this model; that effect was formulated in the following function:

$$
\dot{V}_{h}=\Gamma|I|\left(M(z, \dot{z}, T)-V_{h}\right)
$$

where $\Gamma$ is the hysteresis transition factor (an indication of how fast the hysteresis occurs) and $M$ is the maximum amount of hysteresis voltage that can occur at a specific SoC and temperature.

Finally, the battery voltage is written as:

$$
V_{\text {batt }}=V_{o c}-R_{0} I-\sum_{i=1}^{n} V_{i}+V_{h}
$$

The number of RC circuits in the model needs to be decided to match the desired order of the model. The higher the order of the model is, the better is the frequency response, leading to a better time domain approximation, yet also leading to a complex model. Therefore, the lowest acceptable order is used. After the order of the system has been determined, the model needs to be subjected to asymmetric step current, and the output 
voltage needs to be measured. From the results, the rest of parameters ( $\mathrm{R}_{0}$ and $\left.R C^{\prime} s\right)$ would be determined by a complex algorithm, the genetic algorithm [55].

Equivalent circuit models are inherently simple and fit for real time implementation. Thus, its accuracy is lower than fundamental models. Nevertheless, the simple structure and the low computation effort of the low-order equivalent circuit models make them useful to design control algorithms [53].

The control-oriented models are built, basically, from two subsystems - thermal and electrical - with an intermediate parameter estimation stage as shown in Figure 3-3.

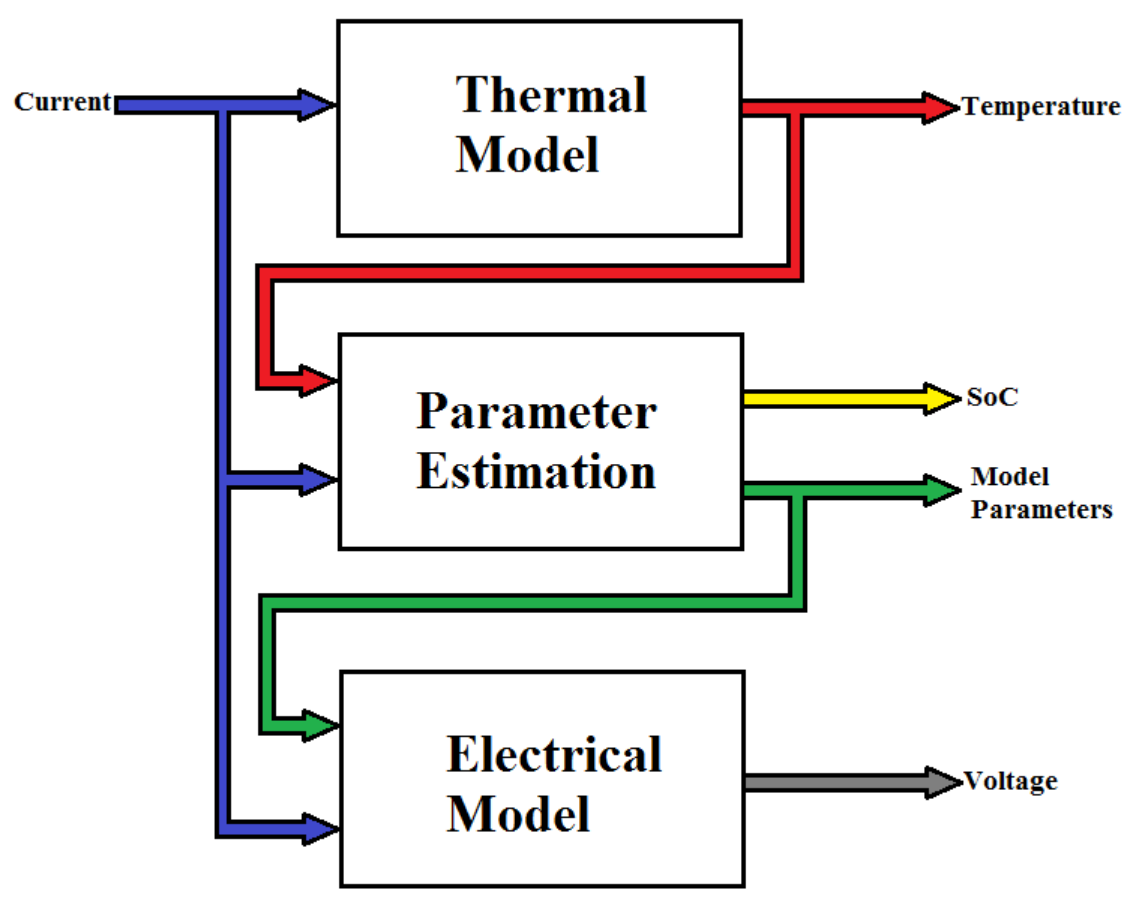

Figure 3-3: Control-oriented Model Block Diagram 
The thermal model calculates the heat generated by the discharge current. After that, the thermal model determines the temperature of the battery, assuming a convection cooling with a given heat transfer coefficient $h$. The thermal model assumes that the battery is a lumped body, the implication being that the temperature distribution of the battery is uniform in all directions at any moment during the transient heat transfer process [56]. The thermal model determines the temperature of the battery by solving Equation 3-6.

$$
\frac{d T}{d t}=\frac{\dot{Q}-A h\left(T-T_{\infty}\right)}{m . c}
$$

where $\dot{Q}$ is the heat generated by the joule effect in the battery, $A h\left(T-T_{\infty}\right)$ is the dissipated heat by convection, $\mathrm{m}$ is the mass, and $\mathrm{c}$ is the specific thermal capacity. Equation 3-7 formulates $\dot{Q}$ for a Randle equivalent circuit of order N.

$$
\dot{Q}=R I^{2}+\sum_{1}^{N} R_{i} I_{i}{ }^{2}
$$

After predicting the temperature, the battery model estimates parameters for the Randle equivalent circuit (e.g. SoC, OCV). The first parameter to estimate is the state of charge SoC. The model estimates SoC by applying the discharge current to Equation 3-8.

$$
\operatorname{SoC}(t)=\operatorname{SoC}_{0}-\int_{0}^{t} \frac{\eta I(t)}{C_{n}} d t
$$

where $\mathrm{SoC}_{0}$ is the initial state of charge, $\mathrm{C}_{\mathrm{n}}$ is the nominal cell capacity, and $\eta$ is the Coulombic efficiency factor assumed to be equal to unity.

After determining the SoC, the model calculates the open circuit voltage OCV, the internal resistance and the capacities and resistances of the Randle circuits. The OCV is a 
function of current and temperature, while other parameters are determined using different lookup tables for charge and discharge processes.

Finally, the estimated parameters take place in the Randle equivalent circuit (electrical model). And the battery voltage is eventually determined as shown in Equations 3-1 to 35.

\subsection{Heat Generation Modeling}

Energy balance calculations are required for the design and thermal management of battery systems. A proper cell energy balance will give reliable predictions of thermal characteristics such as heat generation. The temperature of a cell changes as a result of electrochemical reactions, phase changes, mixing effects, and joule heating. In 1985, heat generation mathematical modeling analyses of Lithium-ion batteries were presented in Bernardi et al. [15]. The authors developed equation that incorporates these effects in a complete and general manner. They discussed simplifications and special cases; they applied the results to a mathematical model of the $\mathrm{LiAl} / \mathrm{FeS}$ secondary cells discharged through two different reaction mechanisms. This example illustrates how the energy equation may be applied to a specific system to examine the relative contributions corresponding to the terms in the equation. Furthermore, it shows that the processes involved in estimating heat generation may be complex and that the application of a sufficiently general energy equation is advantageous [15].

Bernardi et al. found that the simplified energy balance equation to describe electrochemical system is given by: 


$$
\dot{Q}=I\left(V-V_{o c}+T \frac{\partial V_{o c}}{\partial T}\right)+C_{p} \frac{d T}{d t}
$$

where $\dot{Q}$ is the rate of heat transferred from the surroundings to the system, $I$ is the current (positive during discharge), $V$ is the cell terminal voltage, $V_{o c}$ is the open circuit voltage, $T$ is the temperature, and $C_{p}$ is the heat capacity. This equation is commonly used in the literature to describe the heat generation rate of Li-ion battery.

The work of Bernardi et al. [15] was extended, in 2003, to consider the effect of lithium concentration in intercalation compounds by Thomas and Newman [17]. They derived a general energy balance equation that includes the four sources of heat generation inside lithium ion batteries during operation. In addition to the irreversible resistive heating, this equation included a second term for the reversible entropic heat, a third term for the heat change of chemical side reactions, and a fourth term the heat of mixing due to the generation and relaxation of concentration gradients. For further details, see [17].

In our study, the energy balance equation adopted was the simplified one that was presented in many papers in the open literature (i.e. [1], [3], [6], [16], and [57]). This equation accounts only for the irreversible ohmic heat loss occurring when the battery current flows through internal resistances. It is caused by the deviation of the cell potential from its equilibrium potential by internal resistance. Therefore, the difference between the terminal voltage and the open circuit voltage is converted into heat according to Equation 3-10 [6,16].

$$
Q_{O}=I\left(V_{o}-V\right)
$$


Practically, the heat $\mathrm{Q}_{\mathrm{s}}$ by entropy change is relatively small compared to the heat $\mathrm{Q}_{\mathrm{o}}$ by ohmic losses. Thus, the heat is mainly generated from the battery during charge and discharge because of the internal resistances [3,57].

\subsection{Overview of Heat Transfer}

Heat transfer is the discipline of thermodynamics that deals with the temperature and the flow of heat between bodies. Temperature represents the amount of thermal energy available, while heat flow represents the movement of thermal energy as a result of a difference in temperature. The science of heat transfer predicts the rate at which the heat is transferred. In this overview, two textbooks were used as references: Incropera [56] and Holman [58].

There are three modes of heat transfer:

1. Conduction is an exchange of thermal energy, in the presence of temperature gradient, from the more energetic to the adjacent less energetic particles of a substance due to interactions between particles;

2. Convection is the transfer of thermal energy between a surface and a moving fluid by the bulk motion of the fluid (i.e. liquids, gases);

3. Radiation is a transfer of energy emitted by matter in the form of electromagnetic waves or photons by atomic and subatomic excitement at the surface of a body. 


\subsubsection{Conduction}

In conduction, the rate of energy transferred per unit is directly proportional to the temperature gradient. Another way to describe this fact for one-dimensional system is Fourier's law of heat conduction:

$$
q=-k \frac{\partial T}{\partial x}
$$

where $q$ is the heat flow rate in $W / m^{2}, \frac{\partial T}{\partial x}$ is the temperature gradient in the direction of heat flow in $K / m, A$ is the cross-sectional surface area in $m^{2}$, and $k$ is the thermal conductivity in $W /(K . m)$. The direction of heat flow in the one dimension case is normal to the isothermal surface ${ }^{4}$ and pointing in the direction of decreasing temperature.

The conduction system is either a one-dimensional system (heat flows in one direction only) or a multi-dimensional system. Furthermore, the system can be either a steady state (the temperature does not change with time) or unsteady state (the temperature changes with time).

\subsubsection{Steady-State Heat Conduction}

In this case, Equation 3-11 can be simply integrated to solve for the temperature:

$$
\frac{d^{2} T}{d x^{2}}+\frac{\dot{q}}{k}=0
$$

and it can be written for 3D as shown in Equation 3-13:

\footnotetext{
${ }^{4}$ Surface characterized at a given moment by an identical temperature in all its points
} 


$$
\nabla(k \nabla T)+\dot{Q}=0
$$

where $\nabla T$ is the gradient of the temperature in three directions.

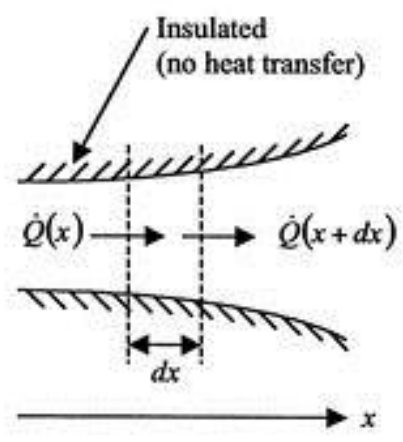

Figure 3-4: Steady-state Heat Conduction

\subsubsection{Unsteady-State Heat Conduction}

In this case, the temperature changes with time; this change might be caused by heat sources or heat sinks in the system. For the element of thickness $(d x)$ shown in Figure 3-4 holds the following energy balance:

Energy in + Heat generated within element $=$ Change in internal energy + Energy out This equation can be rewritten as:

$$
-k A \frac{\partial T}{\partial x}+\dot{q} A d x=\rho c A \frac{\partial T}{\partial t} d x-A\left[k \frac{\partial T}{\partial x}+\frac{\partial}{\partial x}\left(k \frac{\partial T}{\partial x}\right) d x\right]
$$

and to deal with multi-dimensional conduction:

$$
\nabla(k \nabla T)+\dot{Q}=\rho c \nabla T
$$

where $c$ is specific heat of material $\left(\mathrm{J} / \mathrm{kg}^{\circ} \mathrm{C}\right)$, and $\rho$ is density $\left(\mathrm{kg} / \mathrm{m}^{3}\right)$. 


\subsubsection{Convection}

The convection mode is the transfer of thermal heat between a surface and a bulk moving fluid. Regardless of the particular nature of the convection heat transfer process, the appropriate rate equation is given by the Newton's law of cooling.

$$
q_{c o n v}=h\left(T_{s}-T_{\infty}\right)
$$

where $q_{c o n v}$ is the convective heat flux $\left(W / \mathrm{m}^{2}\right), h$ is the convection heat transfer coefficient $\left(\mathrm{W} / \mathrm{m}^{2} . K\right), T_{s}$ is the surface temperature $(K)$, and $T_{\infty}$ is the fluid temperature $(K)$. The convection heat transfer coefficient $(h)$ depends on the geometry of the boundary layer, the flow properties such as velocity, viscosity and other flow and temperature dependent properties.

The convective heat transfer can be either natural (free) convection or forced convection. In the natural (free) convection, the fluid moves naturally by differences in the fluid densities occurring because of temperature gradients. In the forced convection, by contrast, the fluid moves by an external source (e.g. pump, fan).

\subsubsection{Radiation}

Despite the fact that the transfer of heat by conduction or convection needs a material medium, the transfer of heat by radiation does not require the presence of an intervening medium. Radiation occurs efficiently in vacuum and is described by the StefanBoltzmann law; its more general case of a grey surface is shown in Equation 3-17.

$q=\varepsilon \sigma T_{s}^{4}$ 
where $q$ is the surface emissive power in $\left(W / m^{2}\right), \varepsilon$ is the emissivity (a radiative property of the surface), $\sigma$ is the Stefan-Boltzmann constant $\left(\sigma=5.67 \times 10^{-8} \mathrm{~W} / \mathrm{m}^{2} \cdot \mathrm{K}^{4}\right)$, and $T_{s}$ is the absolute surface temperature. A special case involves radiation exchange between a small surface at temperature $T_{s}$ and a much larger isothermal surface that surrounds the smaller one completely at a temperature of $T_{\text {surf }}$. The net rate of heat transfer from the surface is expressed in Equation 3-18.

$$
q=\varepsilon \sigma\left(T_{s}^{4}-T_{\text {surf }}^{4}\right)
$$

In order to solve heat transfer equations in 3 dimensions, numerical method is used, especially, when the geometry is complex. The most common numerical method to solve partial differential equations is the finite element method (FEM).

\subsection{Finite Element Method}

Finite Element Method (FEM) is a numerical technique which provides approximate solutions to partial differential equations (PDE). FEM has a wide range of applications such as fluid flow and heat transfer. In FEM, a given, geometrically complex, domain is divided to a collection of subdomains, called finite elements. Over each finite element, the approximation functions are derived using the basic idea that any continuous function can be represented by a linear combination of algebraic polynomials. The main reason behind seeking approximate solution on a collection of subdomains is the fact that it is easier to represent a complicated function as a collection of simple polynomial. Then, algebraic relations among the undetermined coefficients (i.e., nodal values) are obtained 
by satisfying the governing equations, often in a weighted-integral sense, over each element.

Each individual segment of the solution should fit its adjacent segments in the sense that the function and possible derivatives up to a chosen order are continuous at the connecting points [59]. The approximation functions are often taken to be algebraic polynomials, and the undetermined parameters represent the values of the solution at a finite number of preselected points, called nodes, on the boundary and in the interior of the element. The approximation functions are derived using concepts from interpolation theory and are therefore called interpolation functions. The degree of the interpolation functions depends on the number of nodes in the element and the order of the differential equation being solved.

As an example, the perimeter of a circle of radius R, as shown in Figure 3-5(a), will be determined using finite element method (FEM). The first step is the discretization of the domain (i.e., the perimeter of the circle) by representing it as a collection of a finite number $\mathrm{n}$ of subdomains, namely, line segments. Each subdomain (i.e., line segment) is called an element. The collection of elements is called the finite element mesh. The elements are connected to each other at points called nodes. The line segments can be of different lengths. When all elements are of the same length, the mesh is said to be uniform; otherwise, it is called a nonuniform mesh (see Figure 3-5(b)).

After that, a typical element (i.e., line segment) is isolated and its required properties (i.e., length) are computed by some appropriate means. Let $h_{e}$ be the length of the element in the mesh in the present example. For a typical element, $h_{e}$ is given by: 


$$
h_{e}=2 R \sin \left(\frac{\theta_{e}}{2}\right)
$$

where $R$ is the radius of the circle and $\theta_{e}(<\pi)$ is the angle subtended by the line segment; see Figure 3-5(c). This equation is called element equation.

The approximate value of the perimeter of the circle is obtained by putting together the element properties; this process is called the assembly of the element equations. It is based, in the present case, on the simple idea that the total perimeter of the polygon (assembled elements) is equal to the sum of the lengths of individual elements:

$$
p=\sum_{1}^{n} h_{e}
$$

If the mesh is uniform, then $\theta_{e}=2 \pi / \mathrm{n}$; therefore:

$$
p=n\left(2 R \sin \frac{\pi}{n}\right)
$$

Although this example is simple, it shows how FEM works in solving engineering problem ranging from the circumference of a circle to a system of partial differential equations PDEs. In summary, it is shown that FEM can approximate as closely as is required by a finite number of piecewise-linear functions, which, however, occurs at the cost of complexity. As the number of elements increases, the approximation improves; therefore, the error in the approximation decreases. 


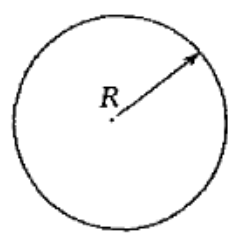

(a)

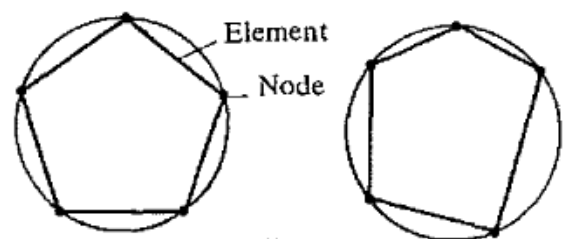

(b)

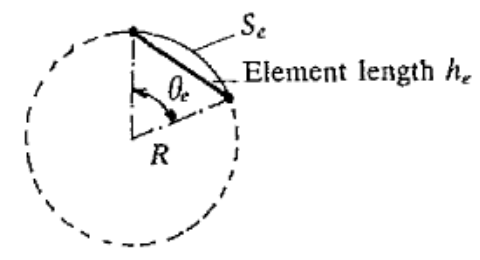

(c)

Figure 3-5: Approximation of the circumference of a circle by line elements: (a) Circle of radius R; (b) uniform and non-uniform meshes; (c) a typical element [59]

\subsection{Literature Review of Mathematical Models}

\subsubsection{Fundamental Models}

The fundamental models are based on first principle physical and chemical properties of the battery, which makes it very accurate. However, they are generally not very suitable for use in control and estimation applications due to their inherent complexity in describing the chemical behavior of the battery $[42,60]$.

The literature on fundamental models of Li-ion battery is extensive. Santhanagopalan et al. in their paper [61] reviewed the work done in the Li-ion modeling. Doyle and Newman [62] presented simplified models to develop design correlations under limiting cases. The development was based on porous-electrode theory, where the electrode is treated as two superimposed continua without regard for the actual geometry detail of the pore structure.

Ramadass et al. [63] extended the first model presented by Fuller et al. [52] to account for the decay in capacity of the cell with cycle number. This capacity fade model could be used as a basis for predicting the cycle life and analyzing the discharge characteristics 
of Li-ion cells after any cycle number. The effect of OCV, DoD ${ }^{5}$, the film resistance, the exchange current density, and the overvoltage of the parasitic reaction were studied qualitatively. It was proposed that a side reaction leading to the formation of a film on the surface of the carbon particles at the anode might occur during the charging process. The potential drop across the film was expressed as a function of the film thickness, which varied with time in accordance with Faraday's law. The loss of active material due to the side reaction and the resultant additional drop in the anodic overpotential were used to account for the capacity to fade in the cell. Further extensions to this model were made by Sikha et al. [64] that included the change in the porosity of the electrode material as a function of time.

In all these models, the concentration of lithium within the solid phase was either calculated using the superposition principle [65] or solved for rigorously, using a pseudo second dimension along the radius of the particle. Since the concentration of lithium at the particle surface is the only variable of interest, this methodology is cumbersome and time consuming.

Subsequently Wang et al. have focused on Electrochemical-Thermal Modeling ECTcoupled modeling for Li-ion batteries, especially for automotive applications [66]. Model validation was performed against experimental data of full cells only. A very good approximation of the concentration profile within the solid phase was presented

5 Depth of Discharge; it is the amount of energy that has been removed from a battery. It is usually expressed as a percentage of the total capacity of the battery. For example, $80 \%$ DOD means that eighty percent of the energy has been discharged, so the battery now holds only $20 \%$ of its full charge. 
independently by Subramanian et al. [67] and was based on the integral approach outlined by Ozisik [2]. In this second approach, the concentration profile within the solid particle is approximated by a second degree polynomial whose coefficients are expressed in terms of the average concentration of lithium inside the particle and the concentration at the surface. Thus, the need to solve for the concentration profile within the solid phase is eliminated. While most of these models adopt the porous electrode approach, Haran et al. [68] presented a simpler representation of the electrode. This was first presented for the metal hydride system and later extended to the lithium ion system [69]. In this model, each electrode is represented by a single spherical particle as shown in Figure 3-6. This approach is popularly referred to as the single particle model.

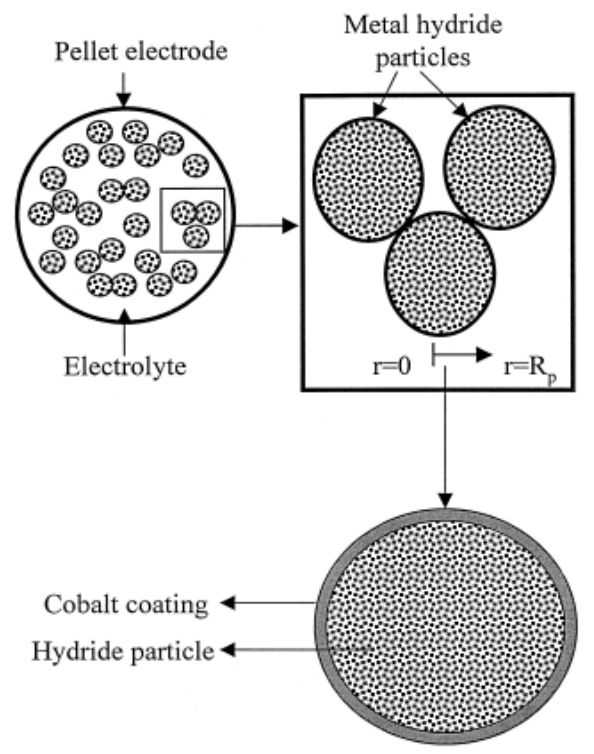

Figure 3-6: Schematic of the spherical hydride particles [68] 
More recent contributions by Fang, his co-workers (the Pennsylvania State University), and Y. Ishikawa (of Honda R\&D Americas, Inc.) evaluated and predicted cell aging [14]. In order to evaluate and predict cell aging, the authors introduced an electrochemistry transport-degradation models by taking the side reactions into account. Such a model is useful for studying Li-ion battery degradation and the voltage prediction during constant current charge/discharge under room temperatures. This model was also validated against experimental data from tests designed for HEV cells under both room and low temperatures.

In another paper, Fang and his co-workers developed and experimentally validated capability to predict performance of individual electrodes of Li-ion cells under HEV conditions that encompass a wide range of ambient temperatures [70]. A commercial 1.2Ah 18650 cells with a graphite anode and a nickel-manganese-cobalt oxide cathode as well as the electrolyte of 1.2M LiPF6 in EC/DMC were used in all experiments.

The model is first validated by constant current charge and discharge experiments at current rates ranging from $1 \mathrm{C}(1.2 \mathrm{~A})$ to $10 \mathrm{C}(12 \mathrm{~A})$, at room temperature $\left(25^{\circ} \mathrm{C}\right)$. The cell then is discharged with constant current until the voltage drops to $2.8 \mathrm{~V}$. A modelexperimental comparison is shown in Figure 3-7, from which it is clear that the predictions match the experimental data quite well for a wide range of C-rates. At low charge/discharge rates, the cell potential stays close to the cell's OCP. As the charge/discharge rate increases, the cell voltage deviates significantly from the OCP due to ohmic (electrolyte ionic resistance), activation ( $\mathrm{Li}$ insertion/ extraction kinetics), and mass transport ( $\mathrm{Li}$ transport in electrolyte and active material particles) losses. The 
measured and predicted cell temperatures are compared in Figure 3-7 at various charge and discharge currents. There is almost no temperature rise for the $1 \mathrm{C}$ case as the generated heat is small and can be readily dissipated to the ambient (fixed at $25^{\circ} \mathrm{C}$ ). As the $\mathrm{C}$ rate increases, the cell temperature starts to rise significantly above the ambient temperature. For the $2 \mathrm{C}$ charge/discharge cases, the cell temperature remains at $\sim 2-3^{\circ} \mathrm{C}$ above the ambient temperature after about $0.2 \mathrm{Ah}$ charge/discharge capacity when the heat generation and dissipation reaches equilibrium.
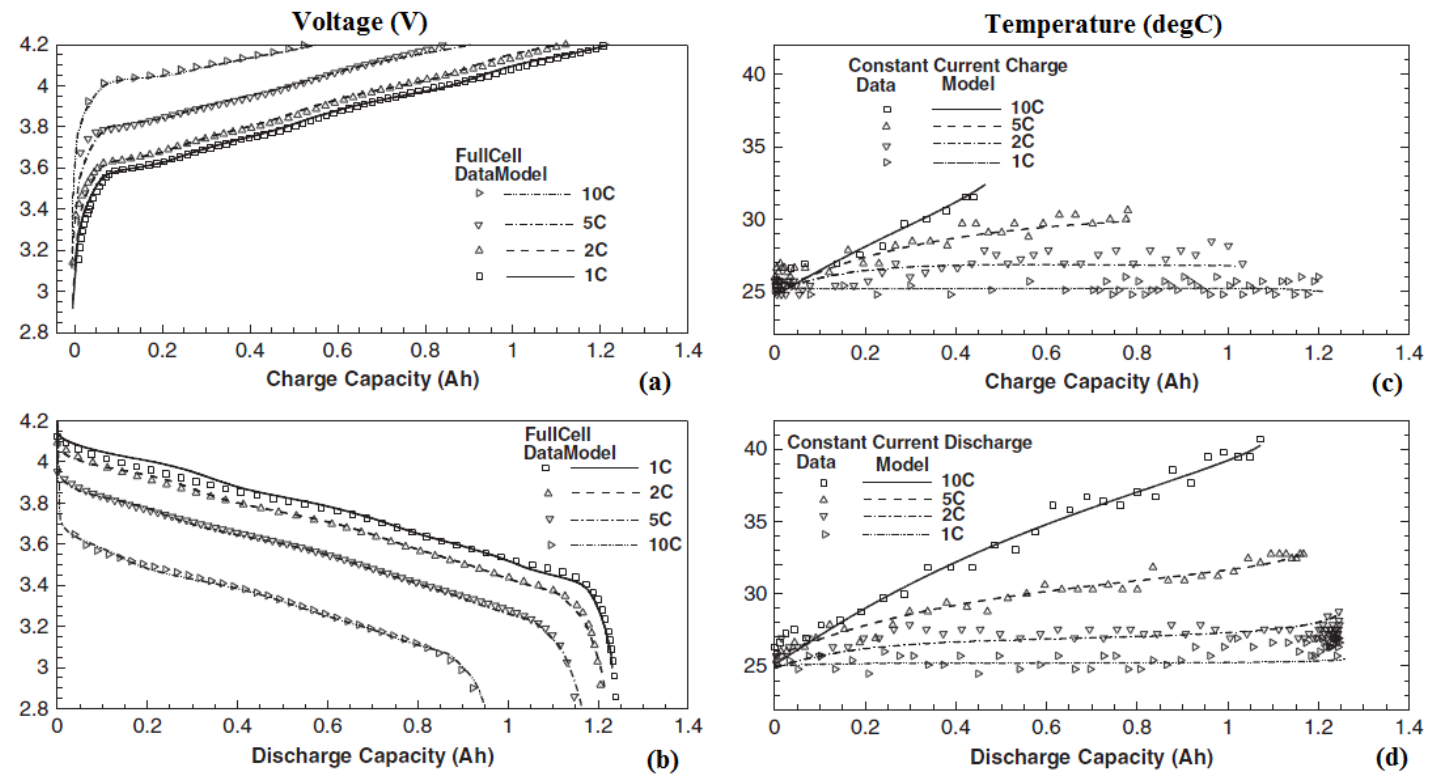

Figure 3-7: Experimental and simulated of cell voltages: constant current (a) charge and (b) discharge, and constant temperature (c) charge and (d) discharge [70]

The model prediction agrees with the experimental data. For all the cases, the model captures the cell temperature reasonably well, indicative of the accuracy of the present ECT model. 
According to the previous papers, the fundamental models allow the total understanding of the physics beyond a Li-Ion battery cell; and they can be used to compare or calibrate other models that neglect the physical diffusion problems.

\subsubsection{Phenomenological Models}

The phenomenological models do not represent the physical foundations principles of the battery cell; instead, they provide a representation of the input/output relationship of the battery. The challenge in using phenomenological models is that in their most basic form, they cannot account for the battery behavior over all applicable operating regions. To date, most work on equivalent circuit modeling and identification available in the open literature focuses on isothermal (single temperature) models [42,53].

Examples of phenomenological models are the equivalent circuit models. The equivalent circuit model has a simple structure but can capture sufficient dynamics under both temperature and SoC variation, thus making it applicable for use with real-time modelbased estimation algorithms in automotive applications [53-54].

This section reviews some of the literature of the equivalent circuit models. This section presents the work of Johnson and Pesaran of the National Renewable Energy Laboratory, who built a resistive equivalent circuit battery model, which is presented in their paper [54]. In the same paper, Sack introduces the "two-capacitance model" developed by Saft America.

In 1994, NREL developed a vehicle simulation tool called ADVISOR, which is Simulink-based software [71]. Using ADVISOR, NREL modeled the Li-ion battery as a 
temperature-dependent resistive equivalent circuit model. This model was called internal resistance model and was referred to as ADV model (see Figure 3-8). The internal resistance of the ADV model was not dependent on the magnitude of the current drawn from the battery. The ADV battery model consisted of an internal resistance $\left(\mathrm{R}_{\text {int }}\right)$, which depends on SOC, temperature, and the direction of current flow charging/ discharging, along with a voltage source (OCV), which depends only on SOC and temperature.

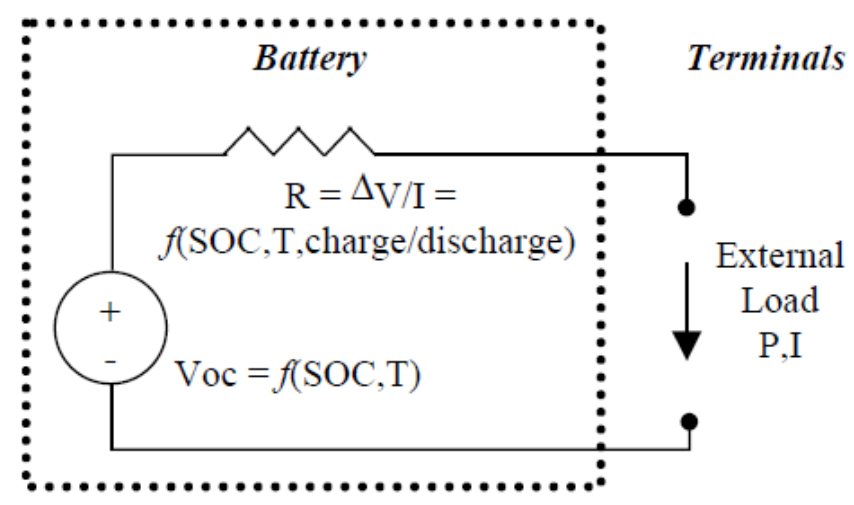

Figure 3-8: Internal Resistance Battery Model (ADV model) [71]

To estimate the internal resistance $\mathrm{R}_{\text {int }}$, a series of pulses of constant current was applied to the battery and the voltage response was recorded, as shown in Figure 3-9. Assuming that the OCV and the resistance are constant during the current pulse, the $\mathrm{R}_{\text {int }}$ could be simply calculated by Equation 3-22.

$$
R=\frac{V_{o c}-V_{t e r m}}{I}=\frac{V_{3}-V_{2}}{I}
$$

The two-capacitance battery model, or the RC model, developed by Saft America is shown in Figure 3-10. Saft tested 12-Ah Li-ion cells and derived state space equations 
(Equations 3-23 and 3-24) to describe the dynamic behavior of the model. The state space equations were solved for the output voltage by Simulink's state space block at a single 200A pulse discharge current.

$$
\begin{aligned}
& {\left[\begin{array}{c}
\dot{V}_{C b} \\
\dot{V}_{C c}
\end{array}\right]=\left[\begin{array}{cc}
-\frac{1}{C b(\operatorname{Re}+R c)} & \frac{1}{C b(\operatorname{Re}+R c)} \\
\frac{1}{C c(\operatorname{Re}+R c)} & -\frac{1}{C b(\operatorname{Re}+R c)}
\end{array}\right]\left[\begin{array}{c}
V_{C b} \\
V_{C c}
\end{array}\right]+\left[\begin{array}{c}
\frac{-R_{c}}{C_{b}\left(R_{e}+R_{c}\right)} \\
-\frac{1}{C c}+\frac{R_{c}}{C_{c}\left(R_{e}+R_{c}\right)}
\end{array}\right]\left[I_{s}\right]} \\
& {\left[V_{o}\right]=\left[\begin{array}{ll}
\frac{R_{c}}{R_{e}+R_{c}} & \frac{R_{e}}{R_{e}+R_{c}}
\end{array}\right]\left[\begin{array}{l}
V_{C b} \\
V_{C c}
\end{array}\right]+\left[R_{t}-\frac{R_{c} R_{r}}{R_{e}+R_{c}}\right]\left[I_{s}\right]}
\end{aligned}
$$

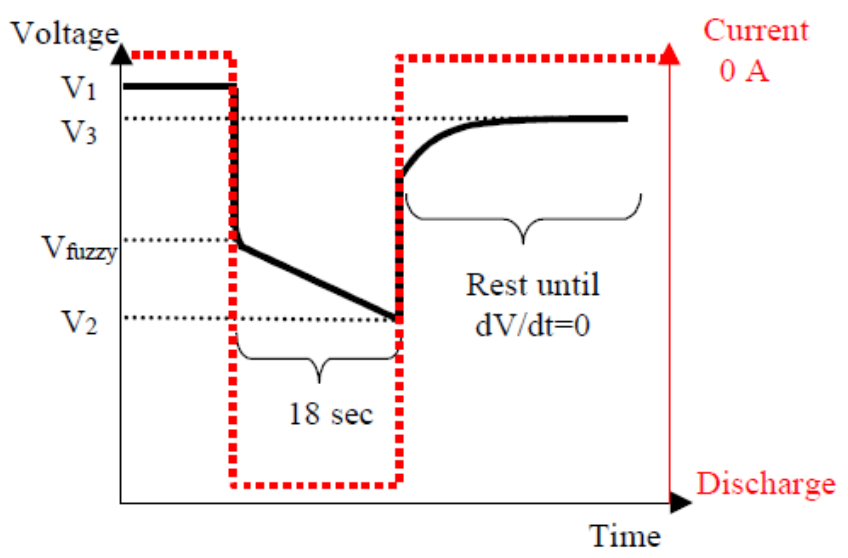

Figure 3-9: The current pulse and the measured voltage [71] 


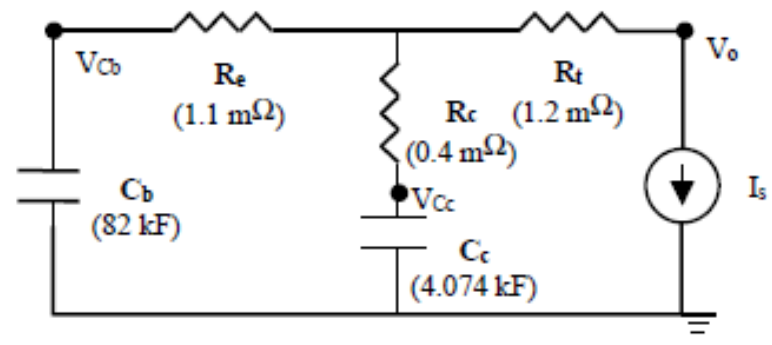

Figure 3-10: Two-capacitance battery model (RC model) [71]

The next step was to validate the two models over a US06 cycle for 600 seconds. Figure 3-11 shows that both models met exactly the requested power. Figure 3-12 shows the voltage comparison between the two models. During both charge and discharge, none of the two models exceeded the voltage limits, but the ADV model overshot the experimental values. During rest, the RC-model voltage dropped gradually, as did the experimental voltage, but the ADV-model voltage was constant and lower than experimental values.

After validating the two models, the co-authors compared the two models for their response of a demanding power request and for their ability to predict SoC. The results of both models were compared to experimental values in order to clarify the differences between the two models. The comparison showed that the ADV resistive model predicts the SOC more accurately than the $\mathrm{RC}$ model. The internal resistance $\left(\mathrm{R}_{\text {int }}\right)$ in the $\mathrm{RC}$ model did not change with SOC, thus reducing the model predictively. In addition, ADV model predicted current and voltage within safe range, while RC model exceeded safety limits. Despite this, RC model provided smooth SOC, voltage, and current behavior, and lower error over entire driving cycle. 


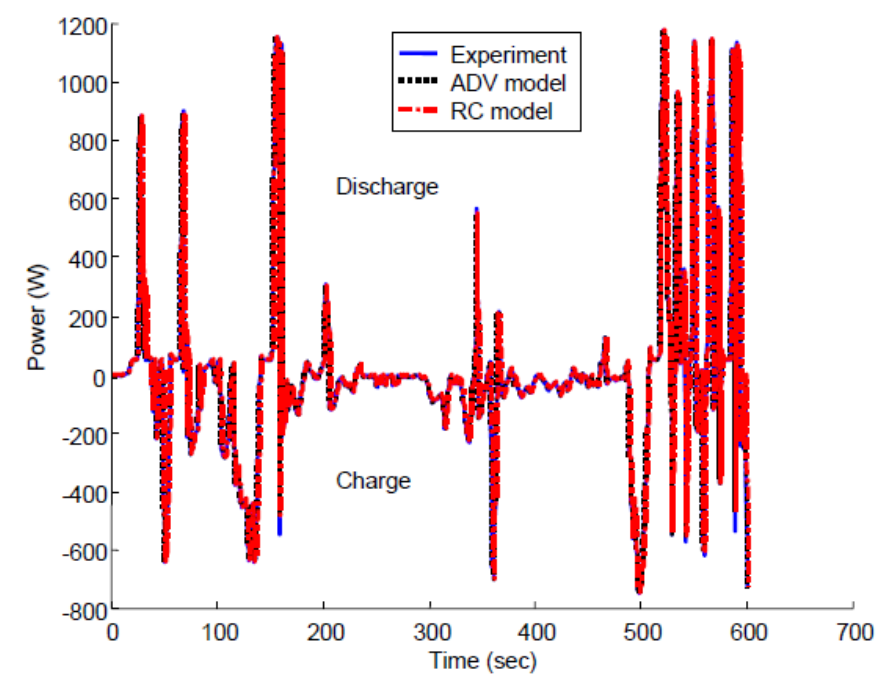

Figure 3-11: Validation of ADV and RC models over a US06 cycle [71]

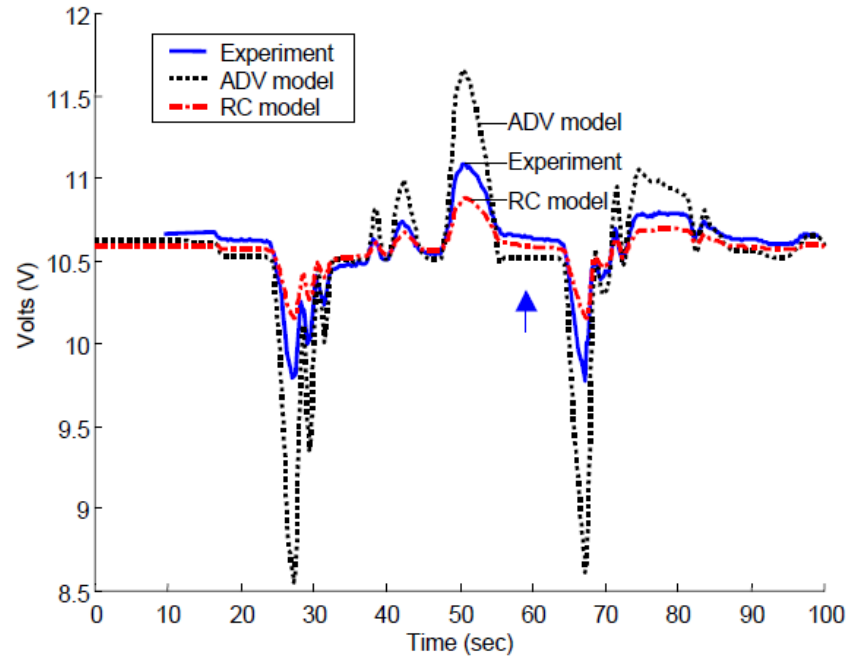

Figure 3-12: Voltage response over the first $100 \mathrm{sec}$ of US06 cycle [71] 
Another electrical circuit to model the Li-ion battery is the Randle equivalent circuit model. Y. Hu et al. introduced this model [42]. The Randle equivalent circuit model was discussed, in details, in Section 3.1.

The Randle model was validated by testing an A123 lithium-ion phosphate battery whose nominal voltage is $3.2 \mathrm{~V}$ and whose nominal capacity is $2.3 \mathrm{Ah}$. The battery temperature region of interest is between $0{ }^{\circ} \mathrm{C}$ and $25^{\circ} \mathrm{C}$, and the $\mathrm{SoC}$ region of interest is between $0 \%$ and $90 \%$ which is larger or equal to standard PHEV and HEV operating regions. The model was selected to be a second order; therefore, two RC elements were considered.

The pulse and step style current profiles are used to excite the battery at the selected temperatures. This current profile was taken from a measured hybrid vehicle dataset. Figure 3-13 and Figure 3-14 depict the model fit at $25^{\circ} \mathrm{C}$ over the step and pulse profile, respectively. In both figures, the model produced a very good fit for both the step and pulse profile at room temperature.

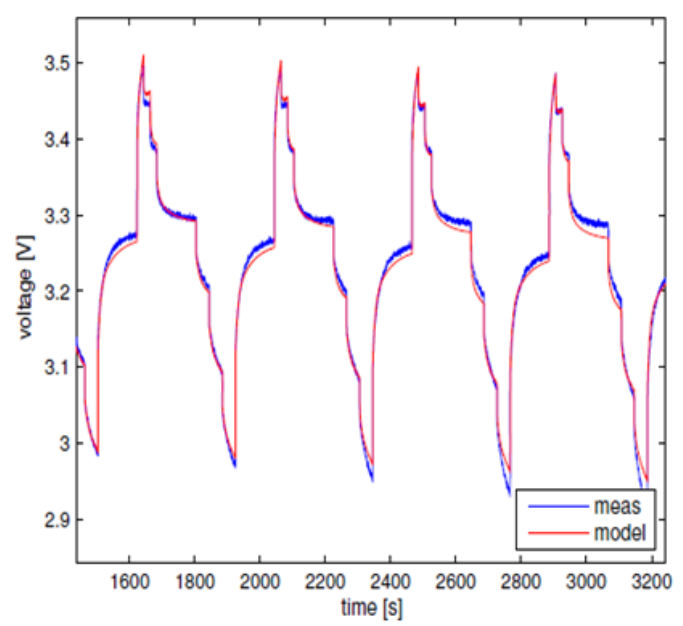

Figure 3-13: Voltage Response to a Current Step Profile [42] 


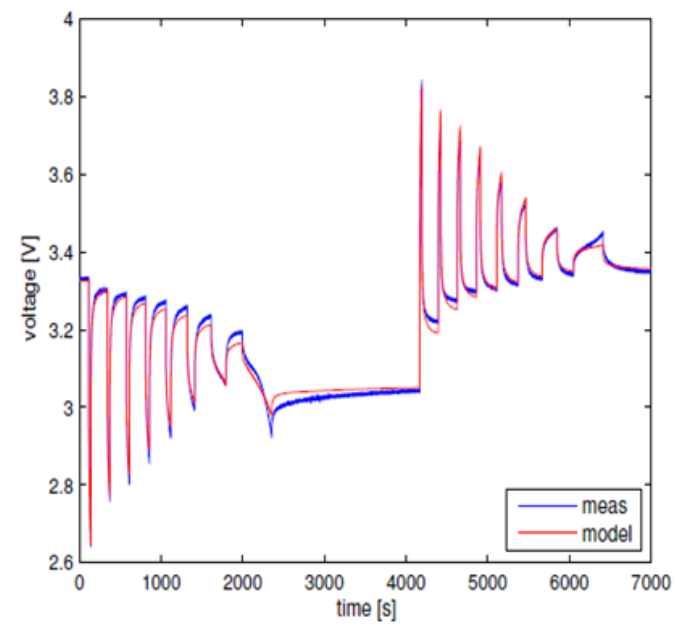

Figure 3-14: Voltage Response to a Current Pulse Profile [42]

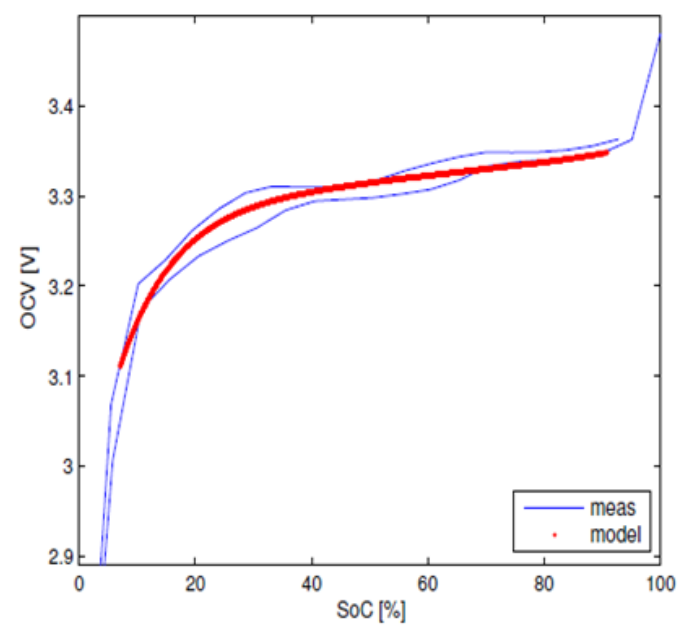

Figure 3-15: OCV versus SoC [42]

For room temperature, an open circuit voltage curve is measured to see if the fitted open circuit voltage is accurate. Figure 3-15 shows the optimized curve by the model, which resides between the two measured curves, thereby demonstrating the accuracy of the identification. Figure 3-16 shows the open circuit voltage as a function of SoC and 
temperature. The surface has relatively little temperature variation because the capacity is modeled a priori, which essentially normalizes the OCV curve at each temperature. This is consistent with the expectation.

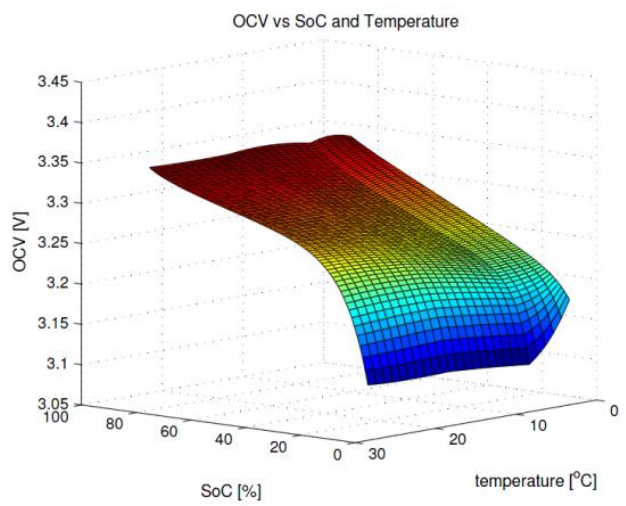

Figure 3-16: OCV vs SoC and Temperature [42]

\subsubsection{FEM Modeling}

In order to evaluate the thermal performance of a battery module or design modules and packs with better thermal performance, NREL used finite element analysis software for performing two- and three-dimensional thermal analysis. NREL have used ANSYS, a widely accepted commercial software package [72]. The first example provided here is a finite element thermal analysis of a slice of a spiral wound lead/acid battery from Optima batteries. Figure 3-17 shows the cross-section of one of the cells. It shows the finite element model representation of the same cell cross-section. Figure 3-19 shows the temperature distribution in the finite element model for 20A discharge. Although the temperature distribution was asymmetrical due to the locations of the two terminals, there was relatively little temperature $\left(<2^{\circ} \mathrm{C}\right)$ difference in the cell. 


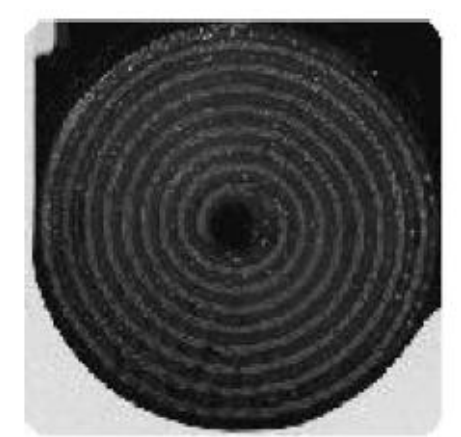

a. cell cross section

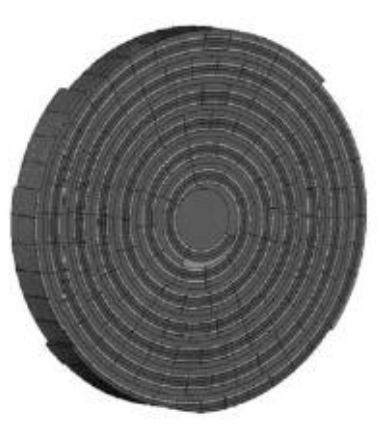

b. computer model

Figure 3-17: (a) Cross-section of a spiral wound lead/acid cell and (b) its FEM model [72]

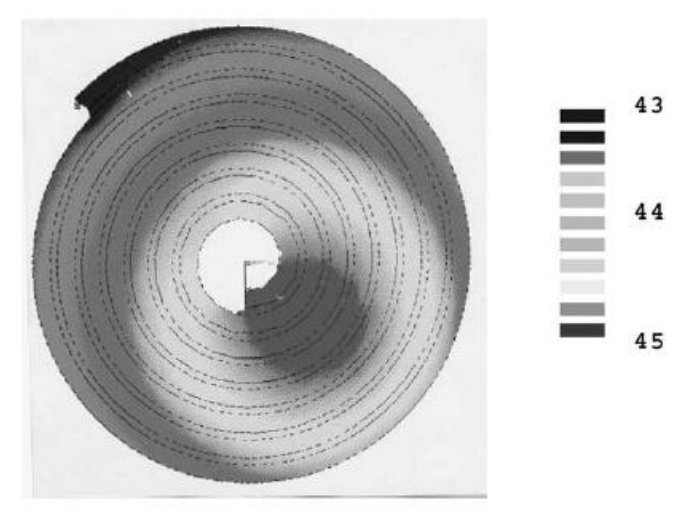

Figure 3-18: Temperature distribution in the spiral wound cell [72]

Figure 3-19(a) shows a 3-D computer model of half of an Optima (16.5 Ah, $12 \mathrm{~V}$ lead/acid HEV) battery. In this model, it was assumed that the active core of each cell consisted of one homogeneous material with average/effective properties of all of its constituents. Three-dimensional finite element analysis determined the steady-state temperature distribution in all directions as shown in Figure 3-19(b). 

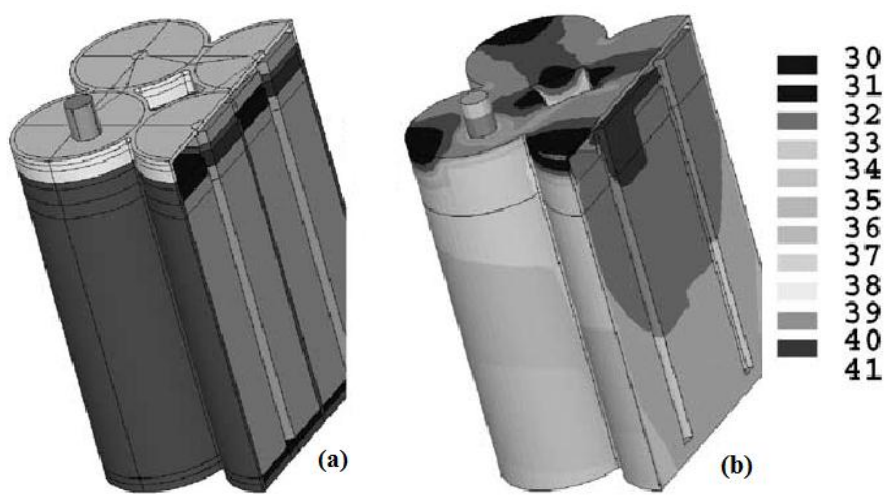

Figure 3-19: (a) Three-dimensional model and (b) temperature distribution for Optima [72]

Finite element analysis can also help evaluate battery pack designs [3]. For example, NREL conducted two-dimensional thermal performance for two air cooling methods for battery pack [3]. The first method is series cooling, where air enters from one end of the pack and leaves from the other, exposing the same air to several modules. The second method is parallel cooling, where the same total airflow rate is split into equal portions and each portion flows over a single module. These two systems were solved by finite element analyzer and the temperature distribution of the pack in the two cases as shown in Figure 3-20. Figure 3-20: The temperature distribution of battery pack with (a) series and (b) parallel cooling systems. 

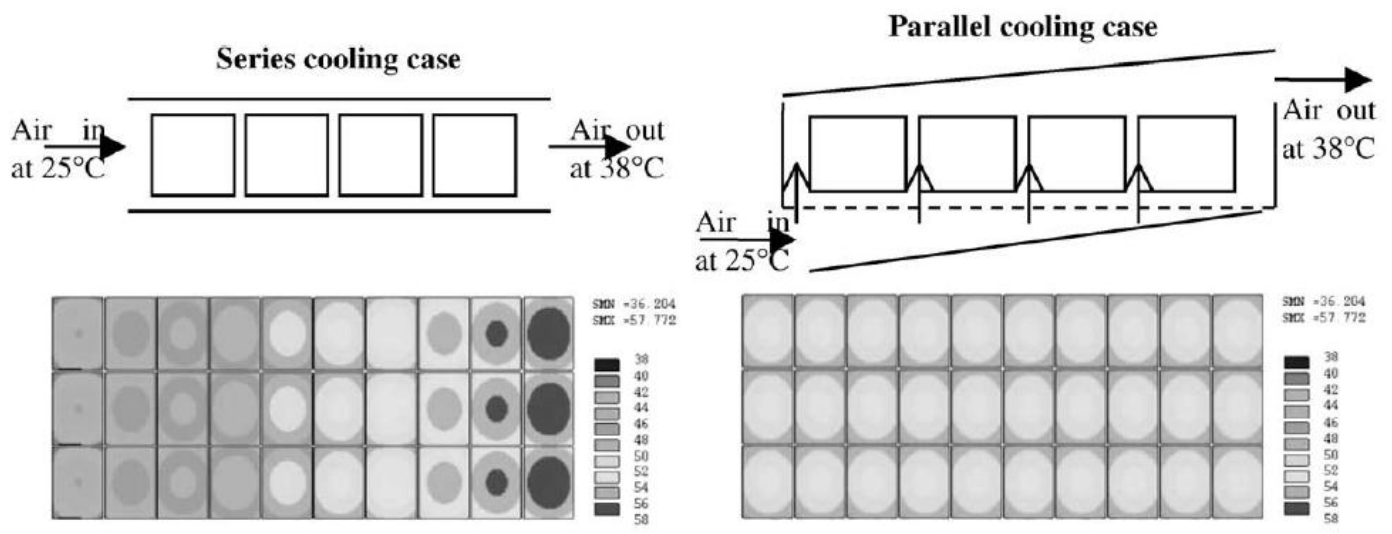

Max Temp $=58^{\circ} \mathrm{C} \quad \operatorname{Min} \mathrm{Temp}=40^{\circ} \mathrm{C}$

(a)

Max Temp $=54^{\circ} \mathrm{C}_{(\mathbf{b})}$ Min Temp $=46^{\circ} \mathrm{C}$

Figure 3-20: The temperature distribution of battery pack with (a) series and (b) parallel cooling systems [3]

In another paper, NREL describe an electro-thermal finite element approach that predicts the thermal performance of a battery cell or module with realistic geometry. NREL simulated the thermal performance of two generations of Panasonic Prismatic nickelmetal-hydride modules used in the Toyota Prius HEV (see Figure 3-21 [73]). This paper focused on integrating the electrical aspects of the cells and modules (including the cell hardware) into a finite element thermal analysis model. One goal of this study was to develop the electro-thermal process or model for predicting thermal performance of cells and modules. 


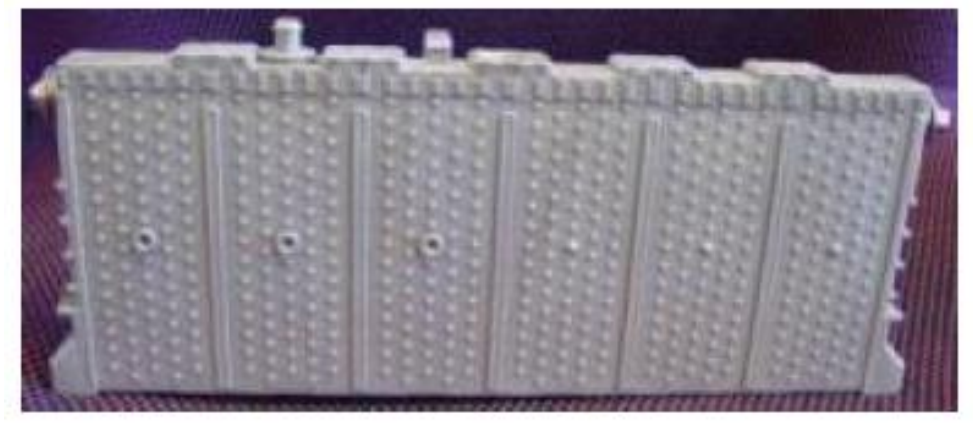

Figure 3-21: Panasonic NiMH module used in 2001 Toyota Prius [73]

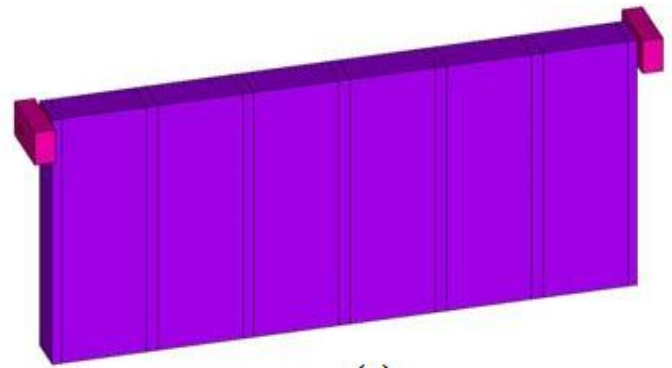

(a)

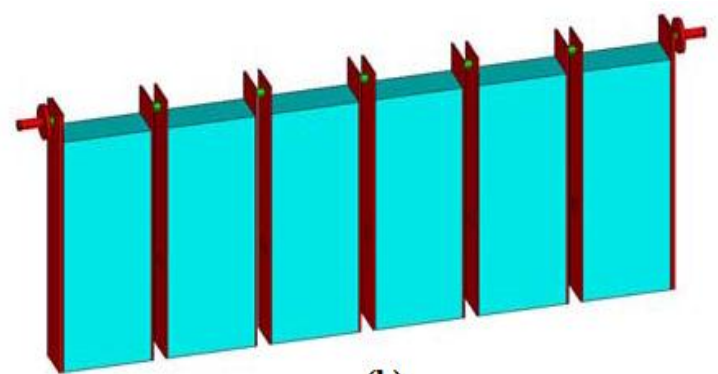

(b)

Figure 3-22: Simulated model of the 2001 Panasonic module: (a) the case with terminal connectors, and (b) the core and current collectors [73] 

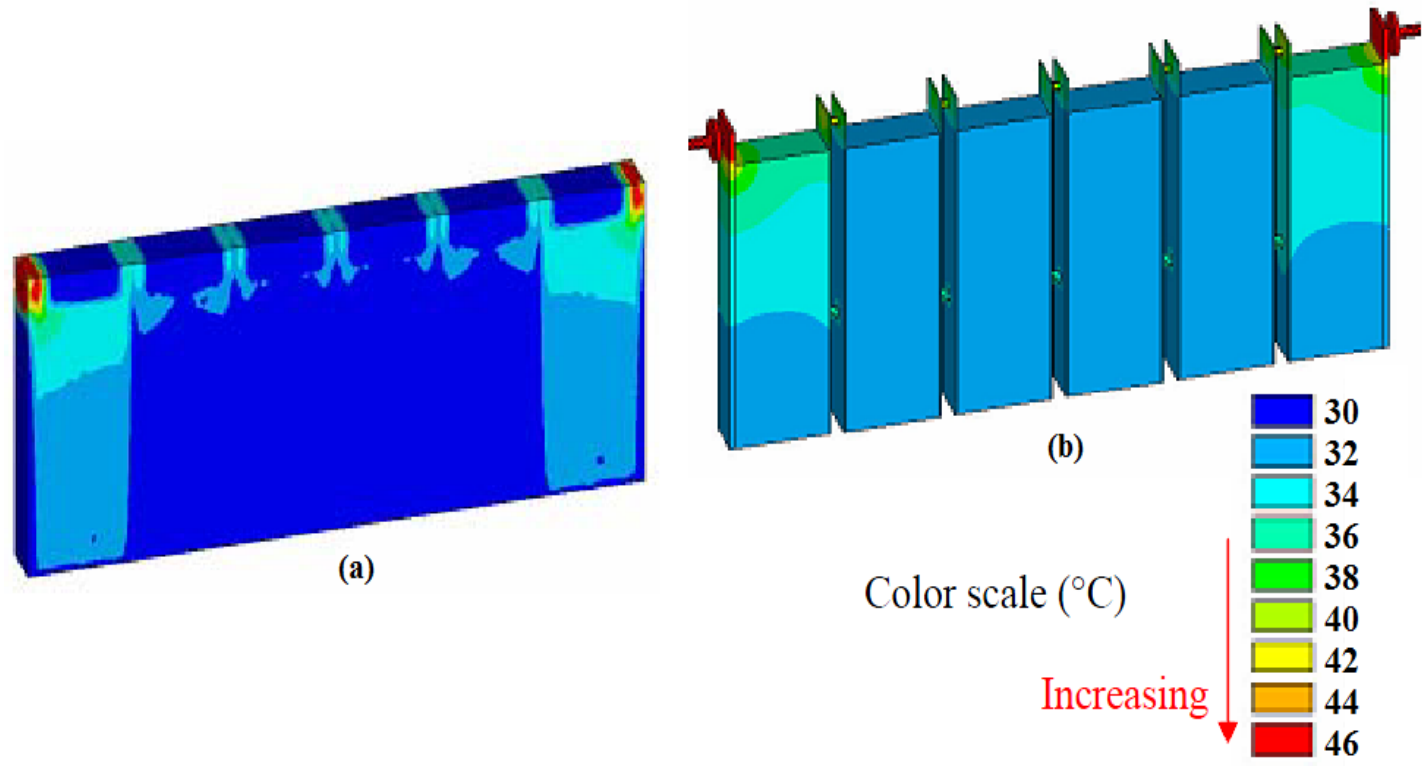

Figure 3-23: Temperature distribution (a) in the case and (b) in the core after 3 minutes from the start of $100 \mathrm{~A}$ discharge [73]

NREL built a detailed virtual model of the module using ProEngineer software, a computer-aided design (CAD) tool. The CAD model consists of the cell core (positive electrode, negative electrode, separator, and electrolyte), the cell or module case, internal connectors from the core to the terminals, connectors to posts of terminals, and (in the case of a module) cell-to-cell interconnects, as shown in Figure 3-22.

The second step was to transfer the CAD model to ANSYS to create a finite element model that can perform both electrical and thermal analysis. Once the geometry and material properties are specified, ANSYS can calculate the electrical resistance of each component. The heat generated by Joule heating and electrochemical reactions was calculated. Finally, ANSYS used the heat generated to estimate the temperature 
distribution in the cell. Figure 3-23 depicts the temperature distribution in the case and inside the module after 3 minutes from the start of 100A discharge.

\subsection{Conclusion}

Li-ion batteries are primary choice for a variety of applications including small devices such as portable electronics as well as larger systems such as stationary electric and hybrid vehicles.

The aim of building a mathematical model of batteries is to estimate battery performance. Mathematical modeling is only beginning to impact battery development. The overwhelming complexity of battery systems encourages battery developers to focus more on developing mathematical models. Approaches for modeling range from simple statistical models to phenomenological models, to complex, fundamentals models. Building the model based on test data becomes problematical when testing becomes impractical (battery aging test).

However, modeling is now more accessible to battery developers because of advanced software such as Simulink, ANSYS, and COMSOL. The development of battery modeling is expected to accelerate dramatically in the near future. 


\section{Chapter 4}

\section{DEVELOPMENT OF BATTERY PACK THERMAL MODEL AND VALIDATION}

This chapter presents an experimental and simulation study aimed at evaluating the thermal behavior of the Li-ion battery pack. A commercial battery pack for power tools applications was adopted as a case study. The power tool application was a DeWalt drill equipped with a $10 \mathrm{Li}$-ion cells battery pack connected in series. The electro-thermal behavior of the battery pack was characterized through combined experimental investigation and 3D Finite Element Method (FEM) modeling to determine the heat generation rate of the battery cells during utilization and to evaluate the thermal behavior of the battery pack. A thermal management solution based on flexible graphite heat spreading material was designed and implemented.

In this chapter, a detailed description of the case study is provided, starting with a physical description of the Dewalt battery pack. Then, the experimental characterization of the battery pack is presented, including a full explanation of the instrumentation and description of the tests that were conducted. The results show the need of implementing a thermal solution for the battery pack. In order to study the effectiveness of different 
thermal solution systems, a FEM model of the pack was built. This chapter covers the determination of the thermal parameters of the different components of the FEM model; then, it shows the step-by-step process of building the FEM model in COMSOL Multiphysics $\AA^{6}$; after that, it shows the mesh sensitivity analysis, and finally, illustrates the validation of the FEM model with the data obtained earlier.

After that, this chapter covers the development of conceptual prototype. It shows the step-by-step fabrication, instrumentation, and testing procedures. Then the experimental results are compared with the simulation results for validation purposes.

\subsection{Description of the Battery Pack}

A DeWalt battery pack for power tools applications, shown in Figure 4-1, was adopted in this study. The pack consists of ten A123-ANR26650 cylindrical cells, shown in Figure 4-2, electrically connected in series and covered by an ABS plastic case. The A123 battery module has been analyzed in detail in literature [16,74-75] and subjected to thorough experimentations at the Center for Automotive Research (CAR ${ }^{7}$ so that all its specifications and thermal parameters could be determined. Table 4-1 shows the A123 specifications, while Figure 4-3 shows its construction.

\footnotetext{
${ }^{6}$ COMSOL Multiphysics® is a finite element analysis, solver and simulation for several physics and engineering applications. www.comsol.com

${ }^{7}$ Center for Automotive Research, College of Engineering, The Ohio State University, Columbus, OH
} 


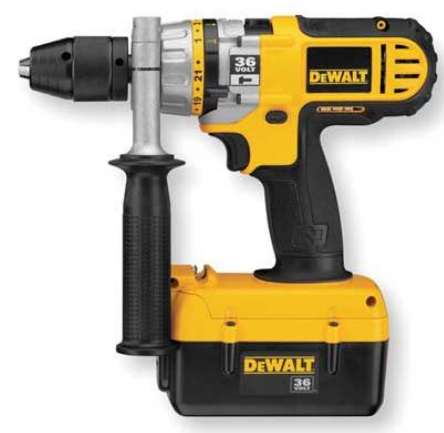

Figure 4-1: DeWalt 36V Cordless Hammer/Drill

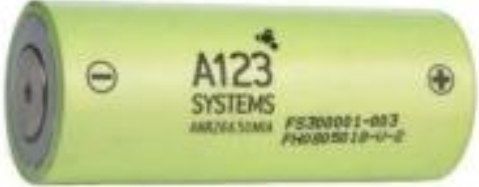

Figure 4-2: A123 Cylindrical Cell

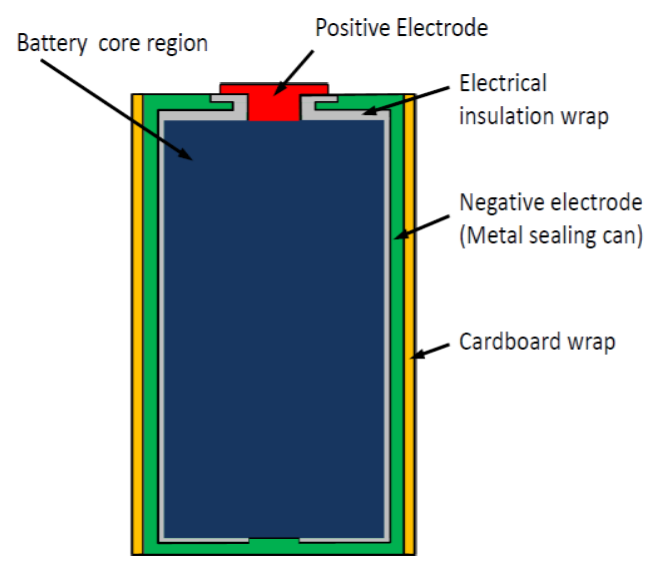

Figure 4-3: A123 Li-ion Cell Construction 
Table 4-1: A123-ANR26650 Cell Specifications

\begin{tabular}{|c|c|}
\hline Parameter & Value \\
\hline $\begin{array}{c}\text { Cathode - Anode } \\
\text { Materials }\end{array}$ & $\mathrm{LiFePO}_{4}-$ Graphite \\
\hline $\begin{array}{l}\text { Nominal } \\
\text { Capacity }\end{array}$ & $2.3 \mathrm{Ah}$ \\
\hline Nominal Voltage & $3.3 \mathrm{~V}$ \\
\hline Core Weight & $70 \mathrm{~g}$ \\
\hline \multirow[t]{2}{*}{ Cell Dimensions } & $\begin{array}{c}\text { Diameter: } \\
25.85 \pm 0.30 \mathrm{~mm}\end{array}$ \\
\hline & Height: $65.15 \pm 0.5 \mathrm{~mm}$ \\
\hline Energy Density & $\begin{array}{l}\text { Volume: } 220 \mathrm{Wh} / \mathrm{l} \\
\text { Mass: } 108 \mathrm{Wh} / \mathrm{kg}\end{array}$ \\
\hline
\end{tabular}

\subsection{Instrumentation and Testing}

The pack has fully been instrumented with multiple K-type thermocouples, as well as pack current, pack voltage, and individual cell voltage measurements. The thermocouples were positioned at different locations inside the pack to provide indication of the temperature distribution across the cells, as shown in Figure 4-4. The pack was mounted on a power drill to perform the test, recording data during typical usage conditions. In all the experiments conducted, the cells were initially charged, then utilized until complete discharge occurred (see Figure 4-5). The pack was cooled by natural convection. The temperatures at various positions inside the pack, pack voltage, pack current, and 
individual voltages were recorded on a PC by National Instrument ${ }^{\mathrm{TM}}$ DAQ and LabVIEW ${ }^{\mathrm{TM}}$ at a sampling time of 0.1 second.

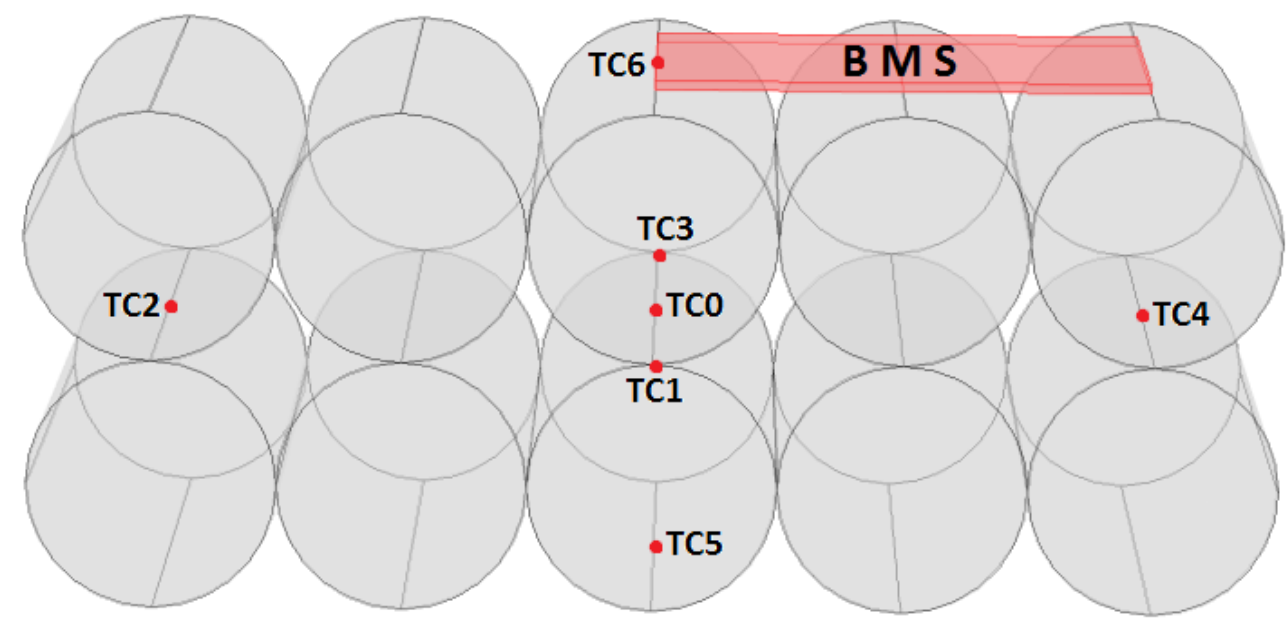

Figure 4-4: Thermocouples Positions

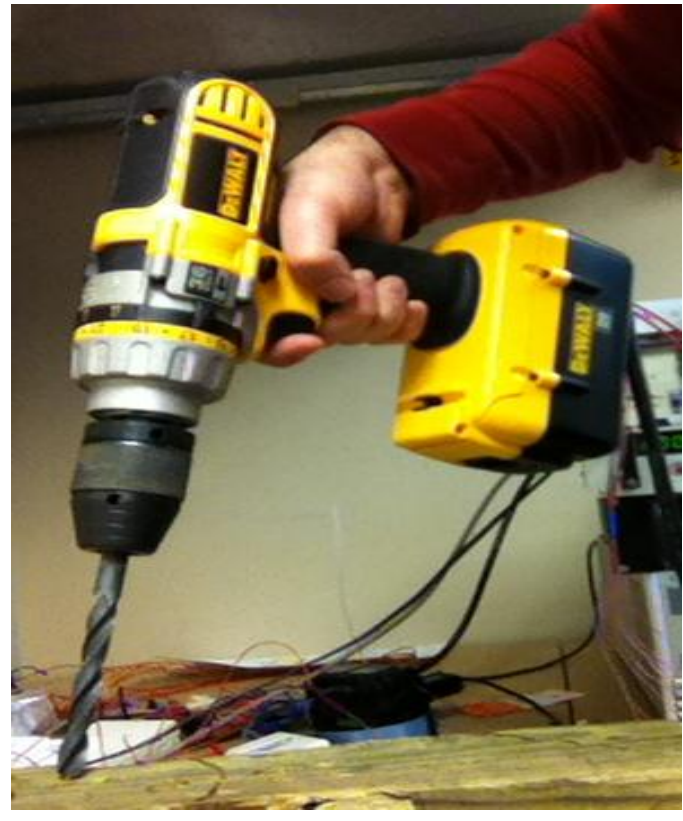

Figure 4-5: Dewalt Drill During the Test 
The results of the test show that the time needed for the battery to reach the complete discharge was approximately 30 minutes. Figure $4-8$ depicts the discharge current profile and the pack voltage. The average current was $-4 \mathrm{~A}$, where the negative sign means that the current is drawn from the battery (discharging). The average terminal voltage was $32 \mathrm{~V}$; this means that the average voltage per cell was around 3.2V. Figure 4-9 shows the power and energy profiles during the test. The average power was $-132 \mathrm{~W}$, while the total energy consumed during the test was $240 \mathrm{~kJ}$. Figure 4-10 depicts the calculated pack state of charge (SoC); the drill started with a full battery and stopped with $8 \%$ SoC battery. The measured temperatures for the entire test are shown in Figure 4-11. The thermocouple close to the BMS (TC6) measured the highest temperature in the pack; it reached $35.4^{\circ} \mathrm{C}$; the thermocouple at the center of the pack (TC0) reached $34.4^{\circ} \mathrm{C}$. The lowest temperature in the pack was $30.6^{\circ} \mathrm{C}$ measured by both TC1 and TC3. Such high temperatures of the battery pack affects the battery's efficiency of delivering energy from the pack, charge acceptance during recharging, and the life of the battery, as discussed in Chapters 2 and 3. In addition to that, the large difference in temperature between cells (about $5^{\circ} \mathrm{C}$ ) lead to variations in the charge/discharge performance between cells in the same pack, resulting in electrical imbalance in the module, which affected the pack overall performance.

Therefore, this battery pack needs a thermal management system in order to maintain an operating temperature within reasonable rang, which doesn't affect its performance, and in order to minimize the differences in temperatures between different battery cells in the same pack. At the same time, the thermal management system needs to be compact 
and light so it can be easily applied without the need of extra space inside the pack and without adding some more weight to the pack.

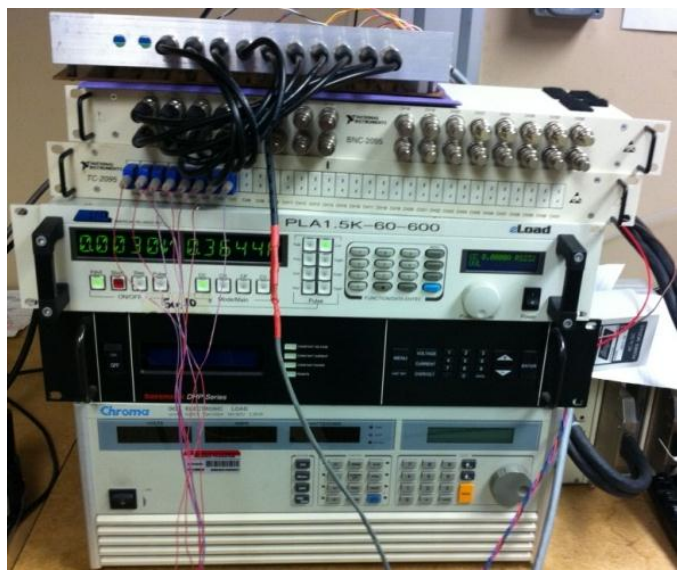

Figure 4-6: Data Acquisition System (DAQ)

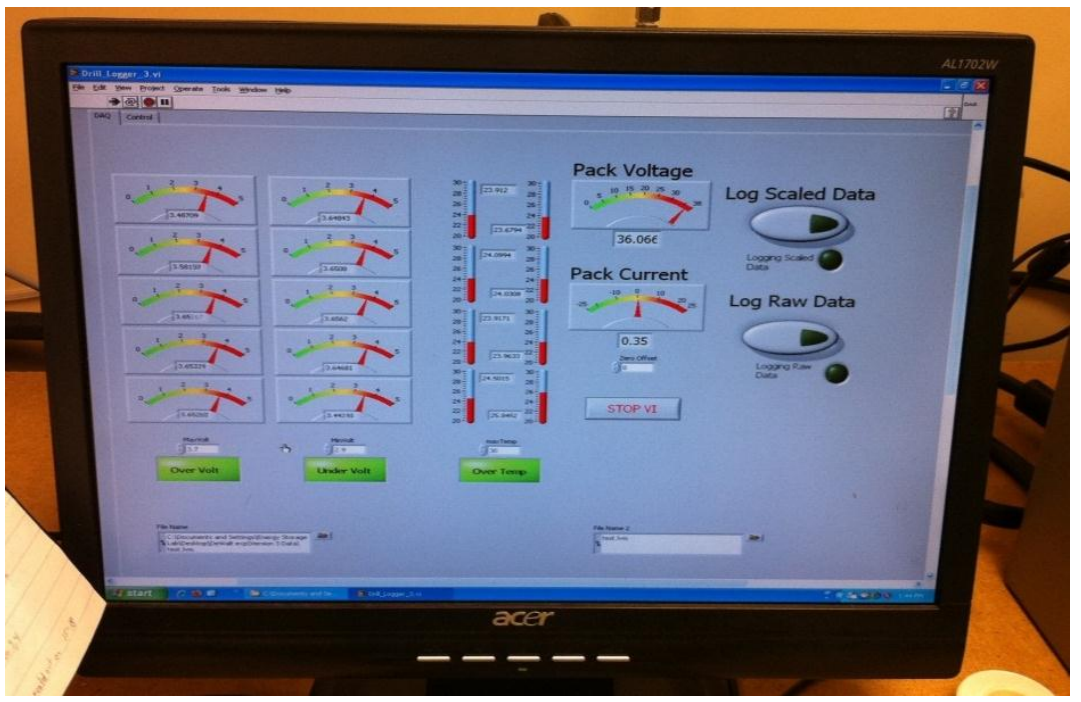

Figure 4-7: LabVIEW $^{\text {TM }}$ Interface 

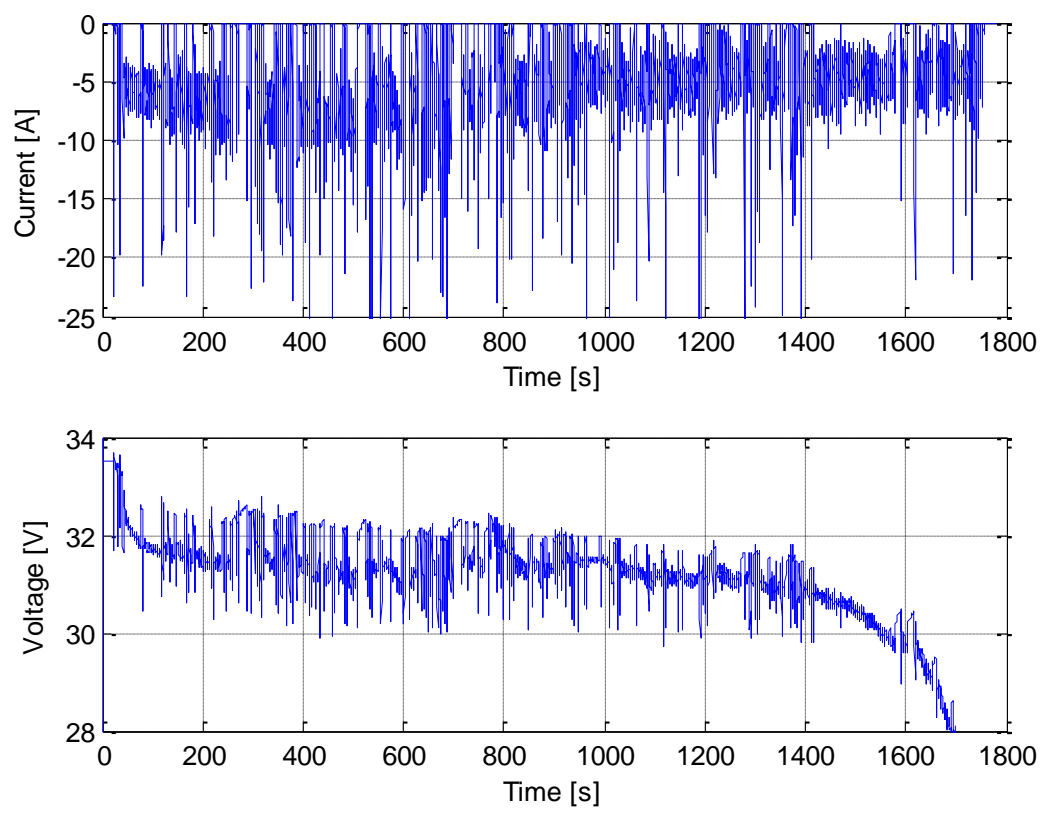

Figure 4-8: Current and Voltage Profiles during the Test
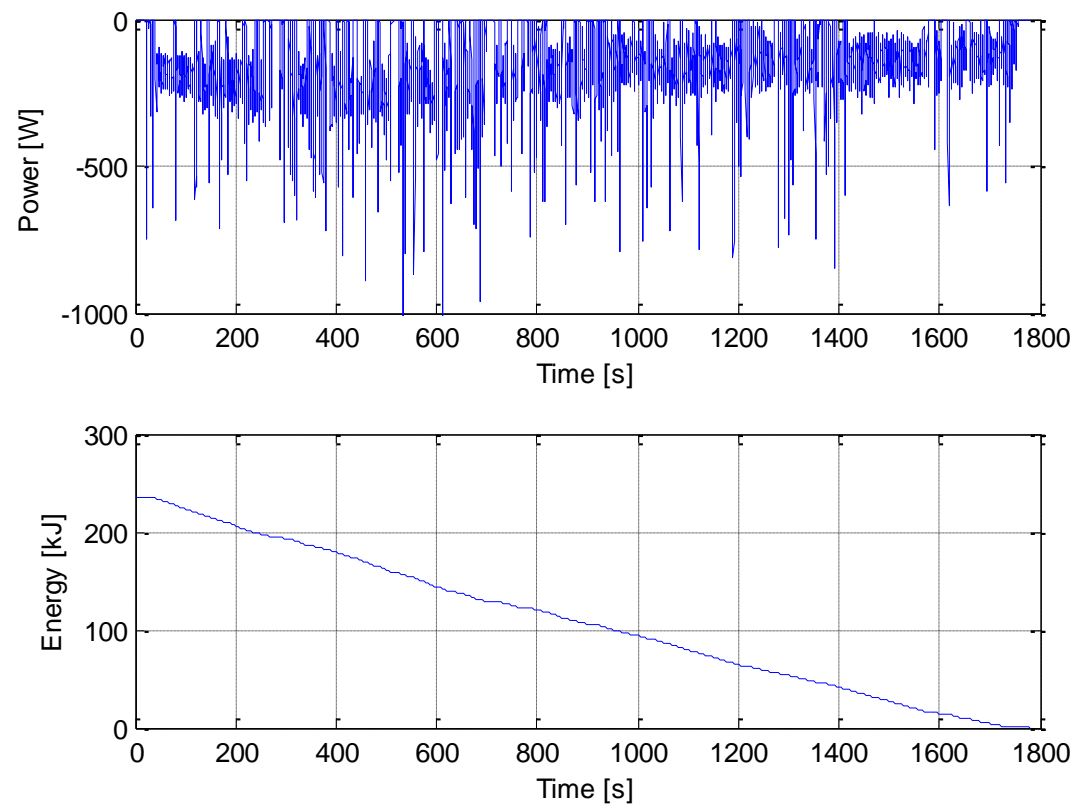

Figure 4-9: Power and Energy Profiles during the Test 


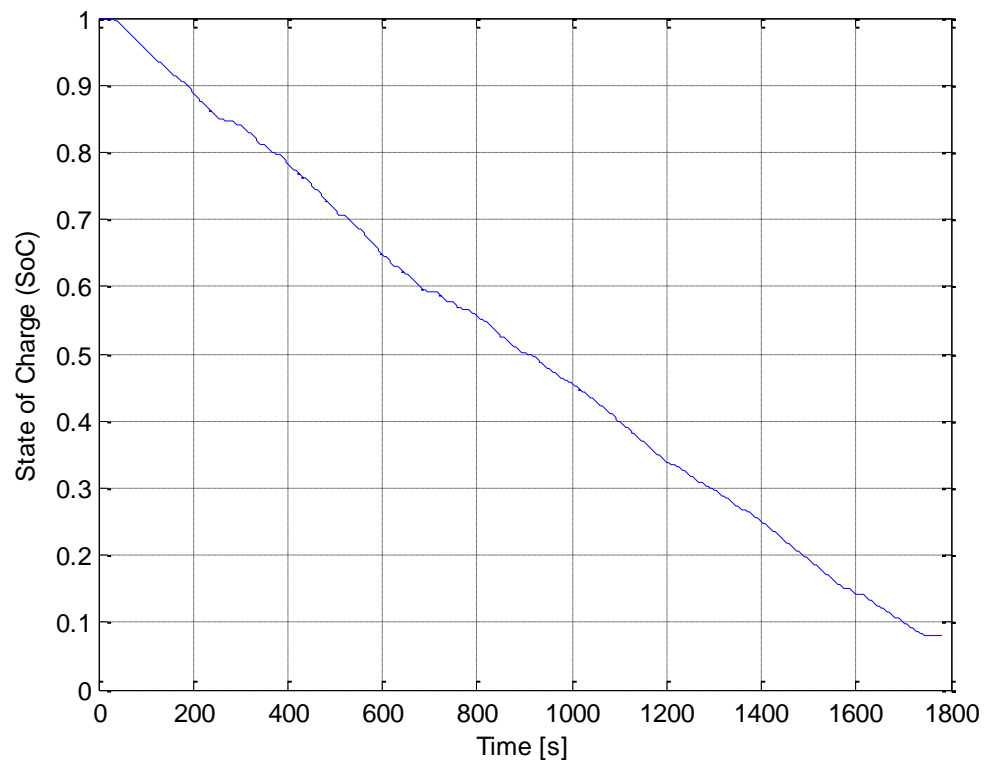

Figure 4-10: Pack State of Charge (SoC)

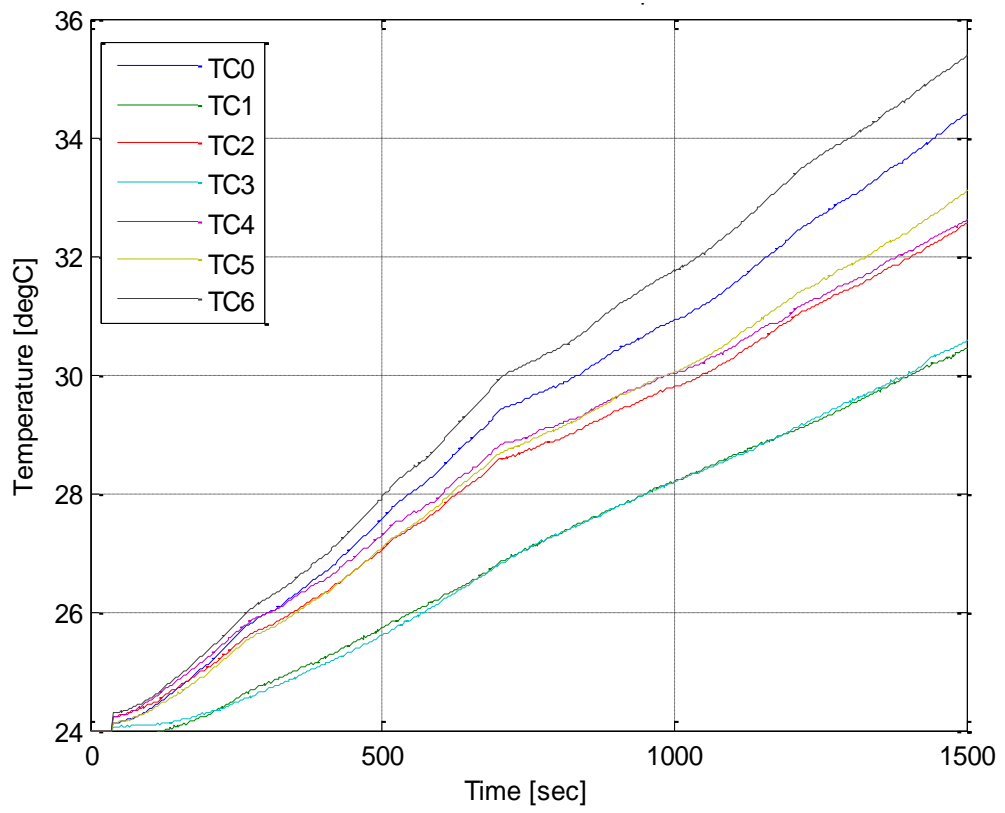

Figure 4-11: The measured temperatures during the test (positions shown in Figure 4-4) 


\subsection{Model Development}

This section discusses the 3D FEM model that was built in order to test and study the thermal behavior of the Dewalt battery pack, and to evaluate the influence of different passive thermal management solutions on the pack temperatures. The model was built using the COMSOL Multiphysics FEM software. However, the COMSOL Multiphysics does not take the discharge current as an input. Instead, it takes the heat generation rate of the battery cells. Therefore, an electro-thermal model was built to estimate the heat generation rate.

\subsubsection{Electro-Thermal Model}

The electro-thermal model for the A123 battery cell was built based on the Randle equivalent circuit model presented in [42] as discussed in Chapter 3. The model was built in MATLAB Simulink $®$ in order to predict the open circuit voltage and heat generation rate during charging and discharging operations at different temperatures. The open circuit voltage of the Li-ion cell was calculated, as described in Equation 3-2. The heat generated by the Li-Ion cells was modeled as a uniform heat generation inside the volume of each cell. The heat generation rate was determined based on a simplified thermal model that considers only the heat generation due to the cell internal resistance [1516,75-76] (see Equation 4-1).

$$
\dot{Q}=I\left(E_{0}-E\right)
$$

where $I$ and $E$ are the pack current and the terminal voltage of each cell. These variables are the considered inputs to the pack thermal model. The parameter $\mathrm{E}_{0}$ represents the 
open-circuit voltage (OCV) of the cell, which is a function of the cell Depth of Discharge (DoD) [42], DoD is determined as shown in Equation 4-2.

$$
D o D=1-\frac{1}{A h} \int I(t) d t
$$

where $A h$ is the nominal capacity of the cell. The expression of $\mathrm{E}_{0}$ was determined from experimental tests on the ANR26650 cell. Figure 4-12 shows the open-circuit voltage curve measured for the cell during discharging conditions.

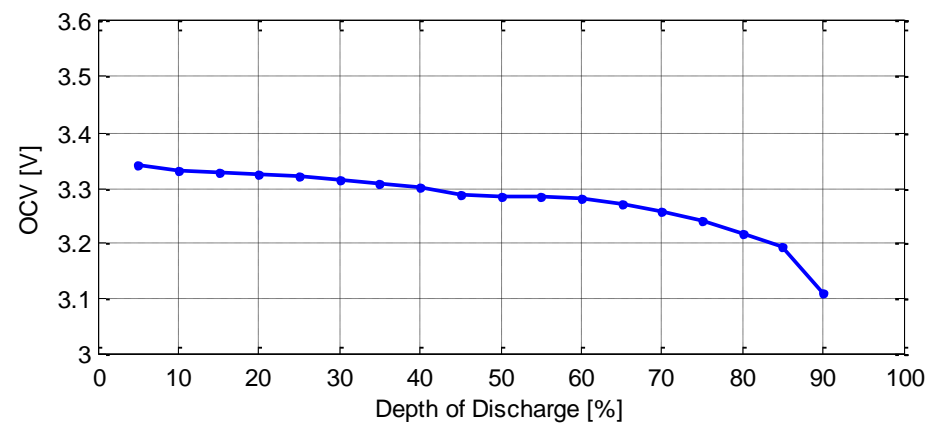

Figure 4-12: Open-Circuit Voltage Curve for ANR26650 Cell [10]

The discharge current shown in Figure 4-8 was the input for the thermo-electro model, the OCV and heat generation rate were calculated. Figure 4-13 and Figure 4-14 show the total open circuit voltage and the heat generation rate per cell, respectively. 


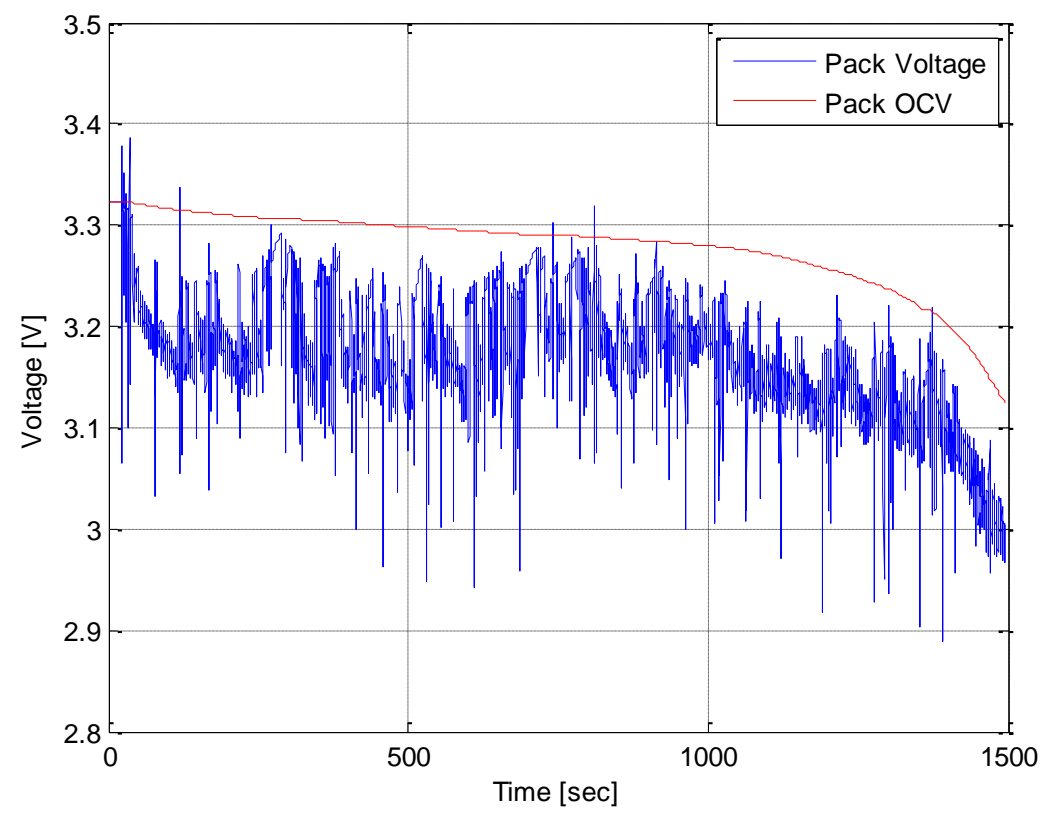

Figure 4-13: Total Terminal Voltage and Open Circuit Voltage

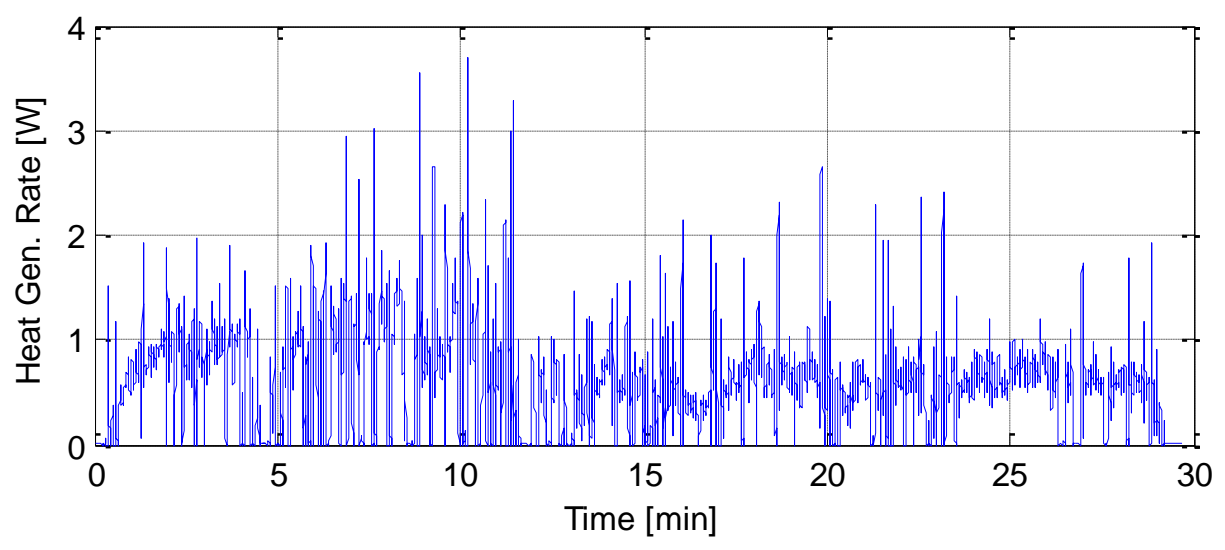

Figure 4-14: Heat Generation Rate per Cell 


\subsubsection{Finite Element Method (FEM) Model}

The FEM model was built using the COMSOL Multiphysics simulation software, which facilitates all steps in the modeling process starting by defining the geometry, specifying the suitable physics, meshing, solving, and then visualizing the results.

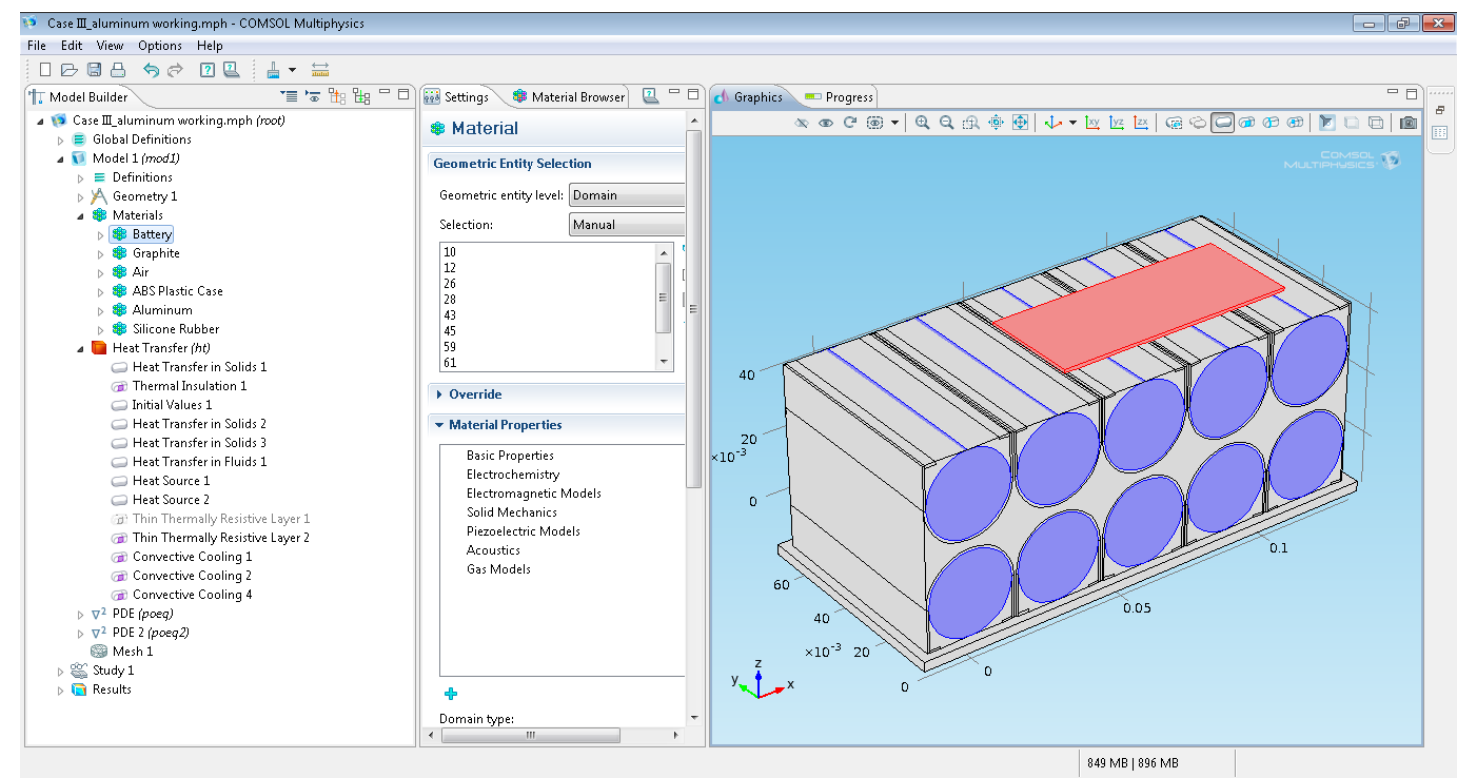

Figure 4-15: COMSOL Multiphysics User Interface

Each battery cell was built as a cylindrical domain, with the dimensions shown in Table 4-1. Second and third domains were defined, respectively, by the plastic casing of the pack and by the containment unit for the Battery Management System (BMS). The remaining domain inside the pack was defined as air (see Figure 4-16). 


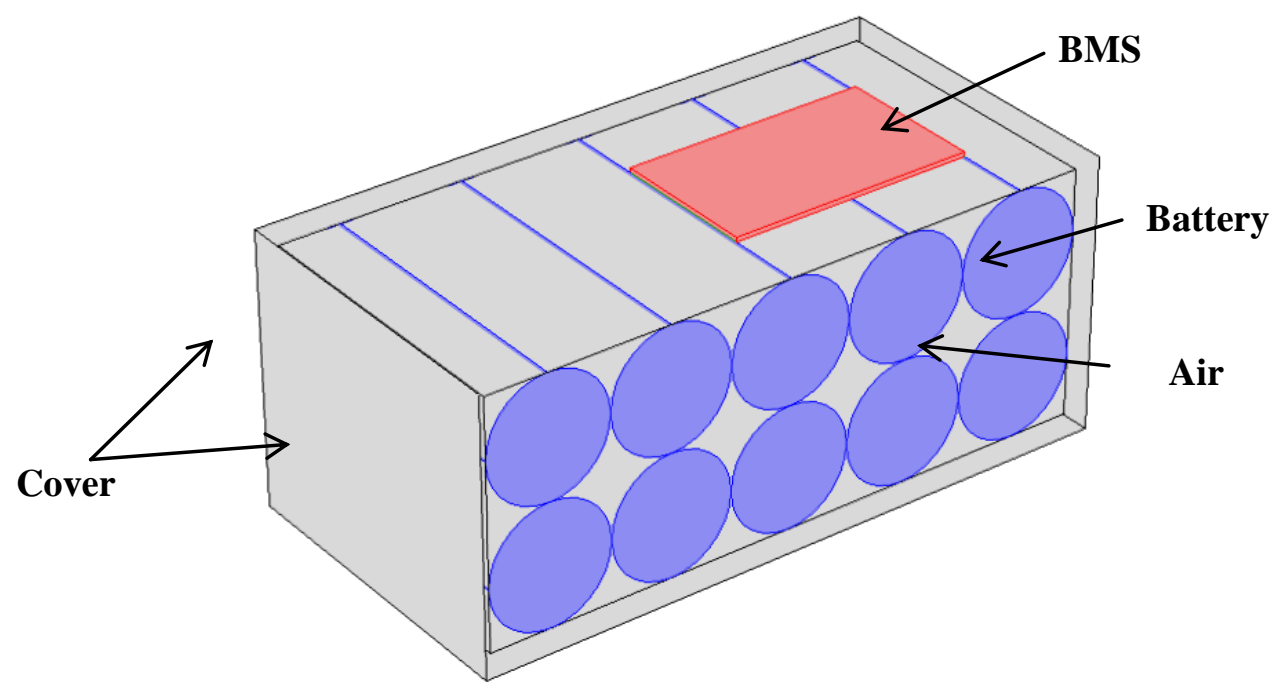

Figure 4-16: The Geometry of the FEM model

The next step was to define the thermal properties for each component in the model. The thermal parameters which needed to be determined are the overall thermal conductivity $k$, the average cell heat capacity $C p$, and the average cell density $\rho$. The thermal parameters have been determined from earlier experimental studies and results have already been published.

The density of the A123 battery was simply calculated by ratio of the battery mass to its volume; the mass and volume values are shown in Table 4-1. The calculated density of the cell is $2118 \mathrm{~kg} / \mathrm{m}^{3}$. The heat capacity of the battery was measured using a twin-type calorimeter [77]. It is assumed to be $789 \mathrm{~J} / \mathrm{kg}-\mathrm{K}$.

The determination of thermal conductivity was more complicated; the thermal conductivity of the Li-ion cell is assumed anisotropic. In the axial direction, the layers of 
the cell shown in Figure 4-3 are in series. The overall thermal conductivity in this direction can be computed as shown in Equation 4-3 [78].

$$
k=\frac{\sum_{i} L_{i}}{\sum_{i}\left(L_{i} / k_{i}\right)}
$$

where $L_{i}$ is the length of the $i^{\text {th }}$ layer in the axial direction and $k_{i}$ is the thermal conductivity of the $i^{\text {th }}$ layer in the axial direction. On the other hand, the layers in the radial directions are in parallel. The overall thermal conductivity for layers in parallel is written as shown in Equation 4-4.

$k=\frac{\sum_{i} A_{i} k_{i}}{\sum_{i} A_{i}}$

where $A_{i}$ is the sectional area of the $i^{\text {th }}$ layer in the radial direction and $k_{i}$ is the thermal conductivity of the $i^{\text {th }}$ layer in the radial direction. The values of thermal conductivity of each material are given in technical datasheets of the conductivity of pure materials and from published researches (i.e., [13], [16], [20], [75-76], [78]).

Based on the theory introduced above, the thermal conductivity in the axial direction (measured along layers) is nearly two orders of magnitude higher than the radial direction thermal conductivity. This is due to the high thermal conductivity of the current collectors and to a lesser extent to the orientation of particles in the layers of electrodes $[13,20]$. Table 4-2 shows the thermal parameters of the battery cell.

Regarding the other domains in the model, the thermal parameters of the ABS plastic case were experimented and determined in CAR. While aluminum and air were built-in materials, so their parameters were determined by COMSOL Multiphysics. Table 4-3 
summarizes the density, thermal conductivity, and specific heat of all the domains of the FEM model.

Table 4-2: Thermal Parameters of the A123 cell

\begin{tabular}{|c|c|c|c|}
\hline \multicolumn{2}{|c|}{ Parameter } & \multicolumn{2}{c|}{ Value } \\
\hline \multicolumn{2}{|c|}{ Density } & \multicolumn{2}{|c|}{$2118\left(\mathrm{~kg} / \mathrm{m}^{3}\right)$} \\
\hline \multirow{2}{*}{ Conductivity } & Axial & 70 & \multirow{2}{*}{$(\mathrm{W} / \mathrm{m}-\mathrm{K})$} \\
\cline { 2 - 3 } & Radial & 0.69 & \\
\hline \multicolumn{2}{|c|}{ Specific Heat } & \multicolumn{2}{|c|}{$789(\mathrm{~J} / \mathrm{kg}-\mathrm{K})$} \\
\hline
\end{tabular}

Table 4-3: Thermal Parameters of the Battery Pack components

\begin{tabular}{|c|c|c|c|}
\hline Domain & $\begin{array}{c}\text { Density } \\
\left(\mathrm{kg} / \mathrm{m}^{3}\right)\end{array}$ & $\begin{array}{c}\text { Thermal } \\
\text { Conductivity } \\
(\mathrm{W} / \mathrm{m}-\mathrm{K})\end{array}$ & $\begin{array}{c}\text { Spec. } \\
\text { Heat } \\
(\mathrm{J} / \mathrm{kg}- \\
\mathrm{K})\end{array}$ \\
\hline Battery & 2118 & $\mathbf{7 0} ; \mathbf{0 . 6 9}$ & 789 \\
\hline $\begin{array}{c}\text { ABS Plastic } \\
\text { Case }\end{array}$ & 1070 & 0.18 & 1400 \\
\hline Aluminum & 900 & 160 & 2700 \\
\hline Air & $\begin{array}{c}\text { Functions of temperature defined } \\
\text { by COMSOL Multiphysics } \AA\end{array}$ \\
\hline
\end{tabular}

The COMSOL Multiphysics software has a number of predefined physics interfaces for a wide spectrum of applications. For this study, the Heat Transfer module was selected.

8 The thermal conductivity along the axial direction of the cell is $70 \mathrm{~W} / \mathrm{mK}$, while it is $0.69 \mathrm{~W} / \mathrm{mK}$ in the radial directions. 
The Heat Transfer interfaces model heat transfer by conduction and convection, and it can also include surface-to-ambient radiation effects around edges and boundaries. The interfaces are suitable for modeling heat transfer in solids and fluids. The module provides the equations, boundary conditions, and sources for modeling heat transfer. The default physical model represents Heat Transfer in Solids, and the default dependent variable is the temperature, T. The battery cells, plastic cover, and BMS domains were selected for the heat transfer in solids model. The Heat Transfer in Solids model uses the heat equation in Equation 4-5 as the mathematical model for heat transfer in solids:

$$
\rho C_{p} \frac{\partial T}{\partial t}-\nabla \cdot(k \nabla T)=\dot{Q}
$$

For a steady-state problem the temperature does not change with time and the first term disappears. It has the following material properties: density $\rho$, heat capacity $C p$, thermal conductivity $k$ (a scalar or a tensor if the thermal conductivity is anisotropic), and $Q$.

On the other hand, the air domain shown in Figure 4-16 was selected as Heat Transfer in Fluids model, which uses the following version of the heat equation as the mathematical model:

$$
\rho C_{p} \frac{\partial T}{\partial t}+\rho C_{p} u . \nabla T=\nabla .(k \nabla T)+\dot{Q}
$$

For a steady-state problem the temperature does not change with time and the first term disappears. The material properties this model has are the following: the density $\rho$, the fluid heat capacity at constant pressure $C p$, the fluid thermal conductivity $k$, and the fluid 
velocity field $u$ (i.e., it can be an analytic expression or a velocity field from a fluid-flow interface).

Among the domains of the Heat Transfer in Solids model, the battery cells domains were selected as a Heat Source which describes heat generation within the domain. The heat source was specified as total heat per volume in the domain. The heat generation rate was imported from the electro-thermal model, specifically shown in Figure 4-14.

Another heat source was specified; the Battery Management System (BMS) is a secondary heat source that affects the temperature readings significantly which makes it essential to take it into account. For this reason, a simplified heat generation model was included to account for the influence of the BMS on the pack temperature.

Since a detailed heat generation model is beyond the scope of this work (this would require modeling the actual BMS circuit model and determining values for the electrical resistance of the different components and proprietary knowledge of the control algorithm), a simplified approach was adopted here; namely, it assumed that a timevarying heat generation rate is produced by the BMS proportionally to the depth of discharge of the pack.

$\dot{Q}_{B M S}=\alpha \cdot D o D$

where the parameter $\alpha$ is calibrated from experimental data.

The assumption presented above is caused by the fact that, at the beginning of each test, the battery pack is completely charged and balanced. As the power tool is being used and the cells are being discharged, the electrical imbalances become more and more 
significant, forcing the BMS to dissipate power, while also attempting to equilibrate the voltage drop across each cell.

The boundary conditions for the thermal model were defined by assuming natural convection between the pack cells and the air in the enclosures, and between the external surfaces of the casing and the external environment. The value of the convection coefficient was determined by the FEM solver after the thermal boundary layer on each surface has been calculated.

The last step before solving the model is to create a mesh. COMSOL Multiphysics creates a mesh that is adapted to the selected physics settings in the model. A free tetrahedral mesh was applied, with constraints applied on the maximum size of the elements.

In order to understand the sensitivity to mesh size, three different meshes were applied to the model; namely, fine mesh, normal mesh, and coarse mesh, see Figure 4-17 and Figure 4-18. A comparison between the different meshes is shown in Table 4-4. The number of elements for the fine mesh is one order of magnitude more than for the normal mesh; however, the simulation time for the fine mesh is 17 minutes, but it is less than 2 minutes for the normal mesh.

A useful indicator for the evaluation of a mesh is relation to the geometry of the domain is the Mesh Quality Index, which concerns the characteristics of a mesh that permit a particular numerical PDE simulation to be efficiently performed, with fidelity to the underlying physics, and with the accuracy required for the problem [79]. It is represented by a number between 0 and 1 . The element quality for the coarse mesh was poor (i.e., 
0.51 ), because of the relatively large size of element. Figure 4-19 shown the poor quality of the coarse mesh; however, it shows a high degree of similarity of the results using the fine and normal meshes. Although the fine mesh had a better quality in the internal boundaries, the complexity and simulation duration increased significantly.

Figure 4-20 shows the temperature at the center of the pack under different mesh sizes. It is obvious that the coarse mesh had poor quality. However, the fine and normal meshes had very close results, as shown in Figure 4-21. This figure shows the last 100 seconds of simulation. The final temperature values were within $0.15^{\circ} \mathrm{C}$, which is an acceptable error margin. As a result, the normal mesh was selected for all the simulations in this study because of the reasonable accuracy and simulation duration.
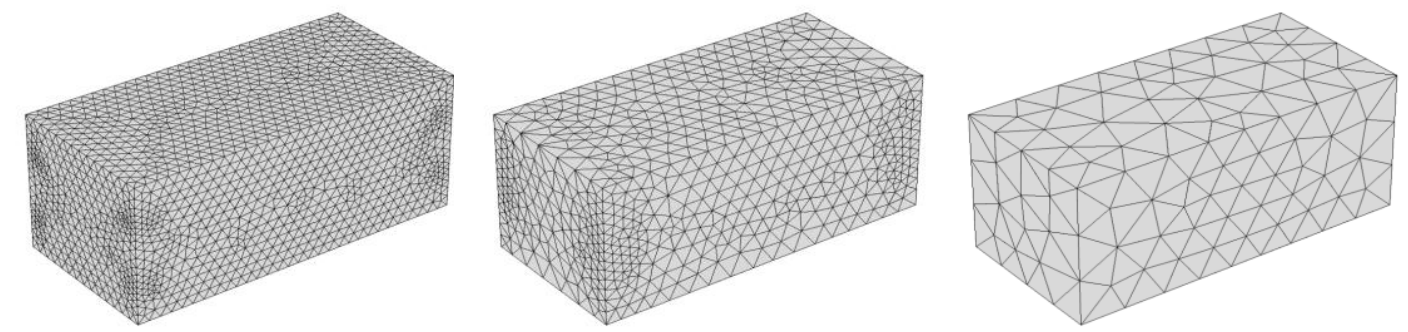

Figure 4-17: Enclosure Mesh, Fine (left), Normal (middle), and Coarse (right)
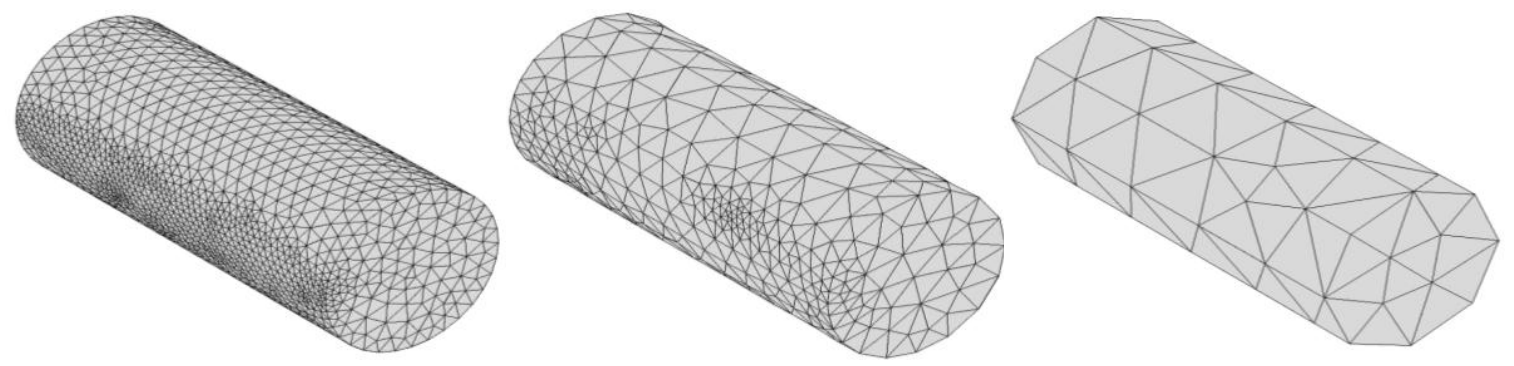
Figure 4-18: Battery Cell Mesh, Fine (left), Normal (middle), and Coarse (right)

Table 4-4: Mesh Sizes Comparison

\begin{tabular}{|c|c|c|c|}
\hline & Fine & Normal & Coarse \\
\hline $\begin{array}{c}\text { No. of Elements of The } \\
\text { Entire Geometry }\end{array}$ & 488135 & 42240 & 6325 \\
\hline $\begin{array}{c}\text { No. of Elements of One Cell } \\
\text { Domain }\end{array}$ & 30435 & 2955 & 154 \\
\hline Mesh Quality & 0.81 & 0.71 & 0.51 \\
\hline Average Element Size (mm) & 0.03 & 3 & 10 \\
\hline Simulation Time & $17 \mathrm{~min} 37 \mathrm{sec}$ & $1 \mathrm{~min} 41 \mathrm{sec}$ & $34 \mathrm{sec}$ \\
\hline
\end{tabular}
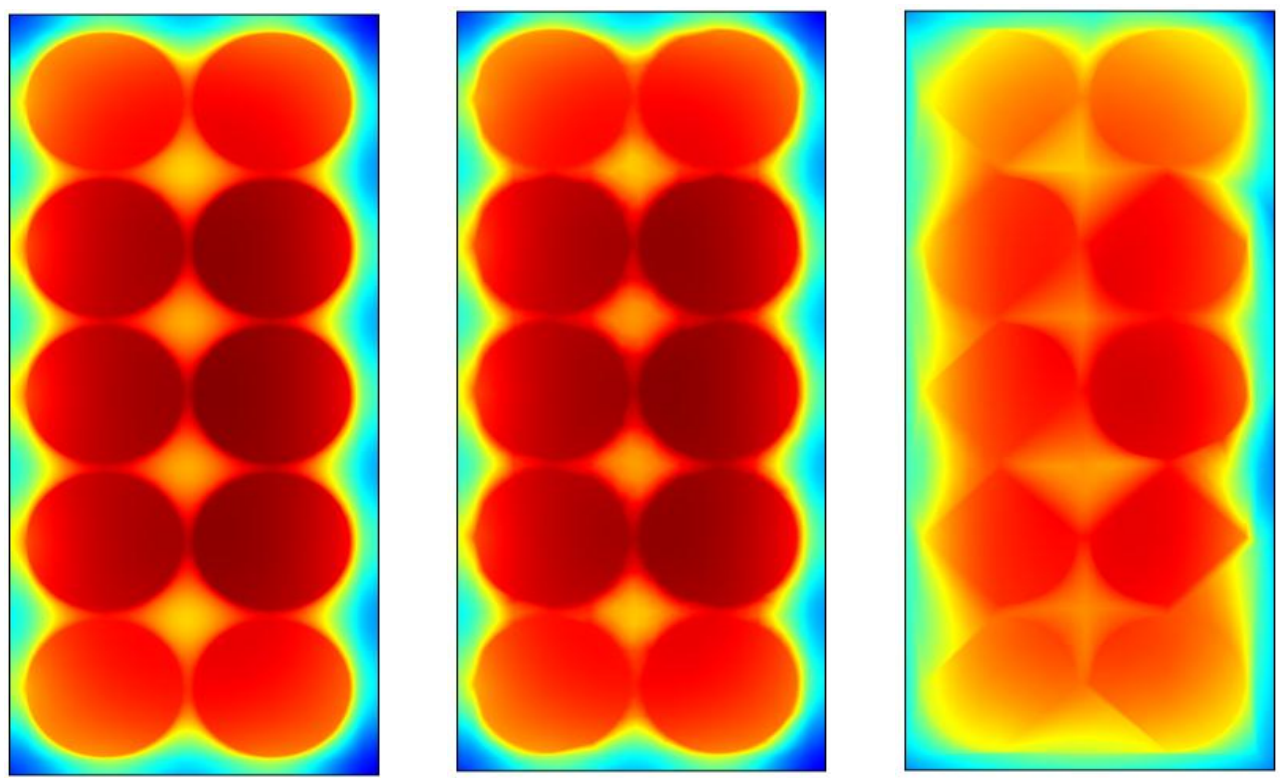

Figure 4-19: Temperature Grid, Fine mesh (left), Normal mesh (middle), and Coarse mesh (right) 


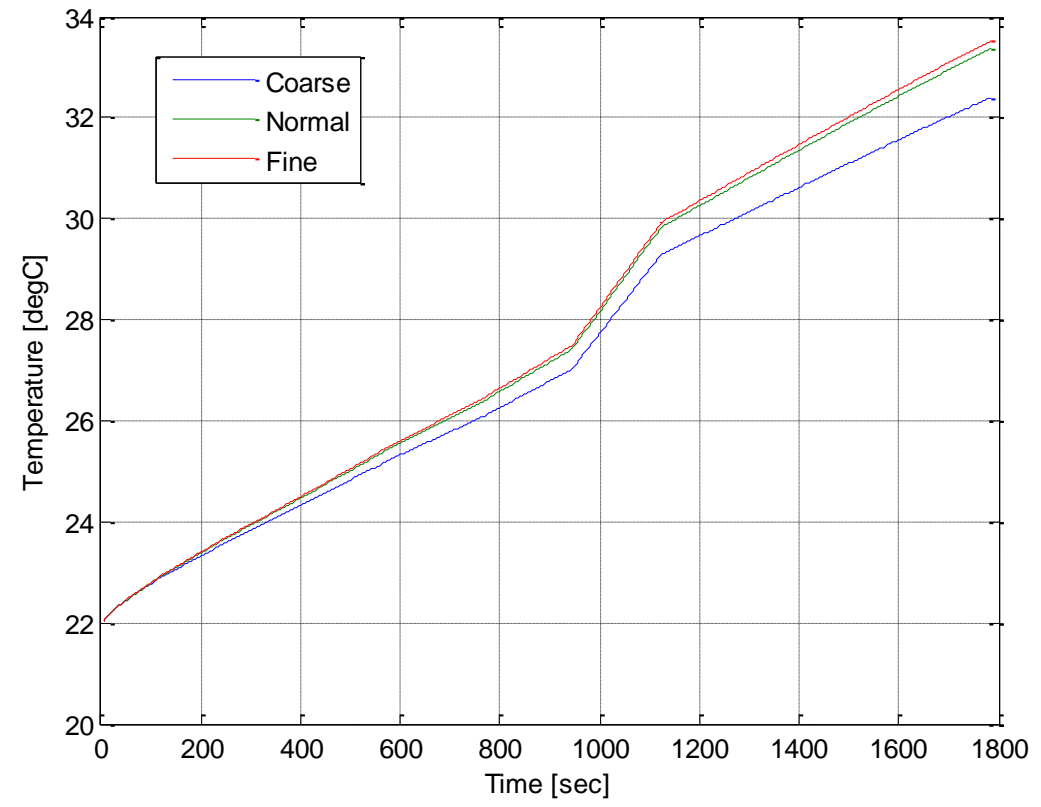

Figure 4-20: Mesh Size Sensitivity Analysis (1 of 2)

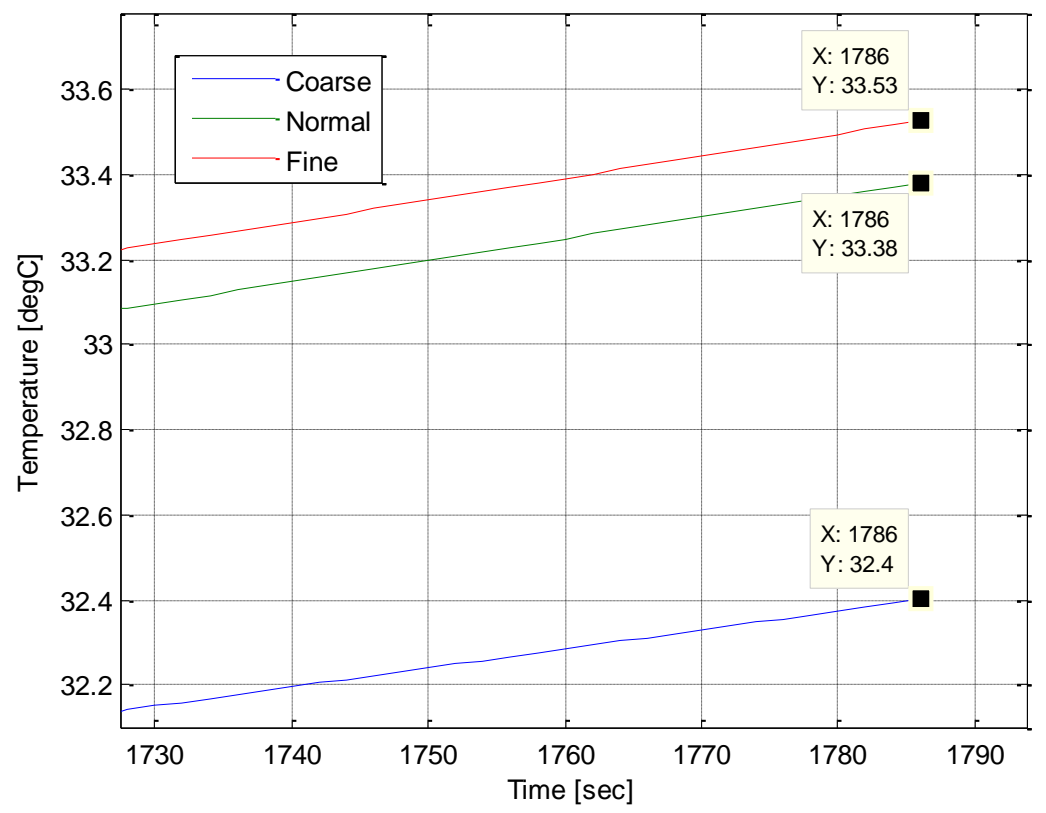

Figure 4-21: Mesh Size Sensitivity Analysis (2 of 2) 


\subsection{Model Validation Results}

The FEM model was validated by comparing the pack temperatures during the experiment performed on the power tool. Seven thermocouples were positioned at different locations inside the pack to provide indication of the temperature distribution across the cells, as shown in Figure 4-4. The measured temperatures are shown in Figure $4-11$.

The heat generation rate per cell was applied equally to the 10 cells in the pack. Similarly, the heat generation rate of the BMS was calculated based on the definition of DoD. The parameter $\alpha$ was calibrated to minimize the RMS error on the seven temperatures obtained from experiments and from the FEM model calculated for the entire duration of the test.

The results of the model validation are shown in Figure 4-22. The plots compare the temperatures measured at three representative locations (TC0, TC2 and TC6 as in Figure 4-4) with the corresponding values predicted by the FEM model for cutpoints located at the exact same positions of the thermocouples. Figure 4-23 shows the error on prediction of cells temperatures at each thermocouple location. The differences observed with the experimental data are mainly to be attributed to the simplifications made in defining the heat generation models for the cells and the BMS, as well as in modeling the cell thermal properties as constant parameters. Nevertheless, all of the temperatures predicted by the FEM model at the end of the 30 -minute test are within a $2.5^{\circ} \mathrm{C}$ margin from the corresponding experimental values, which is within the error of a thermocouple. 
Given that the objective of the developed model is to conduct preliminary design studies on thermal management solution, the errors obtained during the model validation phase were considered reasonable.

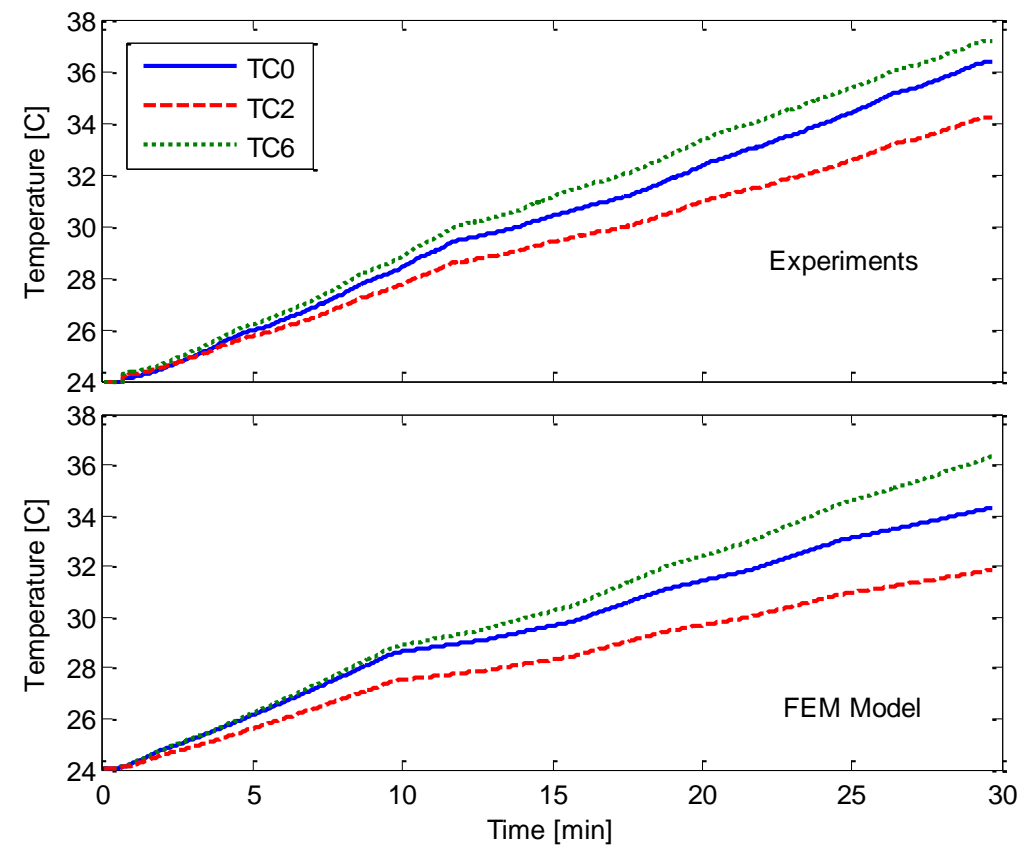

Figure 4-22: Comparison of Experimental (Top) and Predicted (Bottom) Temperatures at Different Locations in the Pack 


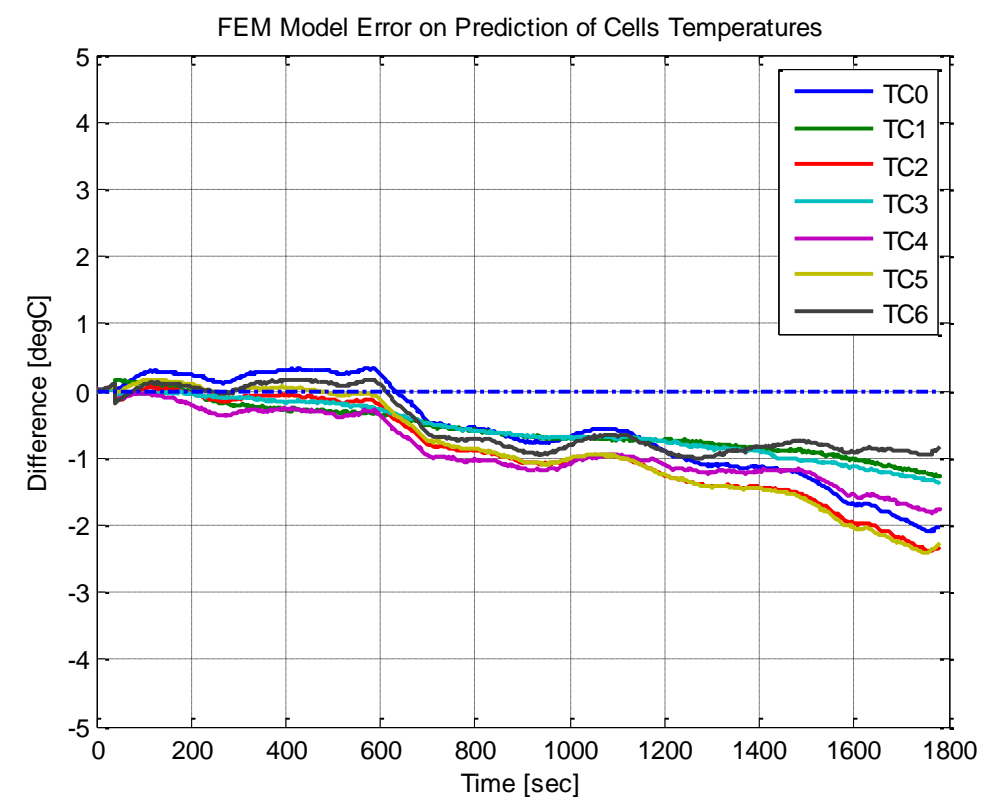

Figure 4-23: FEM Model Error on Prediction of Cells Temperatures

\subsection{Development of Prototype}

In this section, a conceptual prototype that mimics the DeWalt battery pack is introduced. The purpose of this prototype is to test the pack at a pre-defined current profile and compare the results with results of simulation for validation.

The prototype was built with exactly the same A123-ANR26650 battery cells that were used in the case study (DeWalt battery pack). The materials used to build the prototype had similar thermal properties to the real materials in the original pack.

This section lists the fabrication steps of the prototypes, shows the instrumentation used for testing them, describes the test performed, and, finally, shows and discusses the results. 


\subsubsection{Fabrication of the Prototypes}

Ten cells were characterized and tested by measuring each cell's internal resistance, terminal voltage, and capacity; the cells characterization results are shown in Table 4-5. The need for the characterization, which guarantees that all cells are in balance and assures that all cells starts from fully charged state, is increased in this case because the prototypes do not have a BMS.

Table 4-5: Cells Characterization Results

\begin{tabular}{|c|c|c|c|c|}
\hline $\begin{array}{c}\text { Cell } \\
\text { No. }\end{array}$ & Serial No. & $\begin{array}{c}\text { Rint } \\
(\mathbf{m} \boldsymbol{\Omega})\end{array}$ & $\begin{array}{c}\text { OCV } \\
(\mathbf{V})\end{array}$ & $\begin{array}{c}\text { Cap. } \\
\text { (A.h) }\end{array}$ \\
\hline 1 & AL05272 & 7.98 & 3.2955 & 2.2916 \\
\hline 2 & BI04959 & 8.06 & 3.305 & 2.2642 \\
\hline 3 & BJ04560 & 7.87 & 3.3 & 2.3037 \\
\hline 4 & AJ03709 & 8.19 & 3.303 & 2.2748 \\
\hline 5 & AI03442 & 8.23 & 3.301 & 2.2992 \\
\hline 6 & AJ03716 & 8.14 & 3.301 & 2.2713 \\
\hline 7 & BK03505 & 8.1 & 3.301 & 2.276 \\
\hline 8 & BH03063 & 8.07 & 3.301 & 2.2828 \\
\hline 9 & BJ03732 & 8.47 & 3.301 & 2.3078 \\
\hline 10 & AJ03721 & 8.2 & 3.301 & 2.2926 \\
\hline
\end{tabular}

In Table 4-5, it is noticeable that the internal resistances are within $0.67 \mathrm{~m} \Omega$, while their capacities range between $2.25 \mathrm{Ah}$ and $2.32 \mathrm{Ah}$. The $\mathrm{OCV}$ for all of them was around $3.3 \mathrm{~V}$, which is equal to the nominal voltage of A123 cell given in the datasheet.

After that, tabs were spot-welded. The cells were connected in series as they were in the original pack, as shown in Figure 4-24. Then, a case for the packs was manufactured. The 
material of the case was Polycarbonate polymer, known as Lexan, with thermal properties very close to the actual ABS plastic case. The prototype was covered with Lexan from five sides (see Figure 4-25).

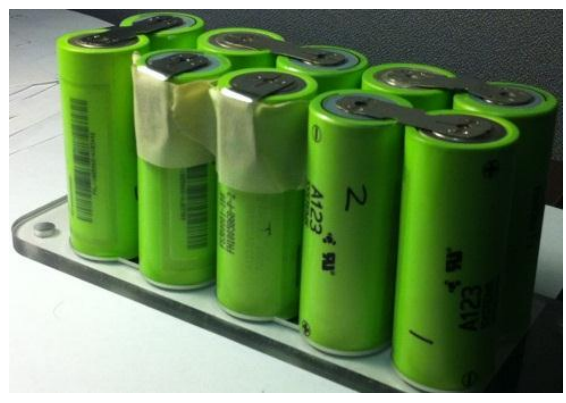

Figure 4-24: Cells with Tabs

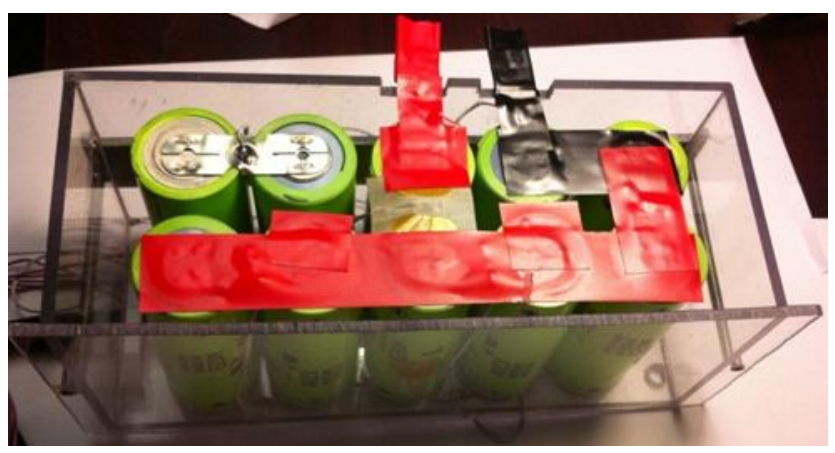

Figure 4-25: Case I (Baseline) Prototype

The upper side of the prototype was covered with $0.5 \mathrm{~mm}$-thickness white IR window, manufactured by Edmund Optics $®$; the thin design consistent across the window surface and minimal thermal expansion make them ideal for a range of infrared applications. 
Figure 4-26 shows the transmission of IR material as a function of wavelength. The prototype with the IR window fixed on the top side is shown in Figure 4-27.

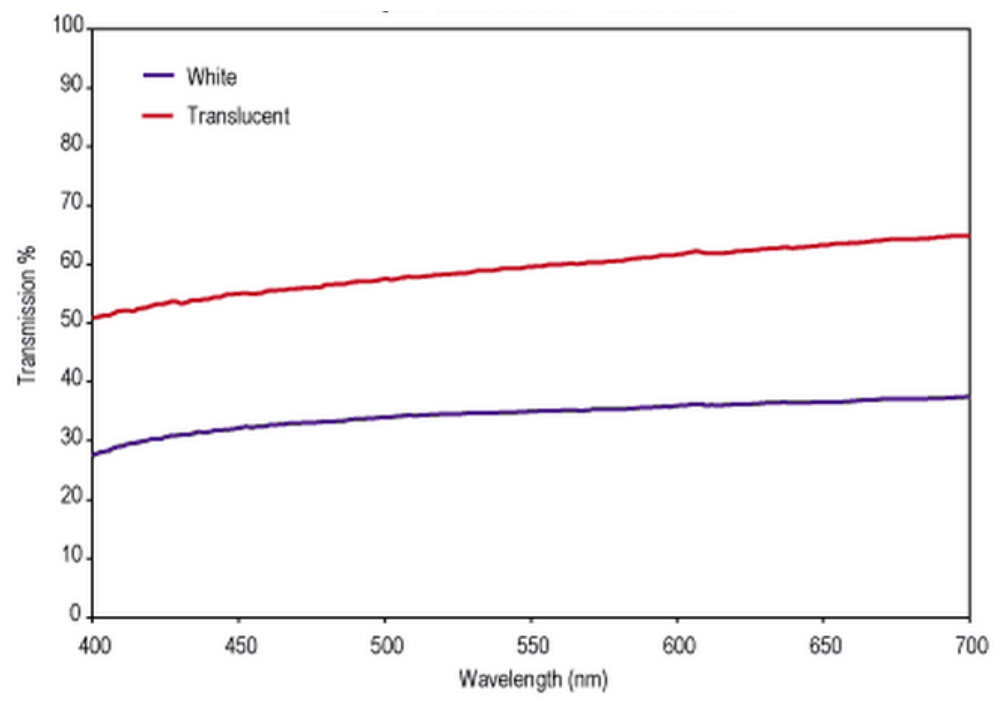

Figure 4-26: Transmission of IR material as a Function of Wavelength'

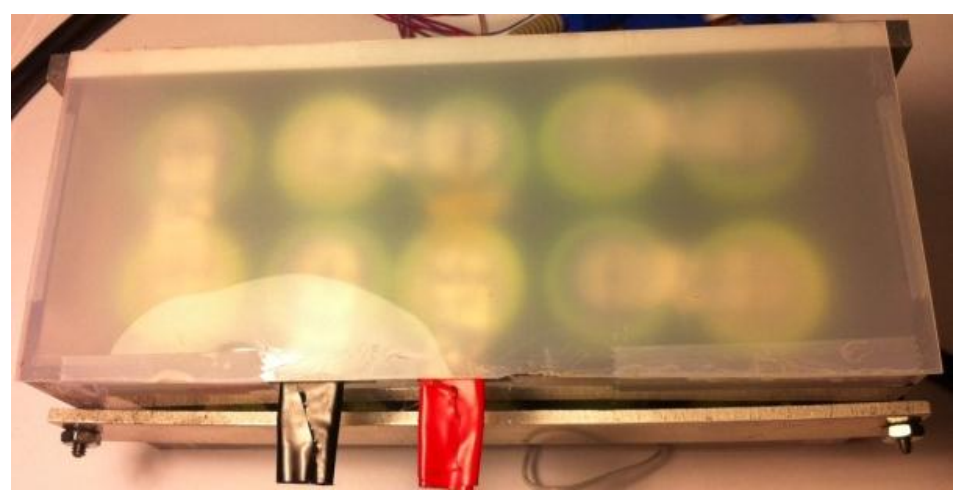

Figure 4-27: Prototype with IR Window

${ }^{9}$ Edmund Optics Inc., www.edmundoptics.com 


\subsubsection{Instrumentation}

The prototype was instrumented with five thermocouples in five different points in the pack. Figure 4-28 depicts both the points at which the thermocouples were fixed and their labels. In addition, the individual voltage of each cell, terminal voltage, and pack current were measured. Furthermore, a thermal video was taken by a mounted thermal camera. The thermal camera was an Electrophysics® PV320 (see Figure 4-29), which measures temperatures in the range of $-10^{\circ} \mathrm{C}$ to $500^{\circ} \mathrm{C}$. It senses any change of temperature more than or equal to $0.08^{\circ} \mathrm{C}$. The output of this camera is a $320 \times 240$ pixels image, and it can provide frames up to 30 frames per second. In these tests, the frame rate of the camera was set to 1 frame per second.

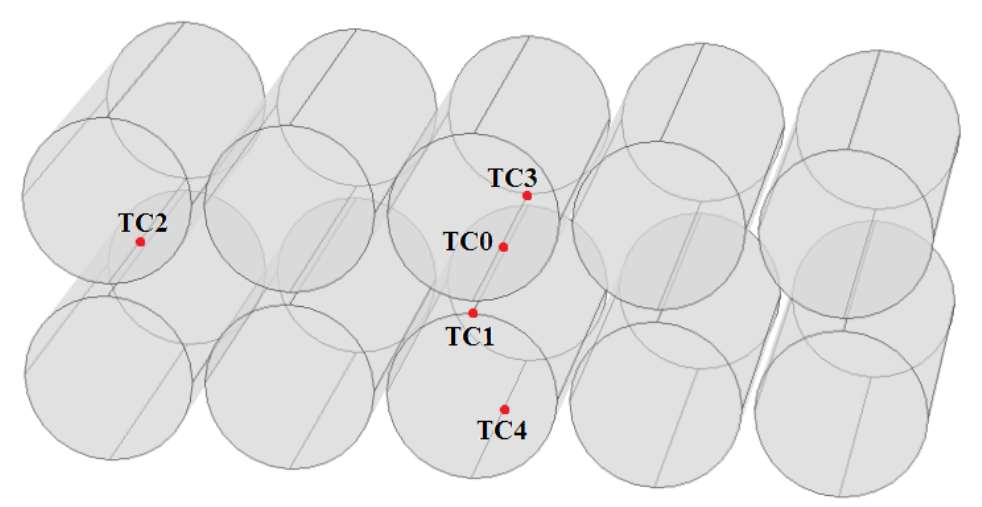

Figure 4-28: Thermocouples Positions 


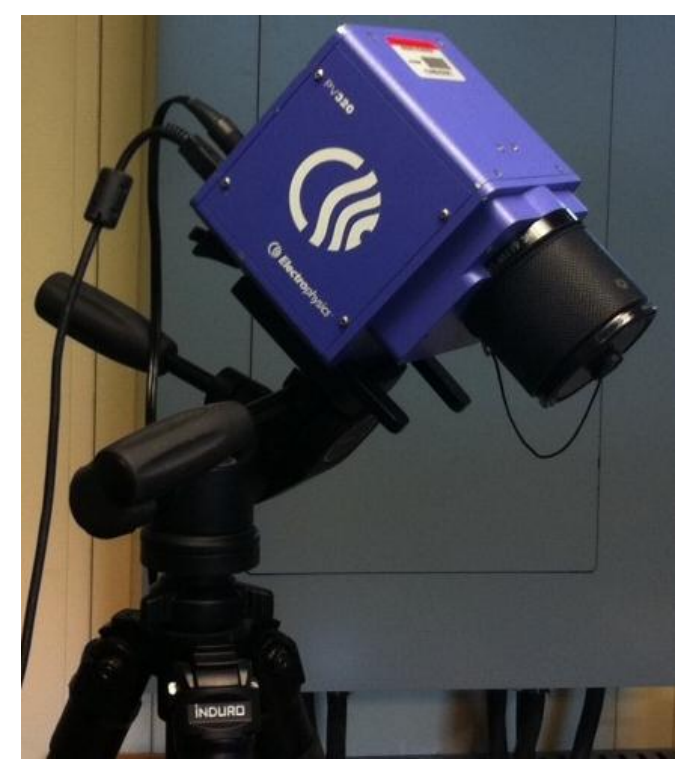

Figure 4-29: Electrophysics ${ }^{\circledR}$ PV320 Thermal Camera

In order to discharge the prototypes at a pre-defined current profile, a current cycler programmable DC electronic load was used. In these tests, the cycler was an AMREL® PLA1.5K-60-600. This cycler has a power rating of $1.5 \mathrm{~kW}$, voltage rating of $60 \mathrm{~V}$, and current rating of 600A. This cycler is shown in Figure 4-30.

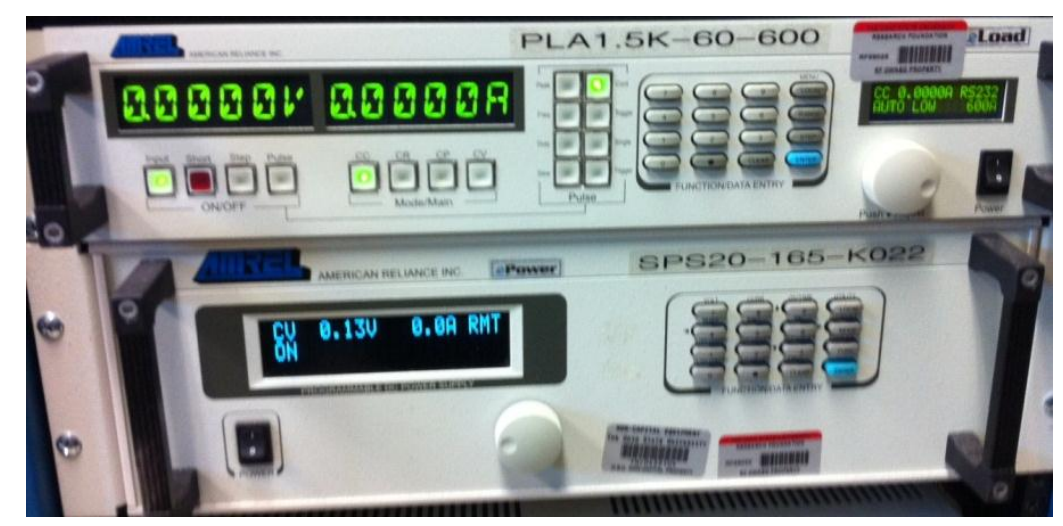

Figure 4-30: Current Cycler Programmable DC Electronic Load 
The measured signals (i.e., temperature, current, voltage) were recorded on a PC by National Instrument ${ }^{\mathrm{TM}}$ DAQ and LabVIEW ${ }^{\mathrm{TM}}$ at a sampling time of 0.1 second. The DAQ which was used in these experiments was NI TC-2095 (see Figure 4-31).

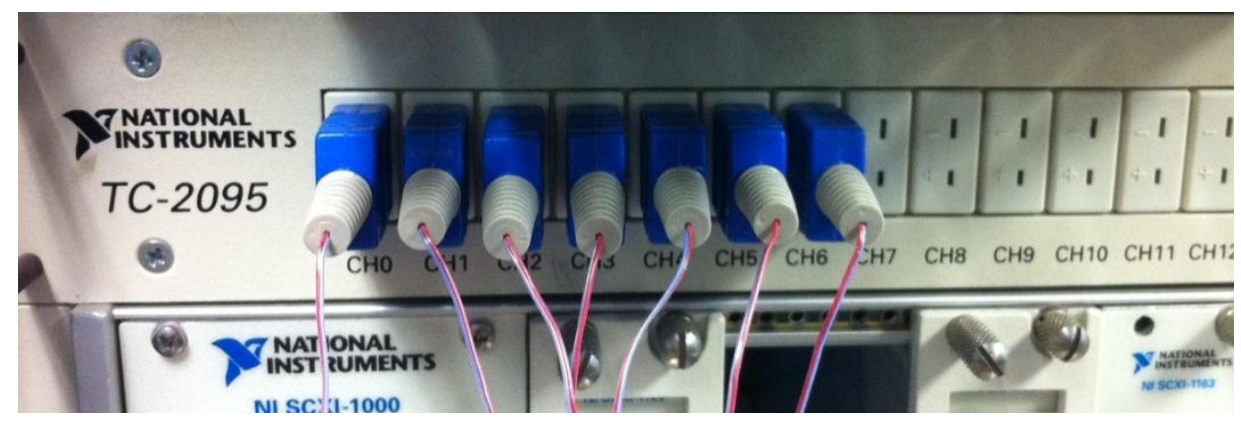

Figure 4-31: National Instrument ${ }^{\mathrm{TM}}$ TC-2095

\subsubsection{Testing Current Profile Synthesis}

At this stage, the data obtained in the experimental test was processed to define a set of statistically representative discharging patterns that could be reproduced in a laboratory environment or used in simulation. The data processing started with isolating individual non-zero discharging events, as shown in Figure 4-32, and continued with characterizing each event with a set of variables; namely, event duration, rest duration, current output, power output, heat generation rate, and temperature. The events were then processed statistically to determine the corresponding probability of occurrence (statistical representation) of each variable. Figure 4-35 shows the statistical distribution of all the variables based on the data obtained from the test. 

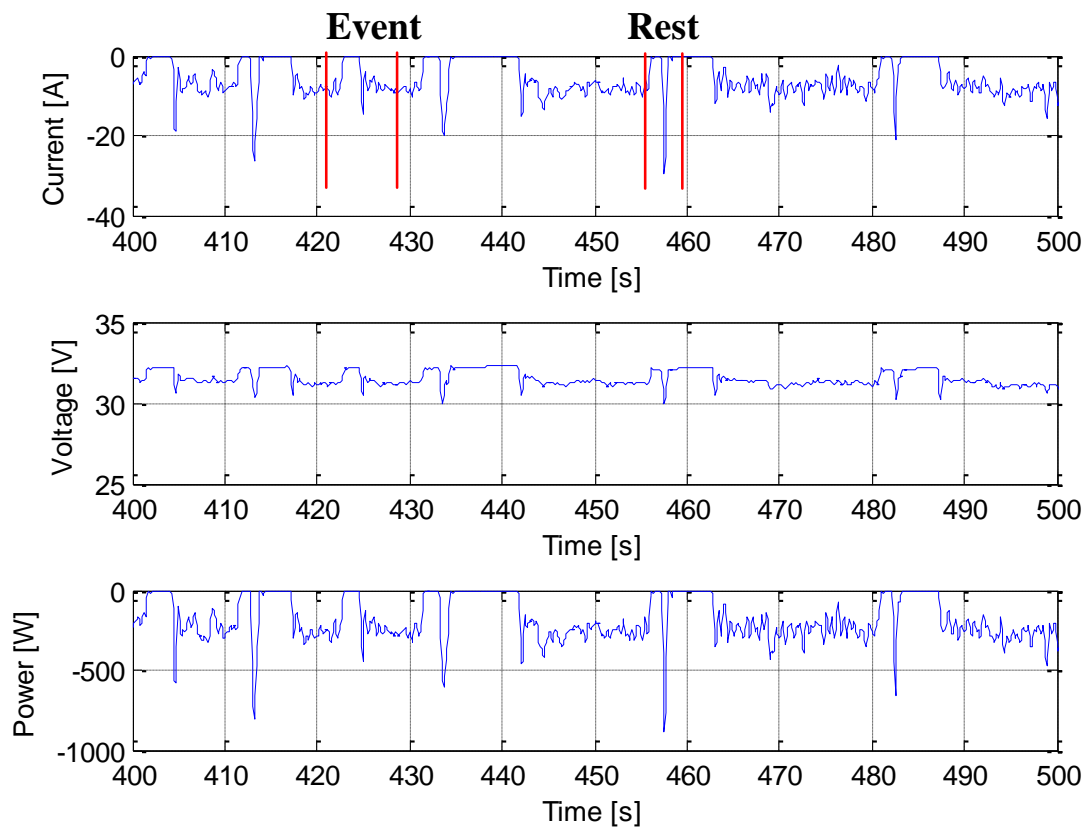

Figure 4-32: Sample Current, Voltage, and Power Profiles for 100 seconds
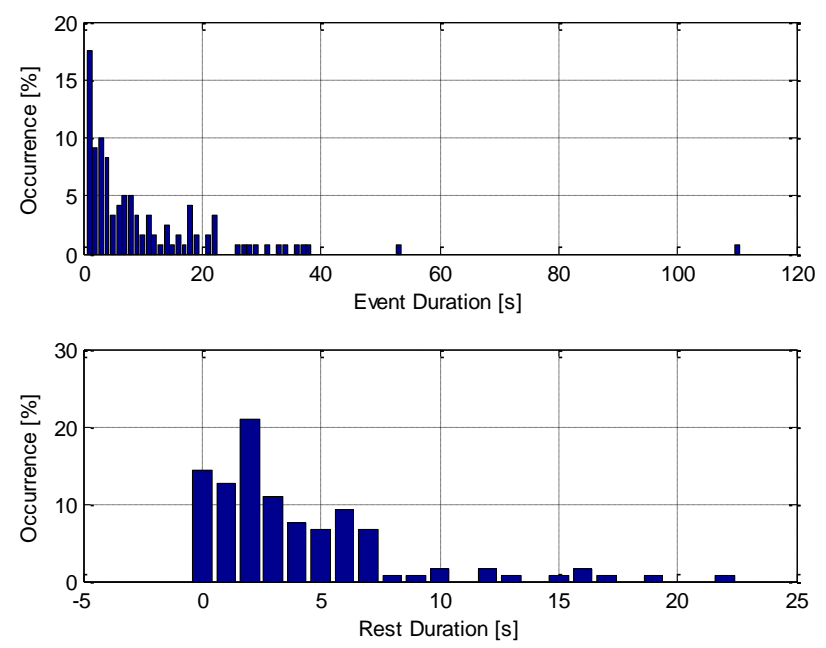

Figure 4-33: Statistical Distribution of Event and Rest Durations 

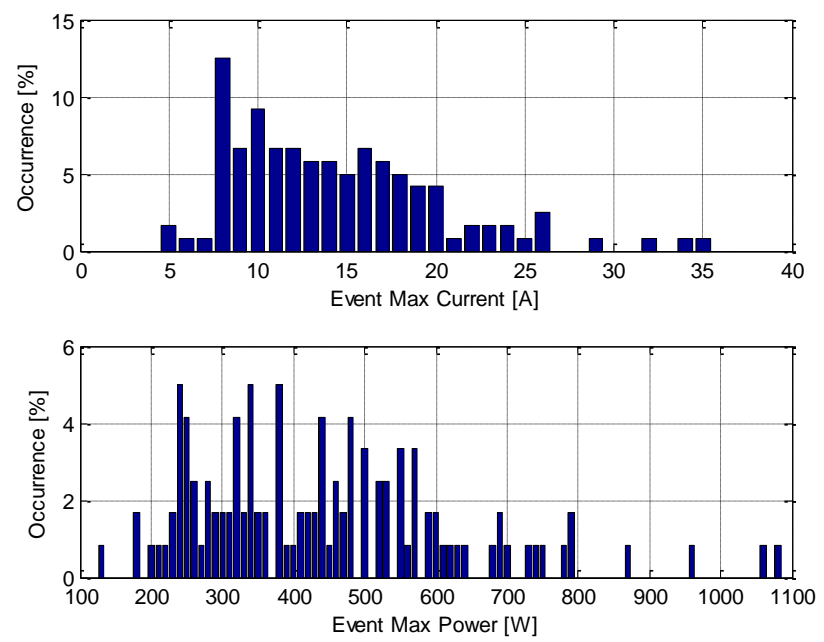

Figure 4-34: Statistical Distribution of Max Current and Max Power
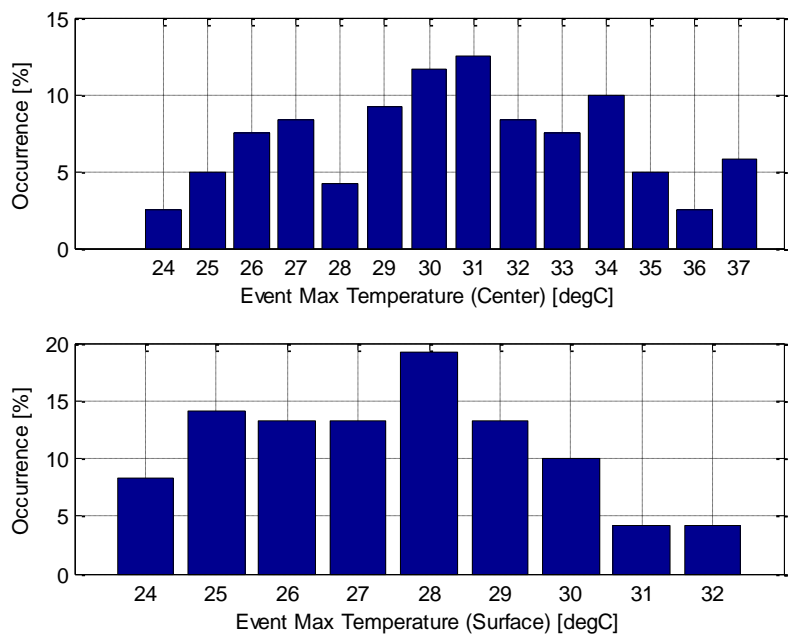

Figure 4-35: Statistical Distribution of Max Center and Surface Temperatures

Once the statistical distributions of the variables were obtained, a set of metrics that are representative of the entire distributions was calculated. The objective was to define a characteristic event that is representative of the entire testing domain. The criteria followed to calculate the metrics contained the simple average (see Equation 4-9), 
weighted average (see Equation 4-10), minimum value, maximum value, and value with highest probability of occurrence. Table 4-6 summarizes the characteristic metrics for the representative event according to different selection criteria.

$$
\begin{aligned}
& \bar{X}=\frac{1}{N} \sum_{i=1}^{N} X_{i} \\
& X_{w}=\sum_{i=1}^{N} X_{i} p_{i}
\end{aligned}
$$

The conducted analysis allowed for synthesizing a duty cycle profile that is statistically representative of the entire set of data collected during the experiment. This duty cycle was used later as a discharge scenario for laboratory and simulation testing. In order to generate this duty cycle, the events (discharge current) were normalized with respect to its maximum value (normalized vertically), then it was normalized with respect to the duration (normalized horizontally). After that, the synthetic cycle was obtained by averaging the normalized events. The average cycle and the synthetic cycle (duty cycle) are shown in Figure 4-36.

The synthetic cycle starts with the peak value of the current for $5 \%$ of the duty cycle, then it drops down to $65 \%$ of the peak value for the remaining time. After that, the current rests for some time. Then the cycle repeats itself again and again until the battery capacity fades. 
Table 4-6: Summary of Characteristic Event Metrics

\begin{tabular}{|c|c|c|c|c|c|}
\hline Parameter & $\begin{array}{c}\text { Simple } \\
\text { Average }\end{array}$ & $\begin{array}{c}\text { Weighted } \\
\text { Average }\end{array}$ & $\begin{array}{c}\text { Minimum } \\
\text { Value }\end{array}$ & $\begin{array}{c}\text { Maximum } \\
\text { Value }\end{array}$ & $\begin{array}{c}\text { Most } \\
\text { Frequent }\end{array}$ \\
\hline Event Duration (s) & 75.56 & 27.46 & 1.00 & 548 & 6.00 \\
\hline Rest Duration (s) & 81.21 & 31.19 & 1.00 & 335 & 1.00 \\
\hline Peak Current (A) & 4.00 & 4.31 & 0.20 & 8.20 & 2.60 \\
\hline Peak Power (W) & 115.45 & 128.31 & 10.00 & 230 & 140 \\
\hline Center Temp. $\left({ }^{\circ} \mathrm{C}\right)$ & 33.0 & 34.3 & 27.0 & 39.0 & 37.0 \\
\hline Surface Temp. $\left({ }^{\circ} \mathrm{C}\right)$ & 30.5 & 30.7 & 27.0 & 34.0 & 30.0 \\
\hline
\end{tabular}

In order to provide more accurate measurements of the pack thermal behavior in transient conditions, the synthetic characteristic event was defined, based on the maximum values obtained from the statistical analysis conducted on the experimental data and reported in Table 4-6. This event is representative of a "worst-case scenario," where the power tool would be used repeatedly by applying a high load (i.e., the highest current value) for long period of time (i.e., the highest event duration), then rest briefly (i.e., the smallest rest duration) before the following cycle. According to Table 4-6, the values of current, duration, and rest were $8.2 \mathrm{~A}, 548 \mathrm{sec}$, and $1 \mathrm{sec}$, respectively (see Figure 4-37). The "worst case scenario" discharge current needs 1200 seconds (20 minutes) to discharge the entire Dewalt pack.

By applying the "worst case scenario" current profile to the electro-thermal model mentioned earlier, the voltage, OCV, and heat generation rate for the "worst case 
scenario" was predicted. Figure 4-38 shows the OCV and output voltage per cell, while Figure 4-39 shows the heat generation rate estimated per cell.

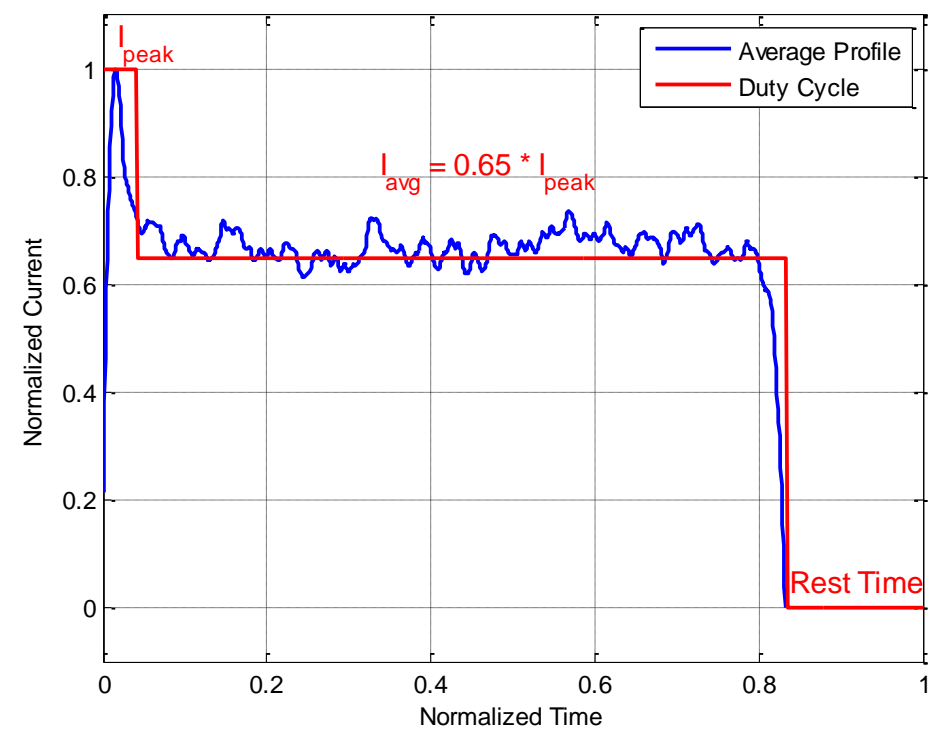

Figure 4-36: Average Profile and Duty Cycle

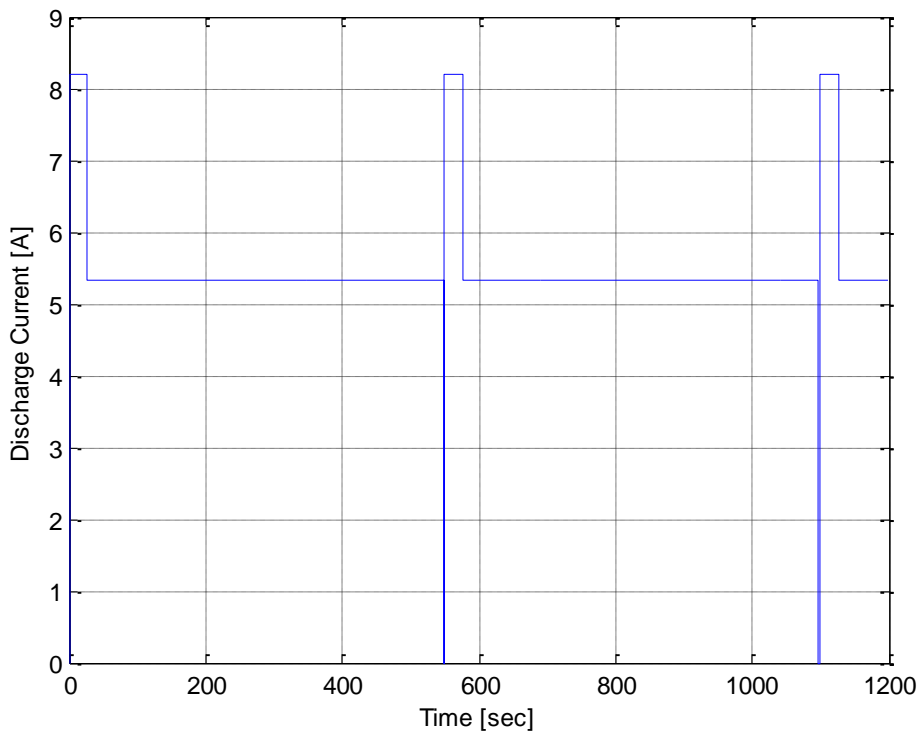

Figure 4-37: The "Worst Case Scenario" Current Profile 


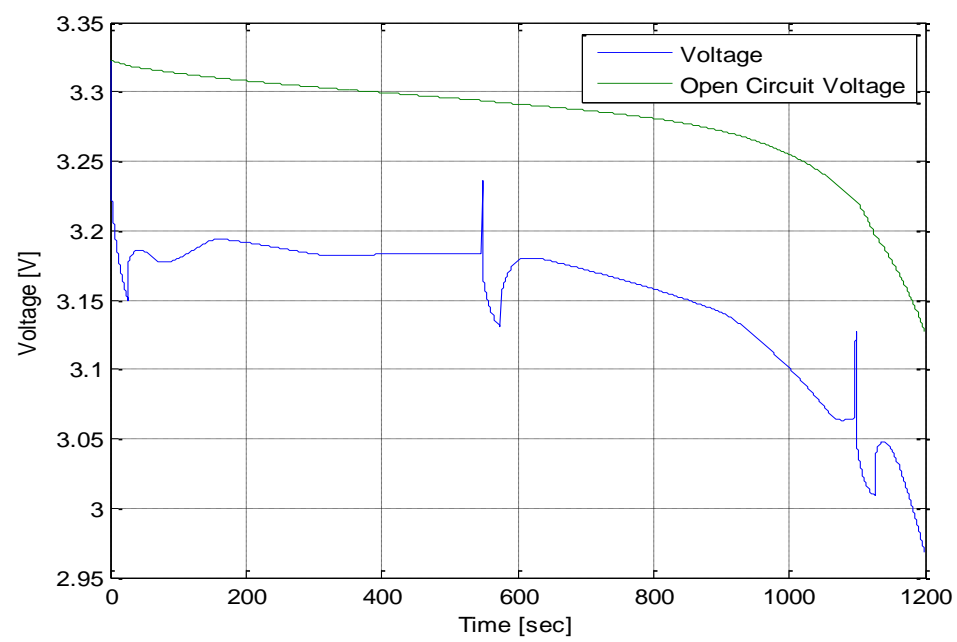

Figure 4-38: OCV and Voltage per cell for the "Worst Case Scenario"

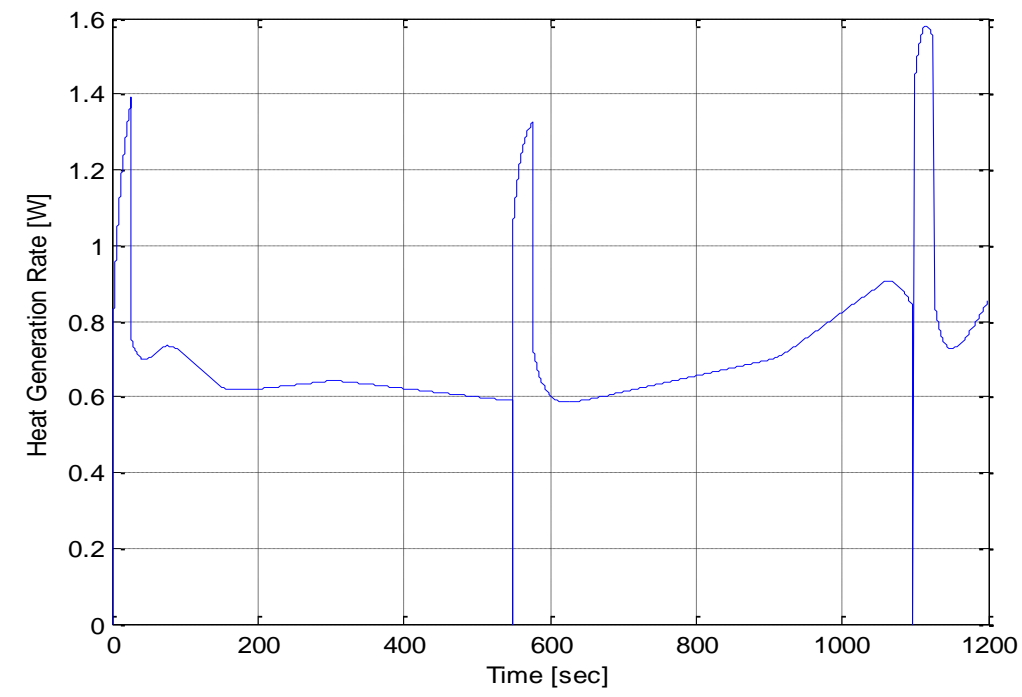

Figure 4-39: Heat Generation Rate per cell for the "Worst Case Scenario"

In order to test the different thermal management solutions explained in Section 4.3, the "worst-case scenario" heat generation profile was considered a Heat Source for the different design cases compared for pack thermal management. 
The current demand and heat generation rate profile of the "worst case scenario" obtained by this analysis, despite its severe nature, is still representative of normal usage conditions. In order to provide a qualitative evaluation of the pack thermal performance in near-abusive usage conditions, two additional scenarios were considered. These scenarios were defined starting from the characteristic event and by doubling (2x) and quadrupling $(4 \mathrm{x})$ the current demand. The duration of the discharging phase was set to the time required to discharge the pack completely, which is 10 minutes for Scenario 2 and 5 minutes for Scenario 3. The current profile and heat generation rate for each of the three scenarios considered is shown in Figure 4-40.
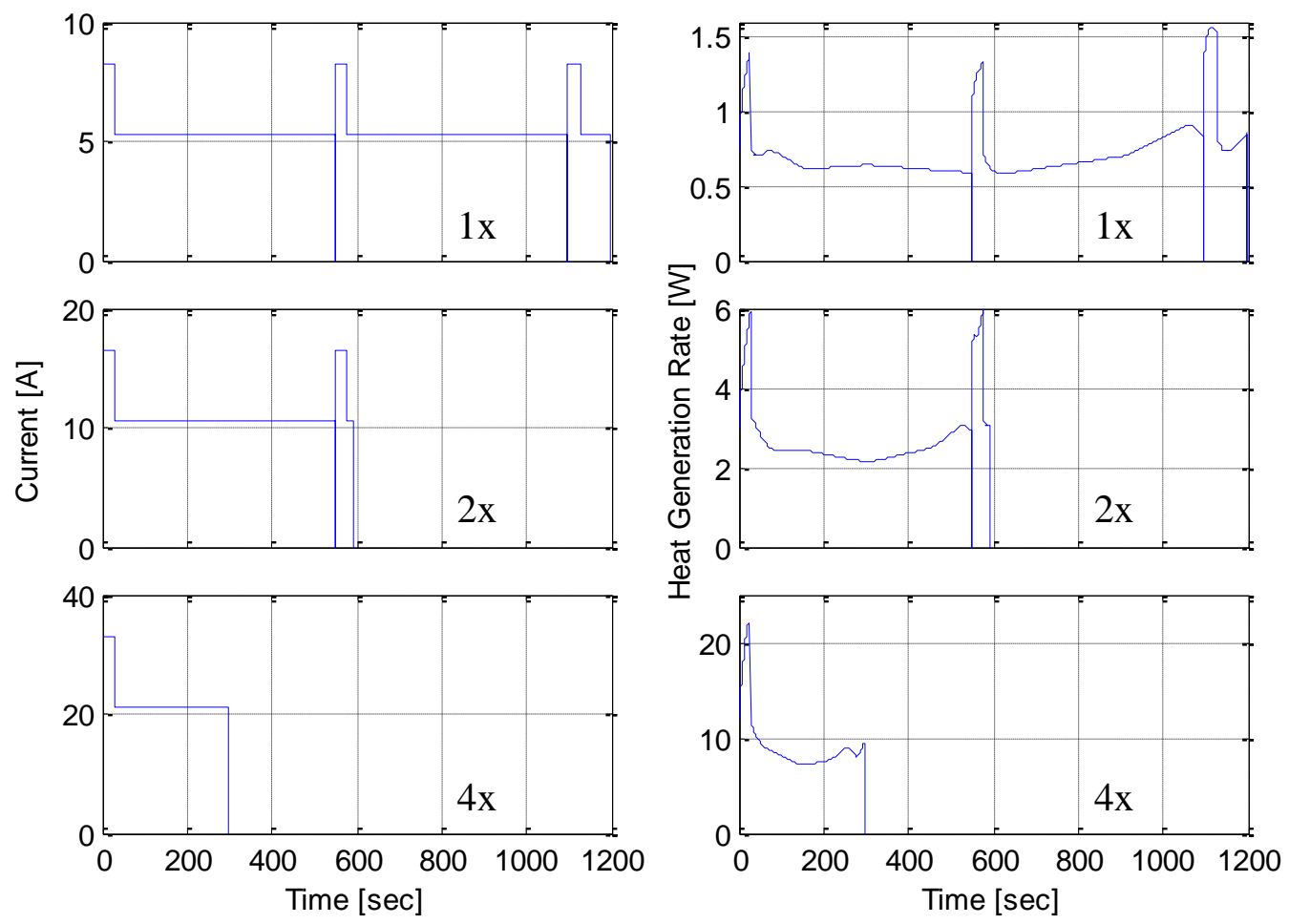

Figure 4-40: Overview of the Three Pack Utilization Scenarios Considered for the Comparative Study 


\subsubsection{Description of Tests}

In this stage of the study, the prototype was fully charged and, then, was left for a sufficient time to cool down to the ambient temperature. Then, a pre-defined current profile was applied by the cycler on the prototypes till the voltage of any cell in the prototype dropped down to $2.0 \mathrm{~V}$; in other words, the test stopped when any cell in the pack ran out of charge.

The pre-defined current profile to test the prototype was picked to be $2 \mathrm{x}$ "worst case scenario". The duration of this test was around 10 minutes. Figure 4-40 shows the current

profile and the estimated heat generation rate. The current profile starts with a pulse of 16.4A (7 C-rate) for 27 seconds, the current holds at 10.7A (4.6 C-rate) to complete the cycle (550 seconds), then it repeats itself. The tests were performed in a room with ambient temperature equal to $22^{\circ} \mathrm{C}$. There were no fans or any cooling system; therefore, only cooling by natural convection was assumed.

\subsubsection{Results}

Figure 4-41 shows a thermal image at the end of the test; it also shows the temperatures at two spots on the cell which varied during the test. It is clear that the baseline pack suffers from high temperatures and poor uniformity (i.e., hot and cold spots). Figure 4-42 confirms the results of the experimental thermal image; it reaches approximately the same peak temperature and shows the same degree of non-uniformity. 

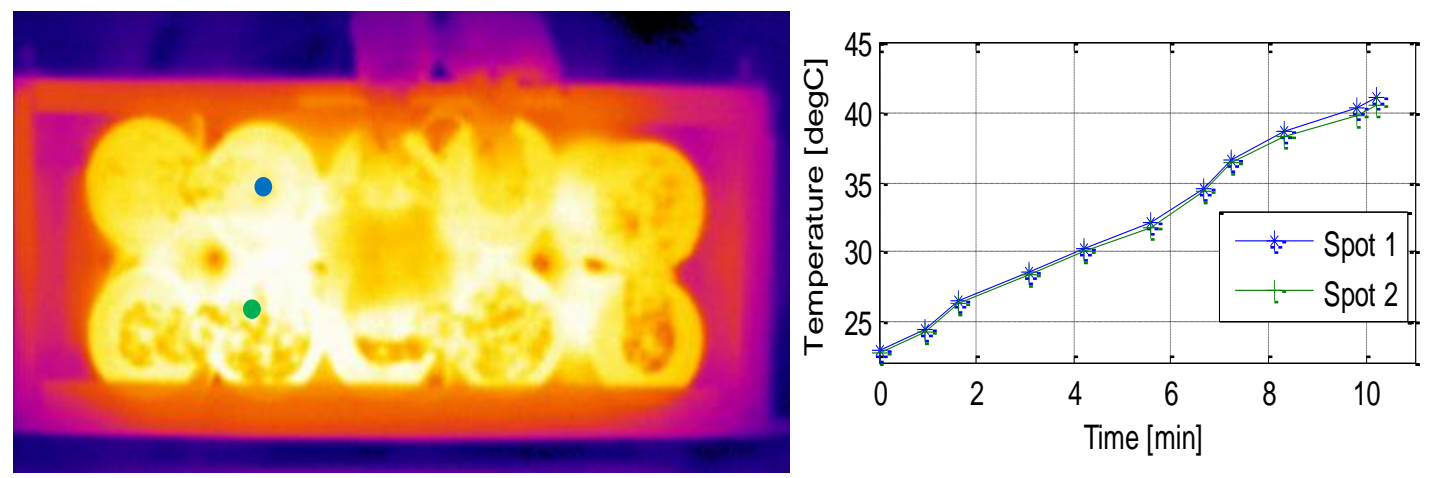

Figure 4-41: Experiment Thermal Image

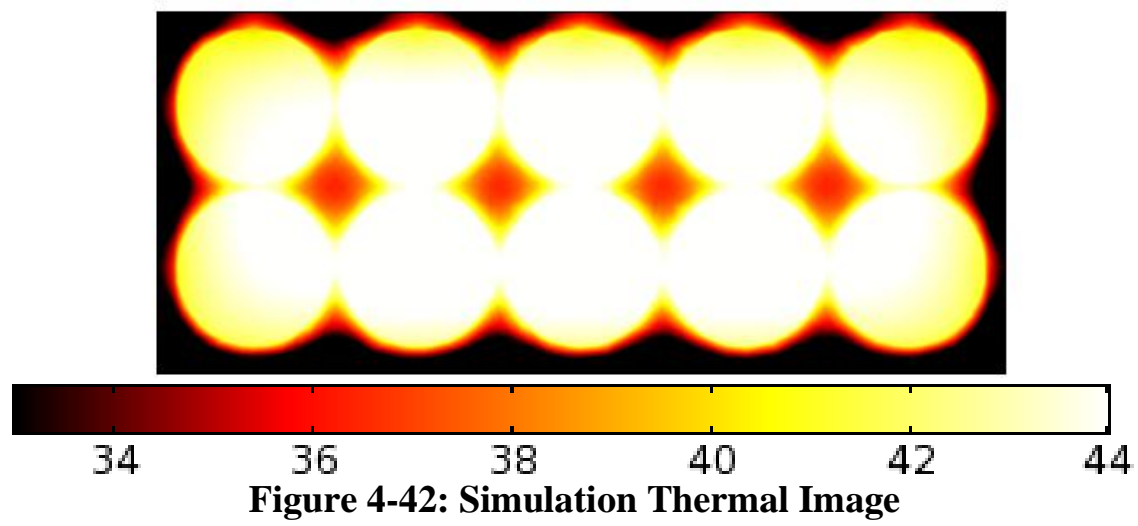

Figure 4-43 shows the validation of the prototype results by comparing them with the simulation results. The differences between the experimental temperatures and their corresponding simulation temperatures were within the error of a thermocouple. This suggests that this prototype is, indeed, valid to describe the thermal behavior of the original Dewalt battery pack. 

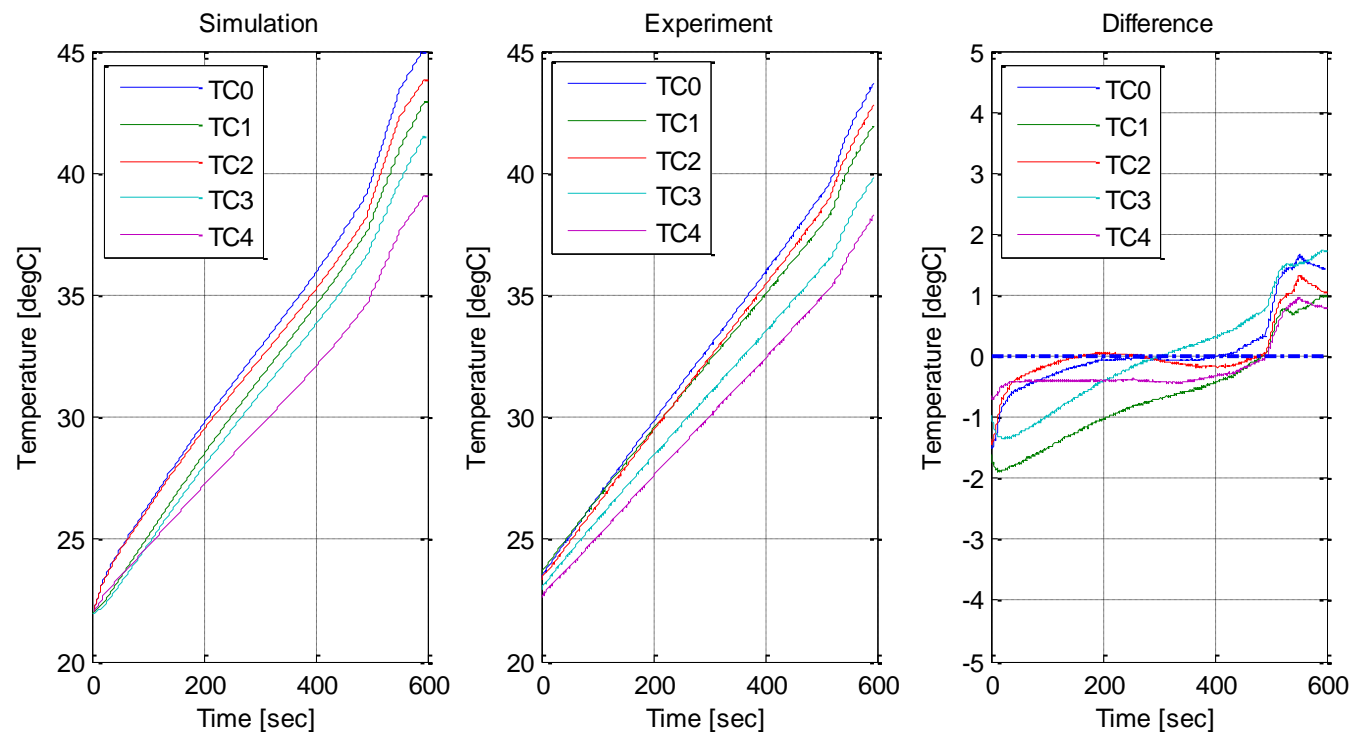

Figure 4-43: Prototype Validation: Simulation and Experiment Temperatures, and Difference 


\section{Chapter 5}

\section{APPLICATION TO THERMAL MANAGEMENT SYSTEM DESIGN}

\section{AND VERIFICATION}

\subsection{Design Study for Thermal Management of Li-Ion Battery Pack}

The validated FEM model was used to conduct a preliminary design study where graphite-based heat spreading materials were inserted in the battery pack to improve the temperature uniformity and heat rejection capability. Flexible graphite heat spreaders are an effective low-cost solution for a passive thermal management system that takes advantage of the high thermal conductivity and very low density of flexible graphite [19]. Flexible graphite used in heat spreaders is an anisotropic material with a thermal conductivity as high as $1500 \mathrm{~W} / \mathrm{m}-\mathrm{K}$ in the plane of the spreader combined with a much lower thermal conductivity through the spreader thickness. Graphite heat spreaders have found widespread application in electronic cooling where heat flux density is low and available space is limited; that is, in plasma display panels, laptop computers, cameras and cell phones, as discussed in Chapter 1 [19,37-40].

Flexible graphite sheets are produced in a range of thermal conductivities and thicknesses. The properties of flexible graphite and other heat spreader materials are 
shown in Table 4. As shown, flexible graphite heat spreaders can have a thermal conductivity in the $300-1500 \mathrm{~W} / \mathrm{m}-\mathrm{K}$ range in-plane directions, whereas the conductivity through thickness is as low as 2.4-3.5 W/m-K.

Table 5-1: Thermal Properties of Heat Spreading Materials

\begin{tabular}{|c|c|c|c|}
\hline Property & $\begin{array}{c}\text { Flexible Graphite Heat } \\
\text { Spreaders }\end{array}$ & $\begin{array}{c}\text { Aluminum } \\
\text { Alloys }\end{array}$ & $\begin{array}{c}\text { Copper } \\
\text { Alloys }\end{array}$ \\
\hline Density $\left(\mathrm{g} / \mathrm{cm}^{3}\right)$ & $1.3-2.2$ & 2.71 & 8.89 \\
\hline $\begin{array}{c}\text { Conductivity } \\
(W / m-K)\end{array}$ & In-plane 300-1500 & \multirow{2}{*}{$180-220$} & 388 \\
\cline { 2 - 3 } & Through-thickness 3.2-4.5 & \\
\hline $\begin{array}{c}\text { Specific Heat } \\
(J / \mathrm{kg}-K)\end{array}$ & 700 & 904 & 385 \\
\hline
\end{tabular}

In the design study presented in this thesis, a flexible graphite material produced by GrafTech International Holdings, Inc., (eGRAF ${ }^{\circledR}$ SPREADERSHIELD $^{\text {TM }}$ SS450-0.25) ${ }^{10}$ was considered as the material for the heat spreader [80]. This material had a thickness of $0.25 \mathrm{~mm}$, an in-plane thermal conductivity of $450 \mathrm{~W} / \mathrm{m}-\mathrm{K}$ and a thru-thickness thermal conductivity of $3.2 \mathrm{~W} / \mathrm{m}-\mathrm{K}$. The thermal contact impedance of this heat spreader is 0.38 $\left({ }^{\circ} \mathrm{C}-\mathrm{cm}^{2} / \mathrm{W}\right)$ per side.

Different design solutions were compared in simulation using the FEM model of the battery pack. Figure 5-1 shows three design solutions (named "Cases") that have been compared in simulation to evaluate different thermal management solutions based on graphite heat spreaders.

10 eGRAF SPREADERSHIELD ${ }^{\mathrm{TM}}$, a trademark of GrafTech International Holdings, Inc. 


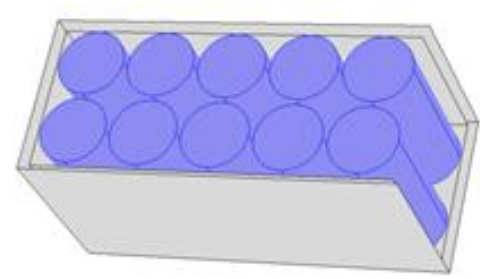

(a) Case I

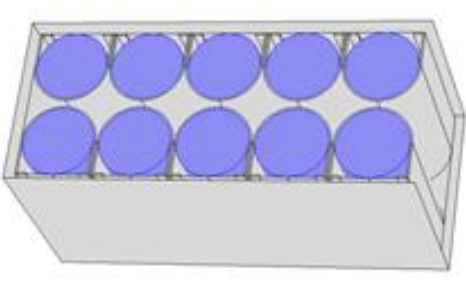

(b) Case II

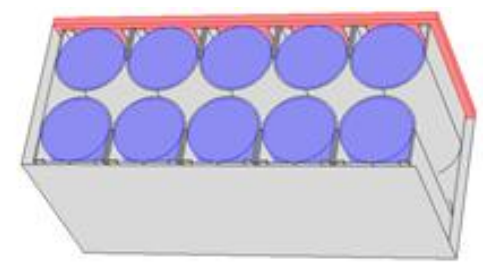

(c) Case III

Figure 5-1: Overview of the Different Design Cases Compared for Pack Thermal Management Solutions

In particular, Case I was considered as the baseline and it is simply representative of the standard battery pack. In Case II, the pack was fitted with graphite heat spreaders wrapped around each cell. In Case III, the same configuration was considered, but with aluminum heat sink replacing one of the pack sides. Case II aims at improving the uniformity of the temperature distribution inside the pack, while Case III aims at enhancing the heat rejection capability.

In Case II and Case III the global coordinate system was not sufficient to be considered for anisotropic thermal conductivity of the curvilinear heat spreaders. Therefore, a local curvilinear coordinate system was defined in order to follow the shape of the graphite spreaders. To achieve this, two Poisson's PDE modules were used in order to define the $\mathrm{x}$ and $\mathrm{z}$ directions for the local curvilinear coordinate system. The y direction for the local curvilinear coordinate system matches it for the global coordinate system, which is clear in Figure 5-2. Poisson's PDE is a classical PDE; it is given in the following equation:

$$
\nabla .(-\nabla u)=1
$$


In this module, the Dirichlet Boundary Condition specifies a value of $\mathrm{u}$ on the boundary of the domain. Figure 5-2(a) and (b) show the determination of the z-direction of the local curvilinear system, in which the boundary selected in Figure 5-2(a) had a value of $u=0$, while the boundary selected in Figure 5-2(b) had a value of $u=1$. The same is for the $\mathrm{x}-$ direction shown in Figure 5-2(c) and (d). The boundary selected in Figure 5-2(c) had a value of $u=0$, while the boundary selected in Figure 5-2(d) had a value of $u=1$. Figure 5-3 illustrates the difference between the resulting curvilinear coordinate system and the global coordinate system.
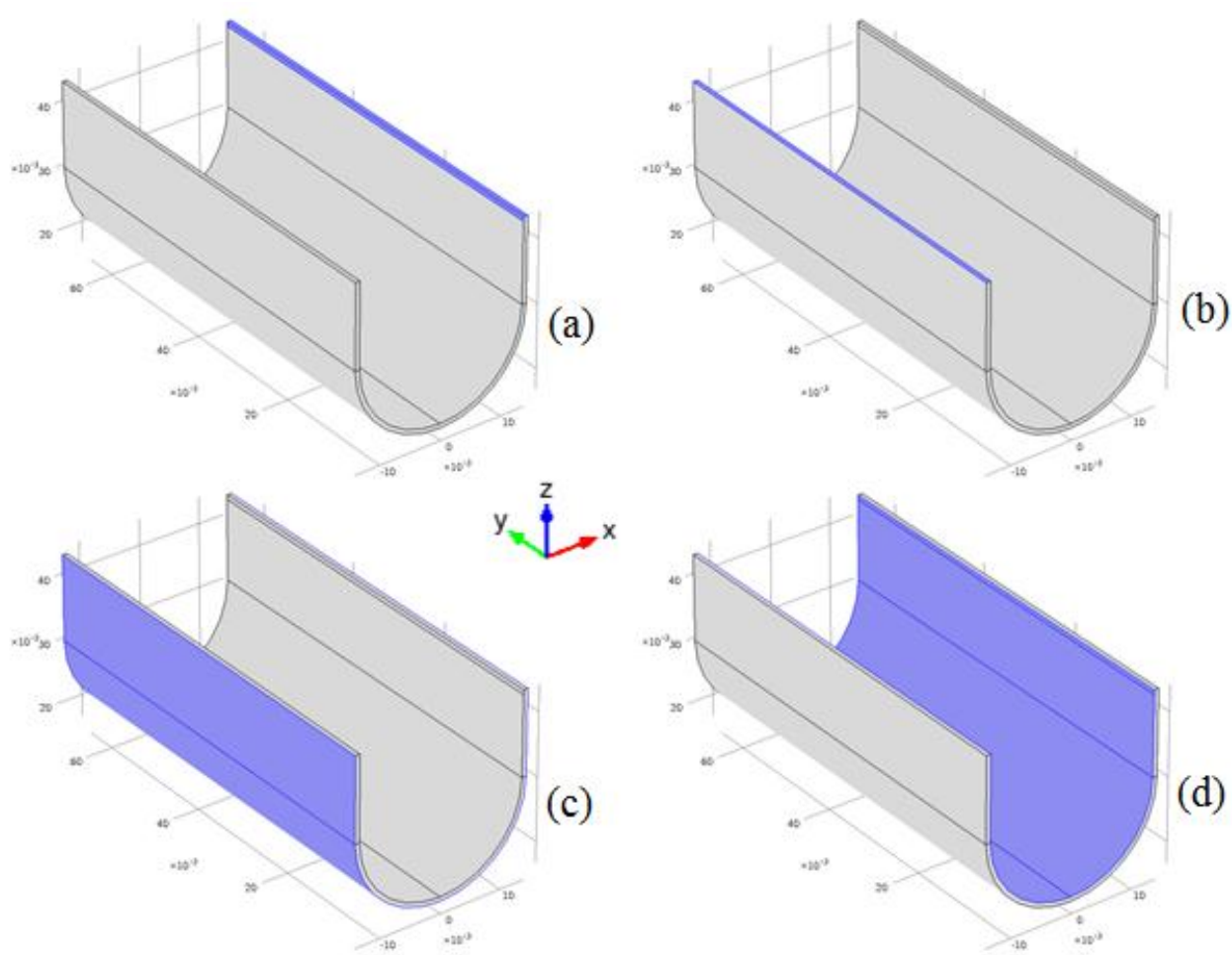

Figure 5-2: Dirichlet Boundary Conditions 


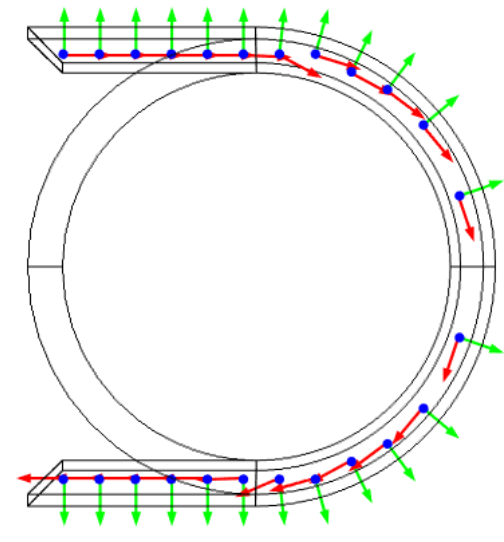

(a) Global

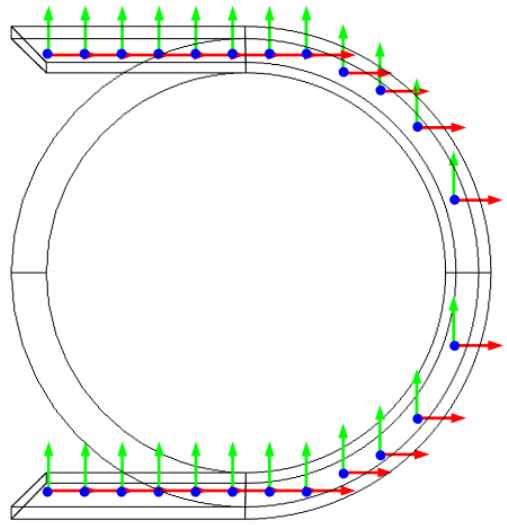

(b) Curvilinear

Figure 5-3: Coordinate Systems Comparison

\subsection{Simulation Results}

The three cases discussed earlier were considered in the simulation; namely, Case I, Case II, and Case III. For each case, the three scenarios, shown in Figure 4-40, were applied for each case. Therefore, there were a total of 9 configurations to be presented in this section.

The temperature grids of the nine configurations are shown in Figure 5-4, Figure 5-5, and Figure 5-6 for 1x "WCS", 2x "WCS", and 4x "WCS", respectively. Each figure shows cross-sectional grids at the middle of the pack and top-view grids of the pack; all of them have the same temperature color scale. 


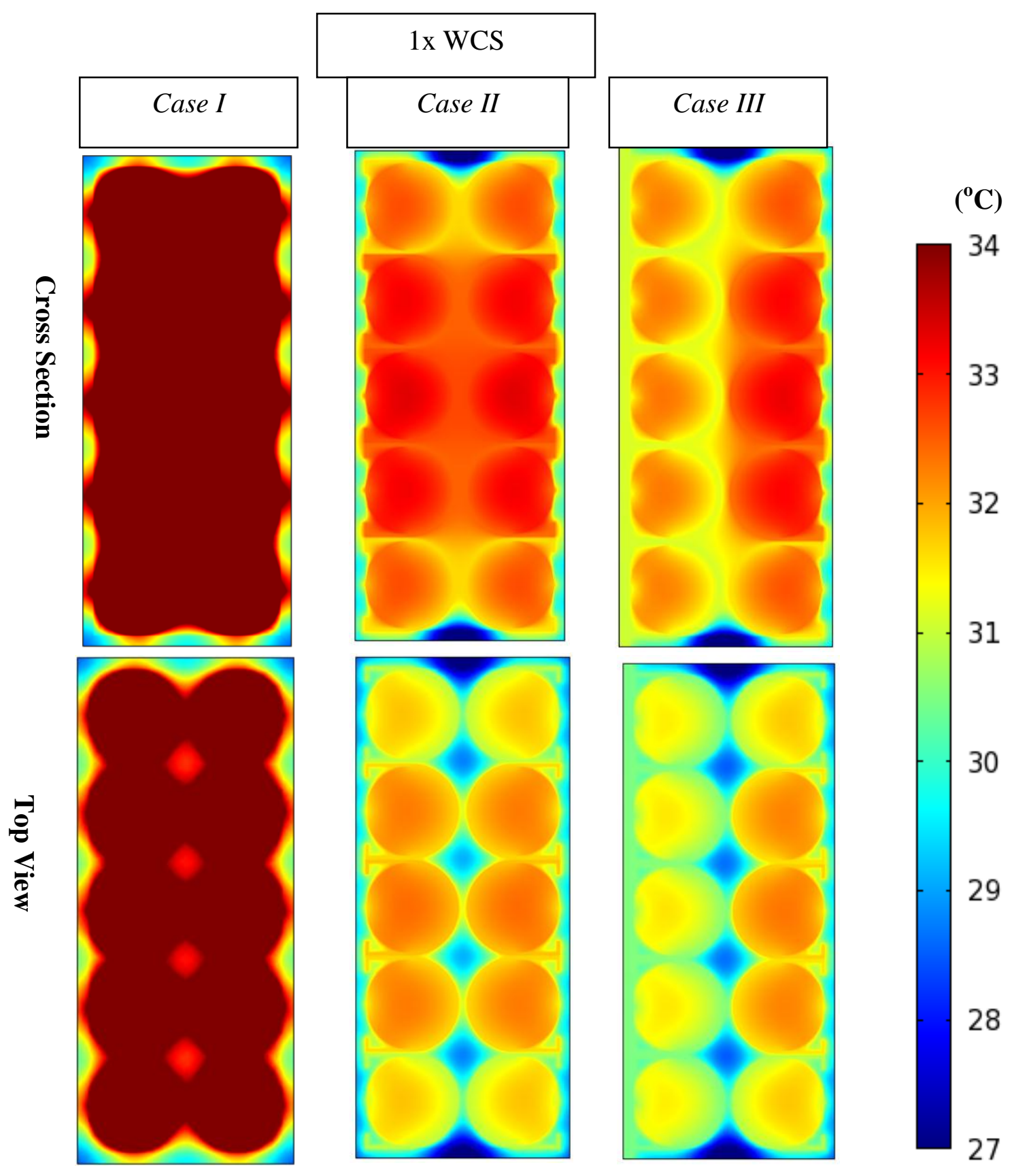

Figure 5-4: 1x "WCS" Temperature Grid 


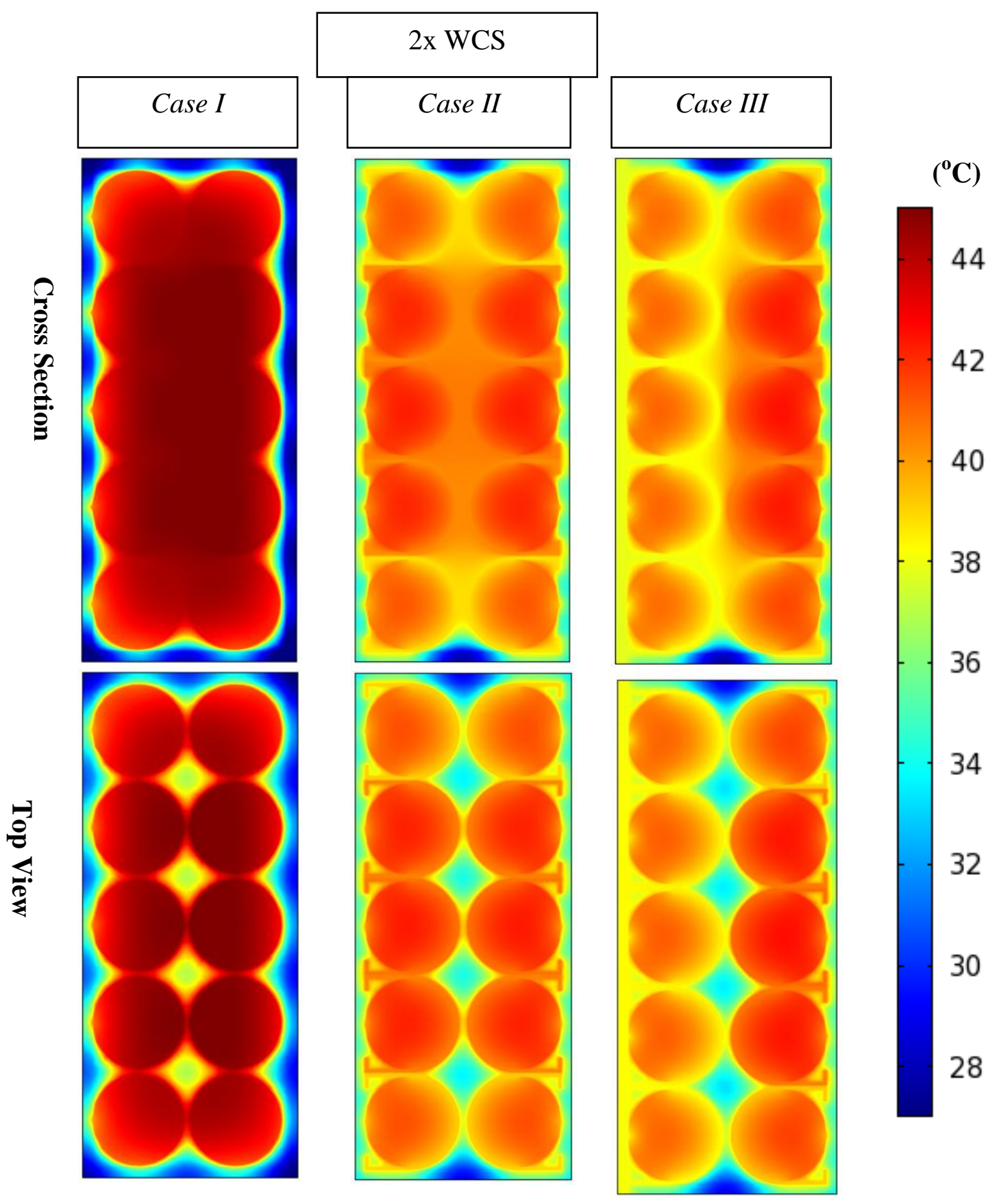

Figure 5-5: 2x "WCS" Temperature Grid 


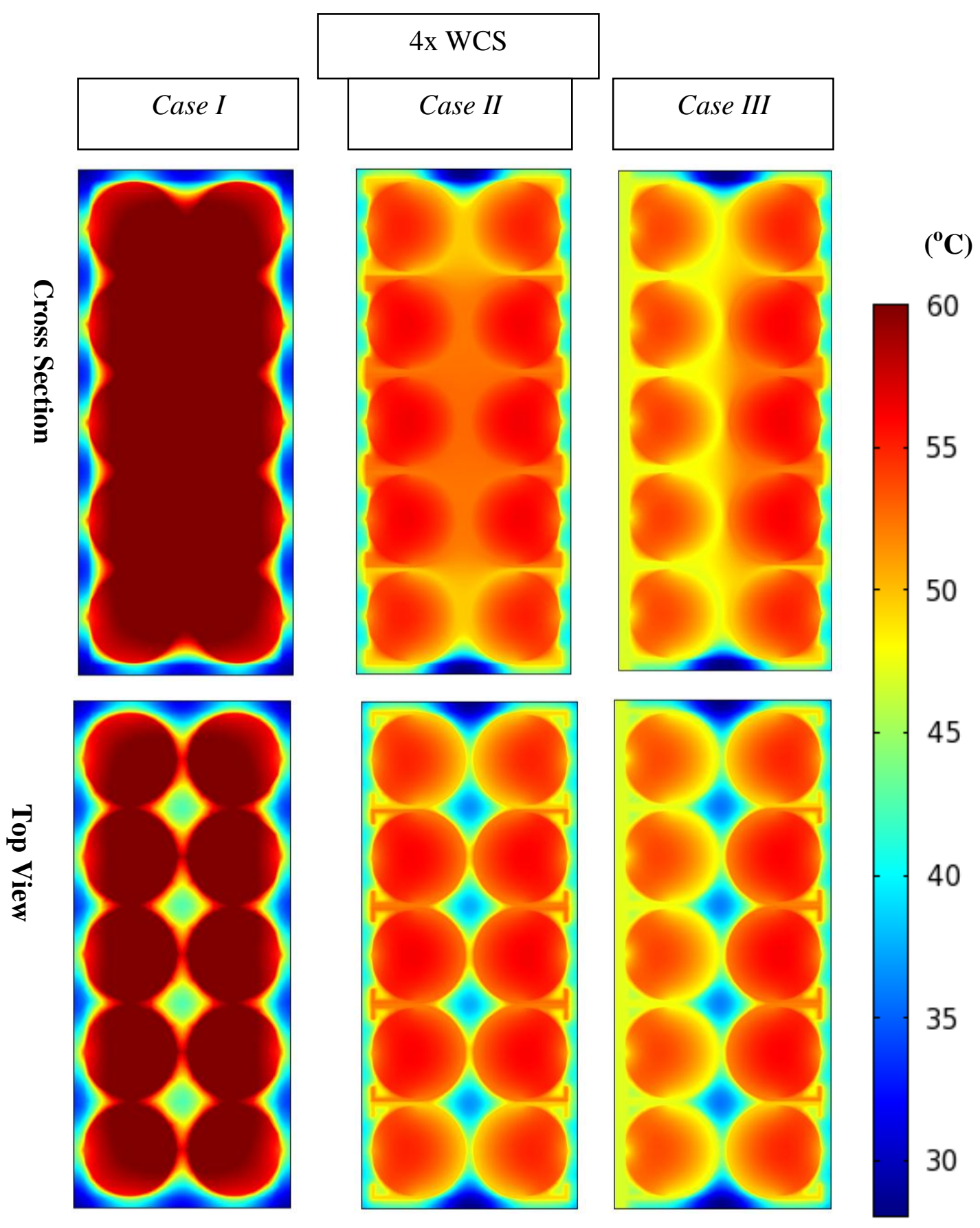

Figure 5-6: 4x "WCS" Temperature Grid 
For better understanding of the simulation results, a comparative metrics were extracted from the battery domain, exclusively. Figure 5-7 shows a sample of the results analysis done, in which the maximum and minimum temperatures were determined within the battery domains; then, the average temperature and temperature gradient were calculated for each case. The processed metrics are tabulated in Table 5-2.

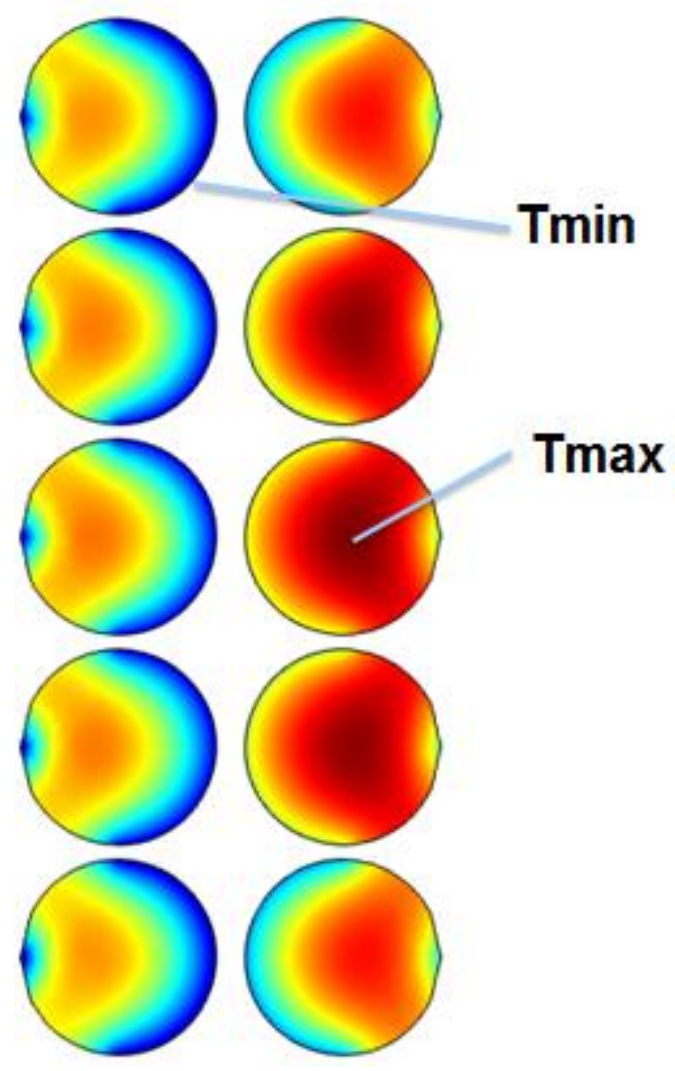

Figure 5-7: Sample of Results Analysis 
Table 5-2: Max, Min, Average and Temperature Gradient Comparison $\left({ }^{\circ} \mathrm{C}\right)$

\begin{tabular}{|c|c|c|c|c|}
\hline Scenario & & Case I & Case II & Case III \\
\hline \multirow{4}{*}{$1 X$} & Tmax & 33.97 & 32.42 & 32.35 \\
\hline & Tmin & 31.23 & 30.95 & 30.46 \\
\hline & Tavg & 32.60 & 31.69 & 31.41 \\
\hline & $\Delta \mathrm{T}$ & 2.74 & 1.47 & 1.89 \\
\hline \multirow{4}{*}{$2 X$} & Tmax & 45.36 & 42.26 & 42.47 \\
\hline & Tmin & 39.69 & 38.77 & 37.77 \\
\hline & Tavg & 42.53 & 40.52 & 40.12 \\
\hline & $\Delta \mathrm{T}$ & 5.67 & 3.49 & 4.70 \\
\hline \multirow{4}{*}{$4 X$} & Tmax & 62.68 & 56.42 & 56.33 \\
\hline & Tmin & 53.24 & 49.51 & 46.87 \\
\hline & Tavg & 57.96 & 52.97 & 51.6 \\
\hline & $\Delta \mathrm{T}$ & 9.44 & 6.91 & 9.46 \\
\hline
\end{tabular}

In all the discharge scenarios, Case I had the maximum average temperature, due to the lack of any thermal solution. Case III had a slightly lower average temperature than Case II because of the aluminum heat sink which dissipated the heat from the adjacent cells.

On the other hand, the presence of the graphite material in Case II enhanced the uniformity; this is clear by comparing the temperature gradients of Case II with the other two cases.

The same results are reflected in a plot shown in Figure 5-8, in which the lower left corner is the baseline. The $\mathrm{x}$-axis represents an indication of the effectiveness of heat 
dissipation, while the y-axis represents an indication of better uniformity across the cell. It is obvious that the heat dissipation in Case III was slightly better that in Case II; because of the existence of the heat sink. However, Case II was significantly better than Case III in terms of uniformity. The uniformity of Case III was not enhanced in comparison to the baseline because of the thermal asymmetry caused by the fact that the heat sink exists in only one side of the pack; for instance, the uniformity of Case III in the most abusive scenario (4X) was slightly below the baseline.

Another important remark is the divergence between the two cases in the plot. This divergence is expected since the more abusive the current profile is, the more less uniform Case III will be; for instance the uniformity of Case III in the third scenario (4x "worst case scenario") is worse than the baseline by $0.02^{\circ} \mathrm{C}$, and it is expected to increase. 


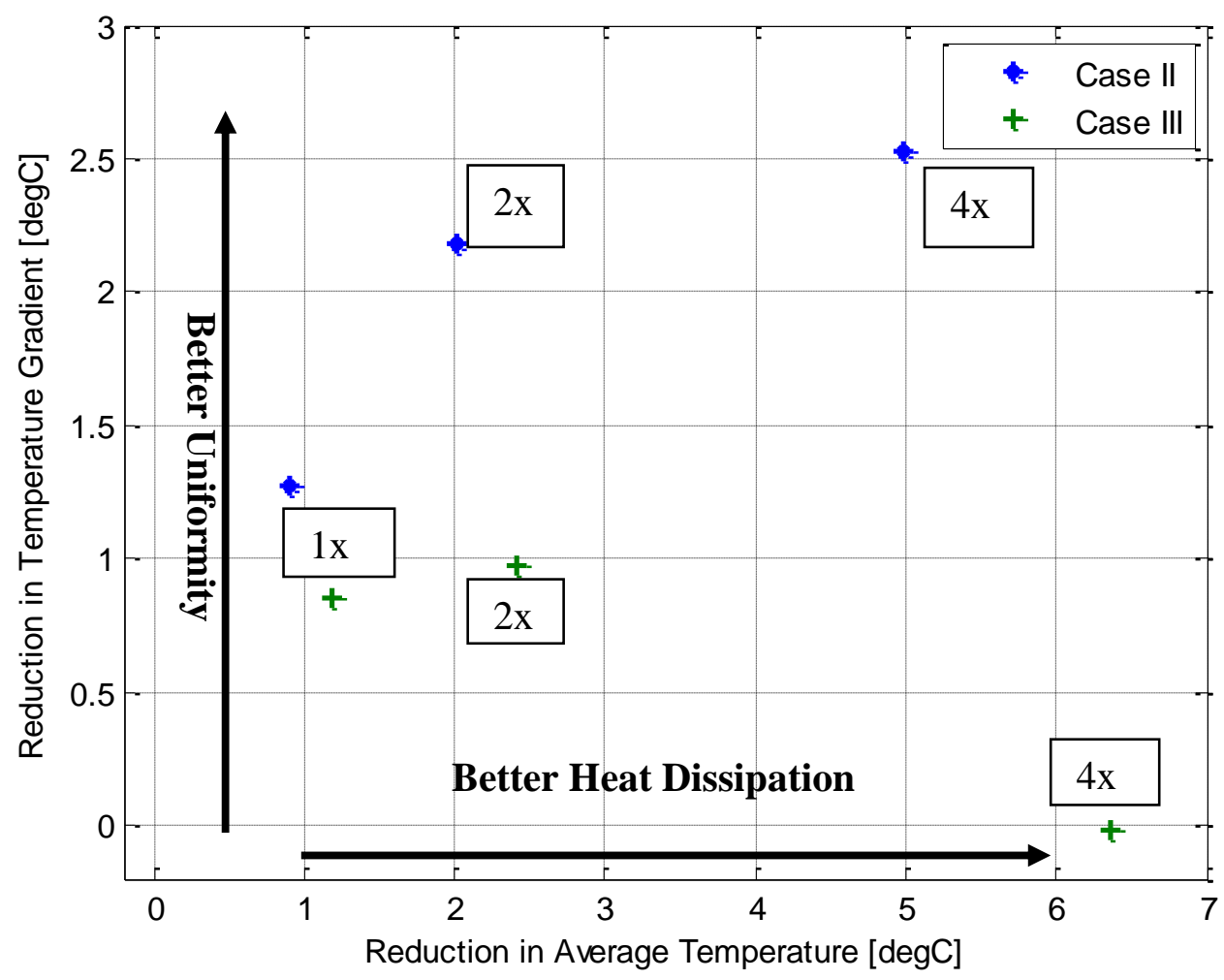

Figure 5-8: Case II and Case III Compared to Baseline for all scenarios

The simulation results showed that the flexible graphite heat spreading materials represented an effective thermal management solution for battery pack applications. In Case II, it was possible to effectively decrease the peak temperatures and improve the temperature uniformity within the pack by taking advantage of the high thermal conductivity of the flexible graphite, which allows for the heat generated by the cells to be dissipated on a much larger surface area. Adding a heat sink to one side of the pack decreased the temperature of the adjacent cells significantly; however, this happened at the cost of uniformity which as some point was below the baseline. Adding a heat sink to 
the other side was not feasible solution since the battery is mounted to the drill. Therefore, a good solution for the future is to change the design of the battery pack so that it makes it possible to add another heat sink. Another suggestion is to change the orientation of the heat spreaders inside the pack so that all the cells are thermally wrapped in a way that direct heat generated by all the cells to one heat sink.

\subsection{Preliminary Verification}

In addition to the first prototype that mimics Case I (which was discussed in Chapter 4), another prototype was built that mimics Case III. This section shows the fabrication of this prototype and preliminary verification with simulation results.

The purpose of this prototype is to test the concept of applying thermal management solution, to express the design of the graphite-bases flexible heat spreaders, and to validate the simulation results shown in Section 5.2.

Another 10 cells were characterized and tested; the cells characterization results are shown in Table 5-3. The need for the characterization, which guarantees that all cells are in balance and assures that all cells starts from fully charged state, is increased in this case because the prototypes do not have a BMS. 
Table 5-3: Cells Characterization Results

\begin{tabular}{|c|c|c|c|c|}
\hline $\begin{array}{c}\text { Cell } \\
\text { No. }\end{array}$ & Serial No. & $\begin{array}{c}\text { Rint } \\
(\mathbf{m} \mathbf{\Omega})\end{array}$ & $\begin{array}{c}\text { OCV } \\
(\mathbf{V})\end{array}$ & $\begin{array}{c}\text { Cap. } \\
\text { (A.h) }\end{array}$ \\
\hline 1 & AJ05860 & 8.09 & 3.301 & 2.2754 \\
\hline 2 & AJ03700 & 8.2 & 3.301 & 2.3219 \\
\hline 3 & BH00074 & 7.89 & 3.302 & 2.2849 \\
\hline 4 & AJ03694 & 8.21 & 3.302 & 2.2933 \\
\hline 5 & AL00248 & 7.85 & 3.302 & 2.2547 \\
\hline 6 & AJ05760 & 7.89 & 3.302 & 2.2728 \\
\hline 7 & AH04629 & 7.98 & 3.302 & 2.2725 \\
\hline 8 & AK00190 & 7.8 & 3.302 & 2.2878 \\
\hline 9 & BH03905 & 8.13 & 3.302 & 2.2856 \\
\hline 10 & AL00160 & 7.83 & 3.302 & 2.2718 \\
\hline
\end{tabular}

This prototype was covered with Lexan only from four sides. An aluminum sheet was placed on the fifth side so that it could function as a heat sink. A thermal solution, namely, a graphite-based flexible heat spreader, was applied to the prototype. The heat spreaders (i.e., SS450-0.25) were wrapped around each cell and were attached to the aluminum heat sink in order to dissipate heat from the battery, see Figure 5-9.

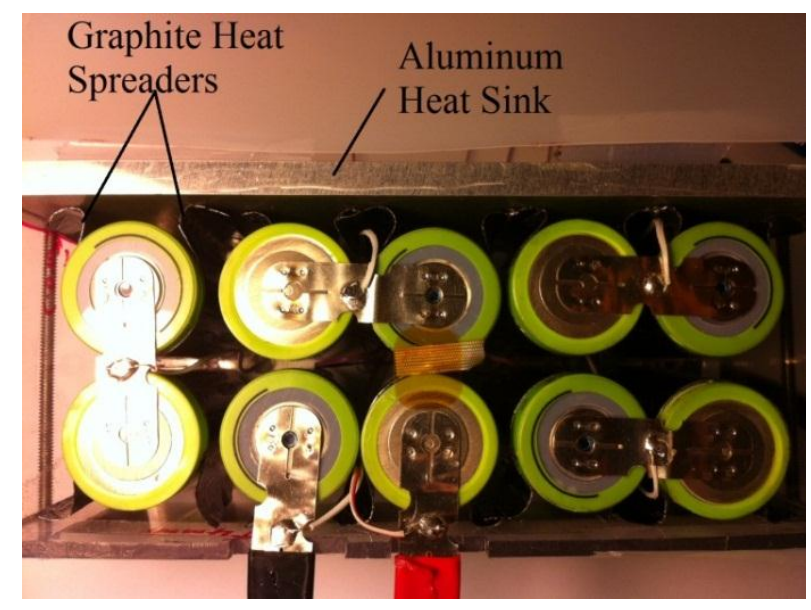

Figure 5-9: Case III Prototype 
Similar to the first prototype, this prototype was instrumented with five thermocouples in five different points in the pack, refer to Figure 4-28. And it was fully charged and, then, was left for a sufficient time to cool down to the ambient temperature (i.e., $22^{\circ} \mathrm{C}$ ). Then, a pre-defined current profile (i.e., 2x "worst case scenario") was applied by the cycler on the prototypes till the voltage of any cell in the prototype dropped down to $2.0 \mathrm{~V}$.

The results of Case III prototype are shown in Figure 5-10 and Figure 5-12. Figure 5-10 shows a thermal image at the end of the test at the same scale of the previous thermal image shown in Figure 4-41. When the two thermal images are compared, it becomes obvious that the uniformity was enhanced significantly; this is due to the thermal solution applied to this prototype. Furthermore, Figure 5-10 shows that temperature of Spot 2 dropped down because of the aluminum heat sink by $3^{\circ} \mathrm{C}$, approximately, which matches the simulation results presented in Chapter 4 .
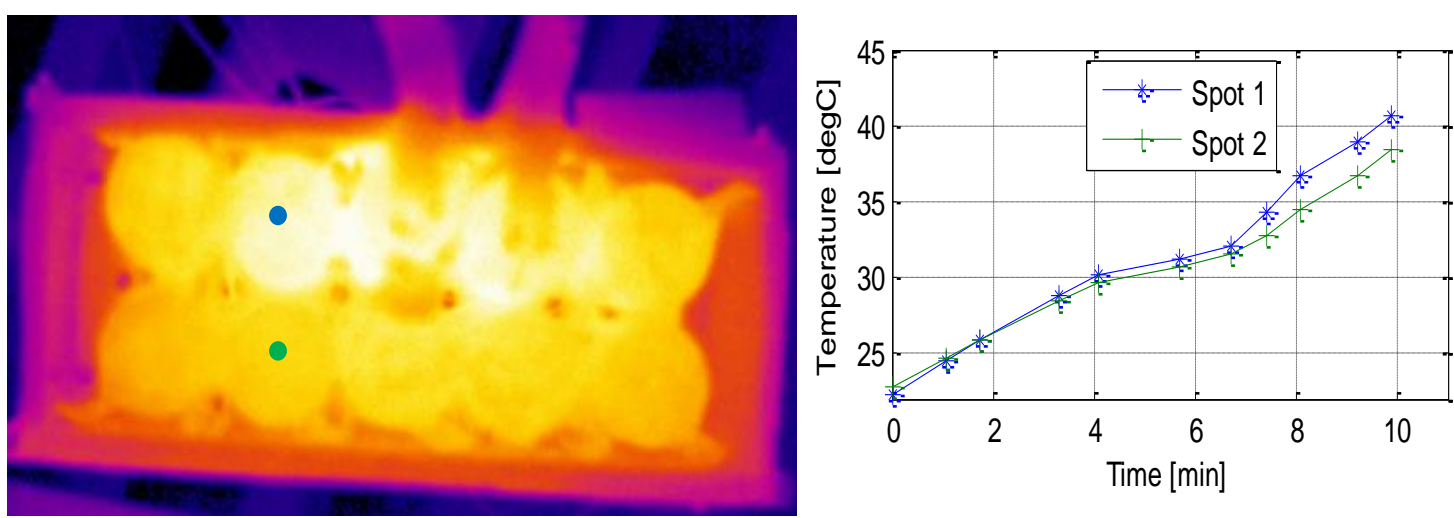

Figure 5-10: Experiment Thermal Image for Case III 


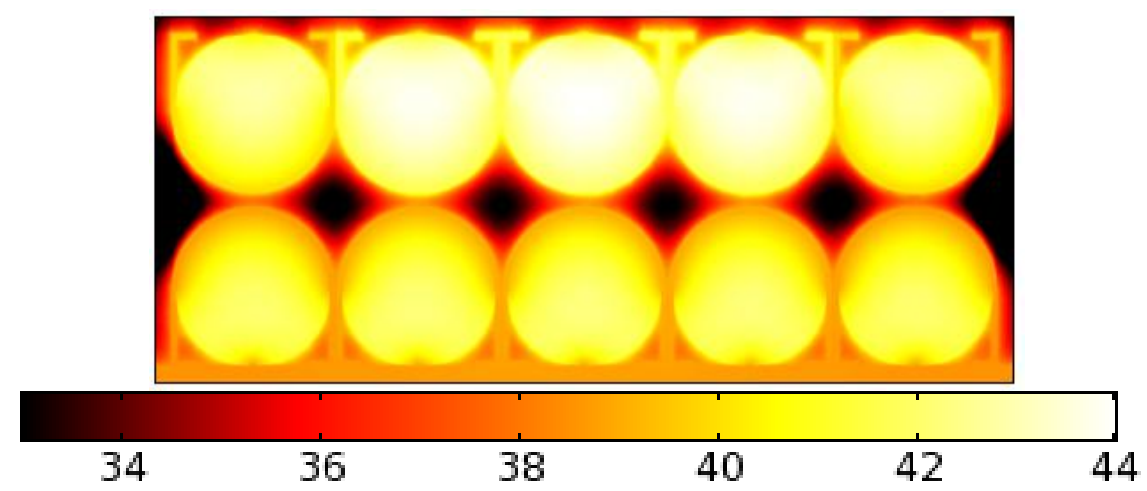

Figure 5-11: Simulation Thermal Image for Case III

Figure 5-12 shows the validation of the prototype results. Similar to the results of the first prototype, the differences between the experimental temperatures and their corresponding simulation temperatures were within the error of a thermocouple (i.e., $2^{\circ} \mathrm{C}$ ).
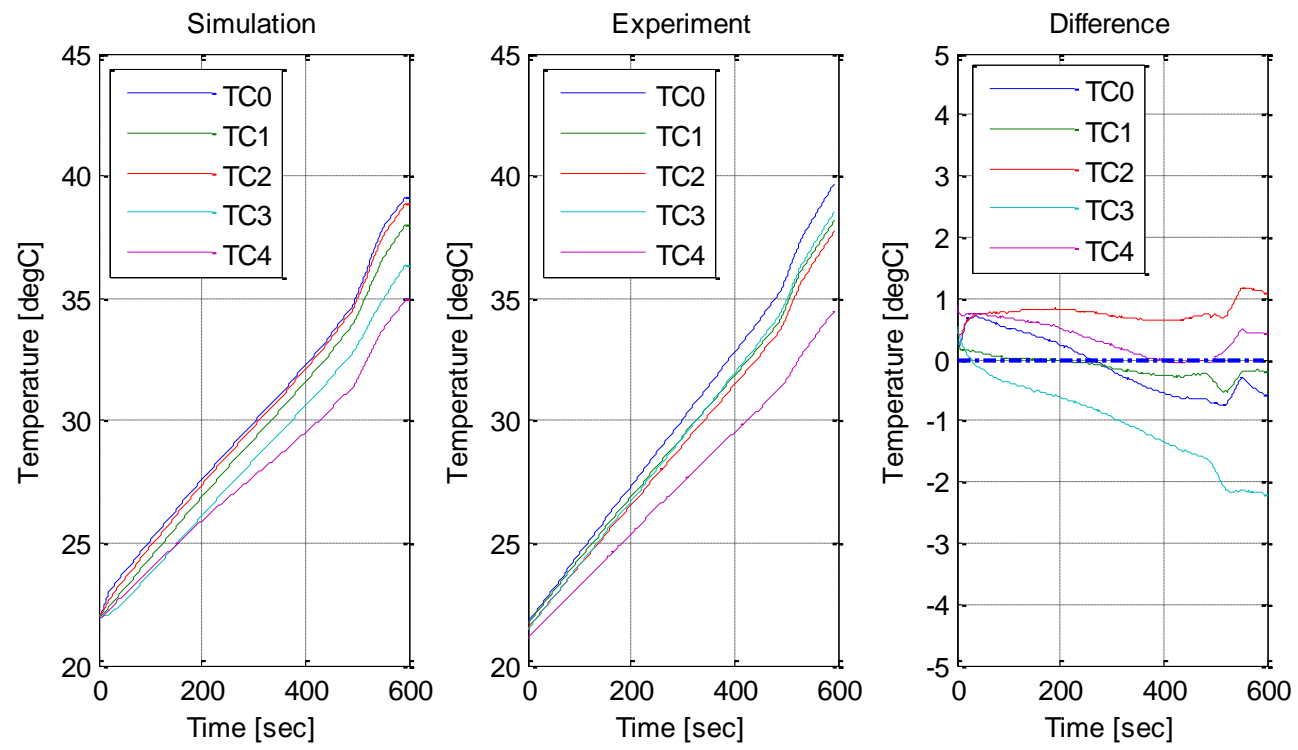

Figure 5-12: Case III (Graphite HS) Prototype Validation: Simulation and Experiment Temperatures, and Difference 
The two conceptual prototypes that were built to mimic two design cases worked with a high degree of fidelity. The effect of the thermal solution (i.e., graphite-based flexible heat spreaders) was clearly seen in the improvement of the uniformity of the temperature distribution inside the pack. Furthermore, the existence of the heat sink decreased the temperature and significantly so.

The results of these tests were confirmed by the simulation results, which, in turn, were validated with the real pack (as shown in Section 4.3). This suggests that these prototypes are, indeed, valid to describe the thermal behavior of the original Dewalt battery pack. 


\section{Chapter 6}

\section{CONCLUSIONS AND RECOMMENDATIONS}

\subsection{Conclusions}

Lithium ion batteries are the enabling technology for storage solutions in many applications. A typical Li-ion cell consists of negative electrode (anode), electrolyte, separator, and positive electrode (cathode). Similar to all electrochemical batteries, the chemical energy is converted into electrical energy. According to the second law of thermodynamics, any conversion between two forms of energy occurs with an energy loss. This energy loss increases the temperature of the cell, which, negatively, affects the battery life, and possibly exceeds safety limits.

The thermal issues caused by the energy losses in Li-ion cells were studied in this thesis. As a first step, an extensive literature review was provided on thermal characterization and issues, followed by a description of mathematical models commonly used to predict heat generation rate.

In order to solve the thermal issues in Li-ion batteries, a thermal management system needs to be installed in order to keep the battery temperature within its operating range and to maintain the temperature uniformity between cells within the pack. An overview of thermal management solution was presented in this thesis, based on an extensive 
literature search. Various thermal management solutions were presented, such as air cooling, liquid cooling, phase-change materials, heat spreaders and heatsinks.

In order to select the better thermal solution, a solid understanding of the thermal behavior of the Li-ion battery is needed. This thesis summarizes the available mathematical models of Li-ion batteries in the published literature. Different models have different ways of describing the battery; this depends on the complexity of the model and on how exactly it describes the essential factors that influence the performance of the battery. Therefore, research in the field of battery modeling aims at increasing the accuracy and the precision of the models without increasing their complexity. To this extent, this thesis presents an overview of the tools and methods used to design and develop mathematical models for Li-ion batteries. It covered fundamental battery models and phenomenological battery models (e.g., Randle equivalent circuit). Furthermore, energy balance calculations were presented in order to estimate heat generation rate. In addition, the finite element method (FEM) models are widely used to study the thermal behavior of Li-ion batteries. This thesis reviewed FEM models that were built in high level simulation software, such as ANSYS, and COMSOL Multiphysics.

The work done in this thesis was an experimental and simulation study aimed at evaluating the effectiveness of flexible graphite materials for heat spreaders in battery thermal management systems. A commercial Li-ion battery pack for power tools applications was adopted as a case study. Starting from the statistical analysis of typical usage patterns, a duty cycle profile (current vs. time) was synthesized for laboratory and simulation testing. Then, the electro-thermal behavior of the battery pack was 
characterized through combined experimental investigation and 3D FEM modeling, using COMSOL Multiphysics, to determine the heat generation rate of the battery cells during utilization and to evaluate the thermal behavior of the battery pack. After that, a conceptual prototype was fabricated and tested to validate the FEM model. The error in prediction was less than $2.5^{\circ} \mathrm{C}$, which is within the error of a thermocouple.

Based on the results obtained, the need for thermal management solutions was demonstrated by studying simulation results. In particular, the elevated temperature reached within the pack and the relatively large temperature gradients during the test that was conducted allow for understanding the need for thermal solution. Furthermore, the peak temperature and the temperature gradient of the pack were expected to be greater for more aggressive usage of the drill. As a result, a potential thermal management solution based on flexible graphite heat spreading materials was designed and implemented. The validated FEM model was then used to conduct a comparative study in order to investigate and evaluate the thermal solution effectiveness and improvements in the pack thermal behavior performance for various het spreader arrangements.

The simulation results presented in the thesis showed that the flexible graphite heat spreading materials represented an effective thermal management solution for battery pack applications. A minimum design modification was applied to the pack by wrapping the graphite-based heat spreaders around each cell and attached the spreader ends to the pack enclosure. By doing this, it was possible to effectively decrease the peak temperatures and improve the temperature uniformity within the pack by taking advantage of the high thermal conductivity of the flexible graphite, which allowed for the 
heat generated by the cells to be dissipated on a much larger surface area. Adding a heat sink to one side of the pack decreased the temperature of the adjacent cells significantly; however, this happened at the cost of uniformity, due to the thermal asymmetry of boundary conditions of the pack.

A recommended design is to reorient the battery pack so that it becomes possible to add another heat sink. In this case, the pack will be symmetric and the two vertical heat sinks will have better heat transfer coefficient than one horizontal heat sink. Another suggestion is to change the orientation of the heat spreaders inside the pack so that all the cells are thermally wrapped in a way heat is dissipated by one heat sink.

In conclusion, the thermal management system based on flexible graphite heat spreaders was the best compromise between reduction in pack average temperature, mitigation of thermal gradients, and fabrication complexity.

\subsection{Future Work}

The work presented in this thesis is currently in progress with ongoing research focused on both experimental and simulation parts of the study. Regarding the experimental part, extra analysis will be done for the conducted tests to investigate battery life for both thermally managed and unmanaged packs under similar (aggressive) usage patterns. In addition, the cell-to-cell electrical unbalance, and the rate of thermal and electrical recovery after the test will be studied, in order to understand how uniform and efficient the pack cools down. 
Moreover, the current research activity is aiming at evaluating different combinations of graphite heat spreaders. One configuration is ready for testing, shown in Figure 6-1. In this configuration, a single graphite-based heat spreader is used to dissipate heat from all cells in the same row. The advantage of this design is the increase in the contact surface area between the cells and the heat spreaders, and the enclosure and the heat spreaders. This leads to better heat dissipation and better heat distribution inside the pack by taking advantage of the high thermal conductivity of the heat spreaders in the planar direction and the very low thermal conductivity through the thickness.

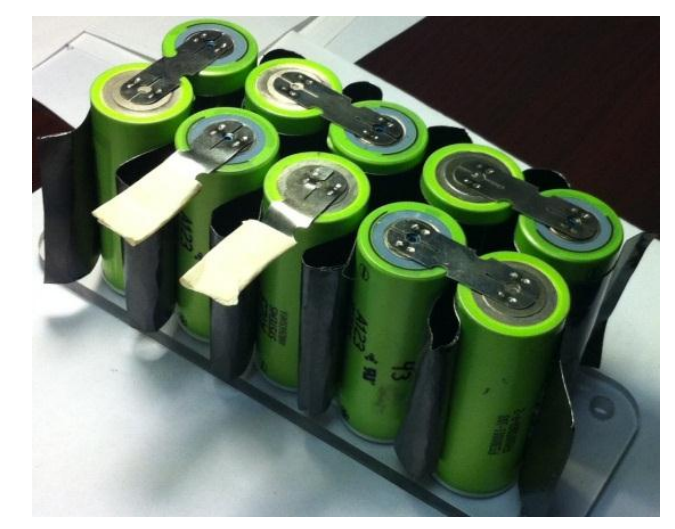

Figure 6-1: New Configuration

On the other hand, some future research activities will be conducted regarding simulation and modeling. These activities aim at enhancing the accuracy of the FEM model. This can be done by conducting better estimation of the battery components thermal properties and by adding more domains that describe more components to the model. Furthermore, 
a better understanding of the thermal behavior of the BMS and the ability to calibrate its heat generation rate are considered a significant development of the FEM model.

It is planned to extend the methodology developed in this thesis to automotive battery packs, for which life and cost are significantly influenced by thermal management systems. 


\section{References}

1) M. J. Moran, H. N. Shapiro, D. D. Boettner, M. B. Bailey, Fundamentals of Engineering Thermodynamics, $7^{\text {th }}$ edition (Wiley: 2010).

2) R. Liang, Z. Wang, H, Guo, "Fabrication and electrochemical properties of lithium-ion batteries for power tools" Journal of Power Sources, 184, pp. 598603, 2008.

3) A. A. Pesaran, A. Vlahinos, and S. D. Burch, "Thermal Performance of EV and HEV Battery Modules and Packs,” 14th Electric Vehicle Symposium, 1997.

4) A. A. Pesaran, S. Burch, and M. Keyser, "An Approach for Designing Thermal Management Systems for Electric and Hybrid Vehicle Battery Packs," 4th Vehicle Thermal Management Systems Conference and Exhibition, 1999.

5) A. A. Pesaran, "Battery Thermal Management in EVs and HEVs: Issues and Solutions," Advanced Automotive Battery Conference, 2001. 
6) Kazuo Onda, Hisashi Kameyama, Takeshi Hanamoto, and Kohei Ito, "Experimental Study on Heat Generation Behavior of Small Lithium-Ion Secondary Batteries,” Journal of the Electrochemical Society, 150, A285-A291, 2003.

7) C. Kuper, M. Hoh, G. Houchin-Miller, and J. Fuhr, "Thermal Management of Hybrid Vehicle Battery Systems,” International Battery, Hybrid and Fuel Cell Electric Vehicle Symposium, 2009.

8) J. Lee, "Battery Thermal Modelling - The Methodology and Applications," Proceedings of the Symposium on Electrochemical and Thermal Modeling of Battery, Fuel Cell, and Photoenergy Conversion Systems, p.p. 206-215, 1986.

9) T. F. Sharpe, R. S. Conell, "Low-temperature charging behaviour of lead-acid cells," Journal of Applied Electrochemistry, 12, pp. 789-799, 1987.

10) H. Khasawneh, J. Neal, M. Canova, Y. Guezennec, “Analysis of Heat-Spreading Thermal Management Solutions for Lithium-Ion Batteries," Proceedings of the ASME 2011 Mechanical Engineering Congress and Exposition IMECE, 2011. 
11) S. Al-Hallaj, H. Maleki, J. S. Hong, and J. R. Selman, "Thermal modeling and design considerations of lithium-ion batteries," Journal of Power Sources , 83, pp. $1-8,1999$.

12) R. Sabbah, R. Kizilel, J. R. Selman, S. Al-Hallaj, “Active (air-cooled) vs. passive (phase change material) thermal management of high power lithium-ion packs: Limitation of temperature rise and uniformity of temperature distribution," Journal of Power Sources, 182, pp. 630-638, 2008.

13) H. Maleki, S. Al-Hallaj, R. Selman, "Thermal Properties of Lithium-Ion Battery and Components," Journal of the Electrochemical Society, 146, pp. 947-954, 1999.

14) W. Fang, O. J. Kwon, C. Y. Wang, Y. Ishikawa, "Modeling of Li-ion Battery Performance in Hybrid Electric Vehicles," SAE International Journal of Passenger Cars- Electronic and Electrical Systems October 2009, 2, pp. 418-423, 2009.

15) D. Bernardi, E. Pawlikowski, J. Newman, “A General Energy Balance for Battery Systems," Journal of the Electrochemical Society, 132, pp. 53-63, 1985. 
16) C. Pals and J. Newman, "Thermal Modeling of the Lithium/Polymer Battery," Journal of the Electrochemical Society, 142, pp. 3274-3281, 1995.

17) K. E. Thomas and S. A. Newman, "Thermal Modeling of Batteries with Porous Insertion Electrodes," Journal of the Electrochemical Society, 150, pp. A176A192, 2003.

18) S. A. Khateeb, M.M. Farid, J.R. Selman, S. Al-Hallaj, "Design and simulation of a Li-ion battery with a PCM thermal management system for an electric scooter," Journal of Power Sources, 128, pp. 292-307, 2004.

19) M. Smalc, G. Shives, G. Chen, S. Guggari, J. Norley, and A. Reynolds, "Thermal Performance of Natural Graphite Heat Spreaders," Proceedings of ASME IPACK05, International Electronics Packaging Technical Conference and Exhibition, 2005.

20) J.S. Hong, H. Maleki, S. Al-Hallaj, L. Redey, R. Selman, "Electrochemicalcalorimetric studies of lithium-ion cells," Journal of The Electrochemical Society, 145, pp. 1489-1501, 2008. 
21) G.H. Kim, A. Pesaran, "Battery Thermal Management System Design Modeling," The 22nd International Battery, Hybrid and Fuel Cell Electric Vehicle Conference and Exhibition, 2006.

22) K. M. Marsh, "Calorimeter" in McGraw-Hill Concise Encyclopedia of Science and Technology, ed. McGraw-Hill, $5^{\text {th }}$ edition (McGraw-Hill Professional, 2004), p. 358 .

23) R. Anderson, "Requirements for Improved Battery Design and Performance," SAE Transactions, 99, pp. 1190-1197, 1990.

24) P. A. Nelson, V. S. Battaglia, and J. P. Henricksen, "Thermal Control of Electric Vehicle Batteries," Proceedings of the 30th Intersociety Energy Conversion Engineering Conference, p.p. 267-273, 1995.

25) R. Kizilel, R. Sabbah, J. R. Selman, S. Al-Hallaj, “An alternative cooling system to enhance the safety of Li-ion battery packs," Journal of Power Sources, 194, pp. 1105-1112, 2009.

26) F. Wicks and E. Doane, "Temperature Dependent Performance of a Lead Acid Electric Vehicle Battery," Proceedings of the 28th Intersociety Energy Conversion Engineering Conference, 1993. 
27) B. Dickinson and D. Swan, "EV Battery Pack Life: Pack Degradation and Solutions," SAE technical papers series, pp. 145-154, 1995.

28) P. Ramadass, B. Haran, R. White, B. N. Popov, "Capacity fade of Sony 18650 cells cycled at elevated temperatures: Part II. Capacity fade analysis," Journal of Power Sources, 122, pp. 614-620, 2002.

29) K.J. Kelly, M. Mihalic, and M. Zolot, "Battery Usage and Thermal of the Toyota Prius and Honda Insight during Chassis Dynamometer Testing," The 17th Annual Battery Conference on Applications and Advances, 2002.

30) M. M. Farid, A. M. Khudhair, A. K. Siddique Razack, S. Al-Hallaj, “A review on phase change energy storage: materials and applications,” Energy Conversion and Management, 45, pp. 1597-1615, 2004.

31) S. Al Hallaj and J. R. Selman, "A Novel Thermal Management System for Electric Vehicle Batteries Using Phase-Change Material," Journal of The Electrochemical Society, 147, pp. 3231-3236, 2000.

32) S. Al Hallaj, H. Maleki, J.S. Hong, J.R. Selman, "Thermal modeling and design considerations of lithium-ion batteries," Journal of Power Sources, 83, pp. $1-8,1999$. 
33) S. Al-Hallaj, J.R. Selman, "Novel Thermal Management of Battery Systems," US Patent 6,468,689 B1, 2002.

34) S. Al-Hallaj, J.R. Selman, "Battery System Thermal Management," US Patent 6,942,944 B2, 2005.

35) S. A. Khateeb, S. Amiruddin, M. M. Farid, J. R. Selman, S. Al-Hallaj, "Thermal management of Li-ion battery with PSM for electric scooters: experimental validation," Journal of Power Sources, 142, pp. 345-353, 2005.

36) Mills, M. M. Farid, J. R. Selman, S. Al-Hallaj, "Thermal conductivity enhancement of phase change materials using a graphite matrix," Applied Thermal Engineering, 26, pp. 1652-1661, 2006.

37) J. J-W. Tzeng, G. Getz, B. S. Fedor, D. W. Krassowski, “Anisotropic Graphite Heat Materials For Electronics Thermal Management," Power Conversion, 183, 2000.

38) M. Smalc and J. Norley, "Thermal Performance of Natural Graphite Heat Spreaders with Embedded Thermal Vias," Proceedings of IPACK2007, 2007. 
39) J. Norley, “The Development of a Natural Graphite Heat-Spreader,” IEEE, 2001.

40) M. Smalc and J. Norley, "Advance Thermal Interface Material Using Natural Graphite," Proceedings of IPACK2003, 2003.

41) M. D. Smalc, J. Norley, J. Schober, R. A. Reynolds, B. Reis, "The Thermal Performance of Graphite Heat Spreaders in Radiant Panel Applications," ASME International Mechanical Engineering Congress and Exposition IMECE, 2009.

42) Y. Hu, B. Yurkovich, S. Yurkovich, Y. Guezennec, "Electro-Thermal Battery Modeling and Identification for Automotive Applications". Proceedings of ASME Dynamic Systems and Control Conference, 2009.

43) G. L. Plett, "Extended Kalman filtering for battery management systems of LiPBbased HEV battery packs (Part 1. Background)," Journal of Power Sources, 134, pp. 252-261, 2004.

44) L. Serrao, Z. Chehab, Y. Guezennec, G. Rizzoni, “An Aging Model of Ni-MH Batteries for Hybrid Electric Vehicles," Vehicle Power and Propulsion, 2005 IEEE Conference, 2005. 
45) S. Piller, M. Perrin, and A. Jossen, "Methods for state-of-charge determination and their applications," Journal of Power Sources, 96, pp. 113-120, 2001.

46) C. Cai, D. Du., Z. Liu, J. Ge, "State-of-Charge (SOC) Estimation of High Power NI-MH Rechargeable Battery with Artificial Neural Network," Proceedings of the 9th International Conference on Neural Information Processing (ICONIP'OZ), 2, 2002.

47) P. Singh, C. Fennie, and D. E. Reisner, "Fuzzy logic modeling of state-of-charge and available capacity of nickel/metal hydride batteries," Journal of Power Sources, 136, pp. 322-333, 2004.

48) S. Malkhandi, "Fuzzy logic-based learning system and estimation of state-ofcharge of lead-acid battery," Engineering Applications of Artificial Intelligence, 19, pp. 479-485, 2006.

49) G. L. Plett, "Extended Kalman filtering for battery management systems of LiPBbased HEV battery packs (Part 3)," Journal of Power Sources, 134, pp. 277-292, 2004.

50) Kim II- Song, "The novel state of charge estimation method for lithium battery using sliding mode observer,” Journal of Power Sources, 163, pp. 584-590, 2006. 
51) M. Doyle, T. F. Fuller, J. S. Newman, "Modeling of Galvanostatic Charge and Discharge of the Lithium/Polymer/Insertion Cell," Journal of The Electrochemical Society, 140, pp. 1526-1533, 1993.

52) T. F. Fuller, M. Doyle, J. S. Newman, "Simulation and Optimization of the Dual Lithium Ion Insertion Cell," Journal of the Electrochemical Society, 141, pp. 110, 1994.

53) M. Muratori, "Thermal Characterization of Lithium-ion Battery Cell,” Summary of CAR Consortium Projects, Advanced Propulsion Systems Thrust Area, 2010.

54) B. Yurkovich and Y. Guezennec, "Lithium Ion Dynamic Battery Pack Model and Simulation for Automotive Applications," Proceedings of DSCC2009, 2009.

55) G. G. Botte, V. R. Subramanian, R. E. White, "Mathematical modeling of secondary lithium batteries - Botte - Electrochemical modeling," Electrochimica Acta, 45, pp. 2595-2609, 2000.

56) F. P. Incropera and D. P. De Witt, T. L. Bergman, A. S. Lavine, Fundamentals of Heat and Mass Transfer, $5^{\text {th }}$ edition, (WILEY: 2001). 
57) J. P. Fellner, G. J. Loeber, S. S. Sandhu, “Testing of lithium-ion 18650 cells and characterizing/predicting cell performance," Journal of Power Sources, 81/82, pp. 867-871, 1999.

58) J. Holman, Heat Transfer, $9^{\text {th }}$ edition (McGraw-Hill: 2001).

59) J. N. Reddy, An Introduction to the Finite Element Method, $2^{\text {nd }}$ edition (McGrawHill: 1993).

60) J. Newman, K. E. Thomas, H. Hafezi, D. R. Wheeler, "Modeling of lithium-ion batteries," Journal of Power Sources, 119-121, pp. 838-843, 2003.

61) S. Santhanagopalan, Q. Guo, P. Ramadass, R. E. White, "Review of models for predicting the cycling performance of lithium ion batteries," Journal of Power Sources, 156, pp. 620-628, 2006.

62) M. Doyle, J. S. Newman, "Modeling the performance of rechargeable lithiumbased cell design correlations for limiting cases," Journal of Power Sources, 54, pp. 46-51, 1995. 
63) P. Ramadass, B. Haran, P. M. Gomadam, R. White, B. N. Popov, "Development of First Principles," Journal of The Electrochemical Society, 151, A196-A203, 2004.

64) G. Sikha and B. N. Popov, "Effect of Porosity on the Capacity Fade of a Li-Ion Battery," Journal of the Electrochemical Society, 151, A1104-A1114, 2004.

65) M. Ozisik, "Boundary Value Problems of Heat Conduction," Dover Publications, NY, 1989.

66) C. Y. Wang and W. B. Gu, "Micro-Macroscopic Coupled Modeling of Batteries and Fuel Cell - Part 1," Journal of The Electrochemical Society, 145, pp. 34073417, 1998.

67) V. R. Subramanian, D. Tapriyal, R. E. White, “A Boundary Condition for Porous Electrodes," Electrochemical and Solid-State Letters, 7, A259-A263, 2004.

68) B. S. Haran, "Determination of the hydrogen diffusion coefficient in metal hydrides by impedance spectroscopy," Journal of Power Sources, 75, pp. 56-63, 1998. 
69) G. Ning and B. N. Popov, "Cycle Life Modeling of Lithium-Ion Batteries," Journal of The Electrochemical Society, 151, pp. A1584-A1591, 2004.

70) W. Fang, O. J. Kwon, C. Y. Wang, "Electrochemical-thermal modeling of automotive Li-ion batteries," International Journal of Energy Research, 34, pp. 107-115, 2010.

71) V. H. Johnson, A. A. Pesaran, T. Sack, "Temperature-Dependent Battery Models for High-Power Li-Ion Battery," 17th Annual Electric Vehicle Symposium, Montreal, Quebec (CA), 2000.

72) A. Pesaran, "Battery thermal models for hybrid vehicle simulations," Journal of Power Sources, 110, pp. 377-382, 2002.

73) D. Bharathan, A. A. Pesaran, G. H. Kim, A. Vlahinos, "Electro-Thermal Modeling to Improve Battery Design,” The 2005 IEEE Vehicle Power and Propulsion Conference, 2005.

74) S. Burch, R. Parish, and M. Keyser, "Thermal Management of Batteries Using a Variable-Conductance Insulation (VCI) Enclosure," The Intersociety energy Conversion Engineering Conference, 1995. 
75) M. Muratori, N. Ma, M. Canova, Y. Guezennec, “A Model-Order Reduction Method for Temperature Estimation in a Cylindrical Li-Ion Battery Cell,” ASME Dynamic Systems and Control Conference, 2010.

76) M. Muratori, M. Canova, Y. Guezennec, "A Spatially-Reduced Dynamic Model for the Thermal Characterization of Li-Ion Battery Cells", Accepted for Publication to International Journal of Vehicle Design (2011).

77) K. Onda, T. Ohshima, M. Nakayama, K. Fukuda, "Thermal behavior of small lithium-ion battery during rapid charge and discharge cycle," Journal of Power Sources, 158, pp. 535-542, 2006.

78) S. Chen, C. Wan, and Y. Wang, "Thermal analysis of lithium-ion batteries," Journal of Power Sources, 148, pp. 111-124, 2005.

79) P. M. Knupp, "Remarks on Mesh Quality," Proceedings of the 45th AIAA Aerospace Sciences Meeting and Exhibit, 2007.

80) Patent Number \#6482520, “Thermal Management System”, 2002. 